Aus der Klinik für Neurologie

(Prof. Dr. med. M. Bähr)

der Medizinischen Fakultät der Universität Göttingen

\title{
Einfluss der Rho-Kinase-Hemmung auf Mikrogliazellen im SOD1-G93A-Mausmodell der Amyotrophen Lateralsklerose
}

\author{
INAUGURAL - DISSERTATION \\ zur Erlangung des Doktorgrades \\ der Medizinischen Fakultät der \\ Georg-August-Universität zu Göttingen
}

\author{
vorgelegt von \\ Johannes Jansen \\ aus Wiesbaden
}

Göttingen 2016 
Dekan:

Referent:

Ko-Referent:

Promotor-Vertreterin:

Tag der mündlichen Prüfung:
Prof. Dr. rer. nat. H. K. Kroemer

Prof. Dr. med. L. Tönges (Betreuer)

Prof. Dr. med. M. W. Sereda

Prof. Dr. hum. biol. M. Schön 


\section{Inhaltsverzeichnis}

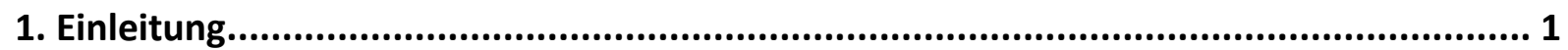

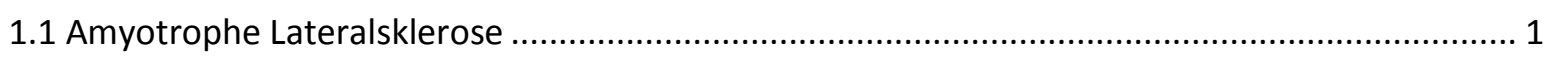

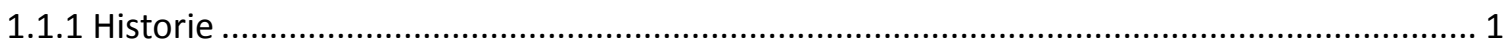

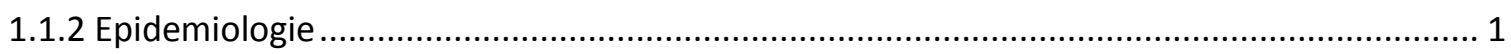

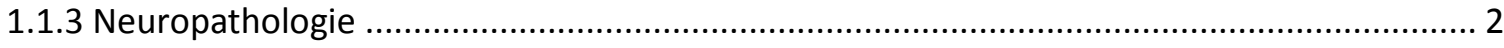

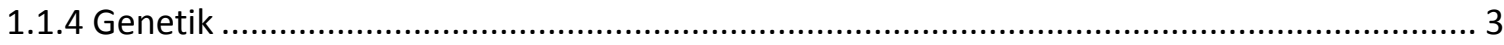

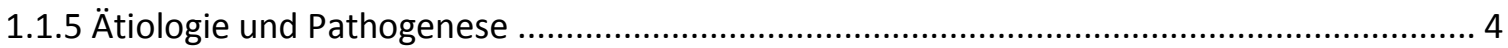

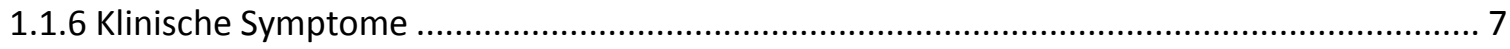

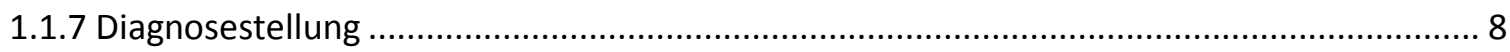

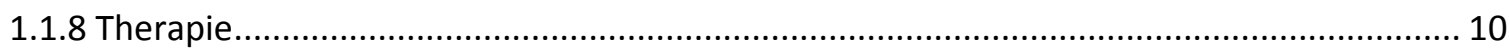

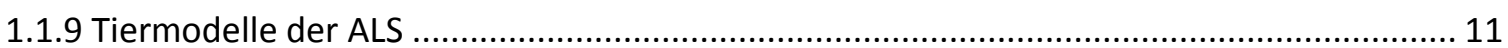

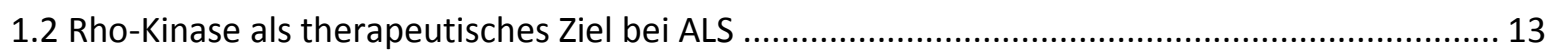

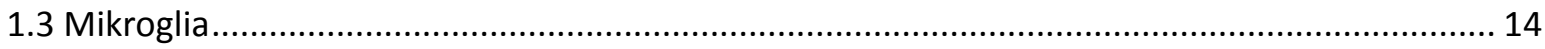

1.3.1 Rolle von Mikrogliazellen und Neuroinflammation in ALS................................................... 16

1.4 Zusammenfassung der vorausgegangenen Studien und Ziele der Arbeit.................................. 18

2. Material und Methoden ................................................................................................ 20

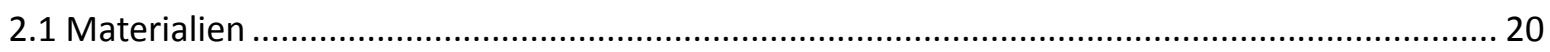

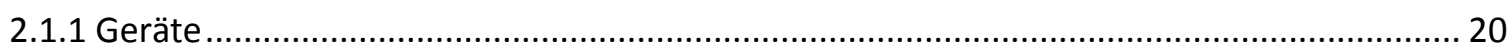

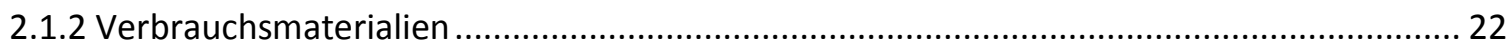

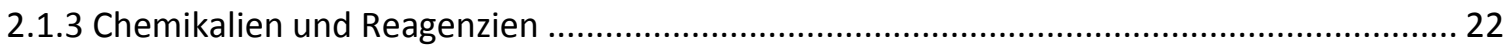

2.1.4 Substanzen für Polymerasekettenreaktion ......................................................................... 23

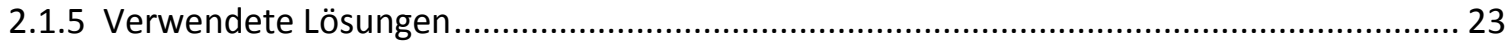

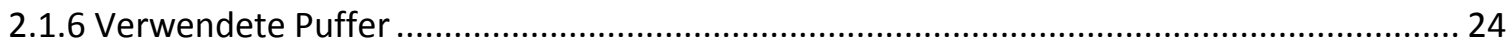

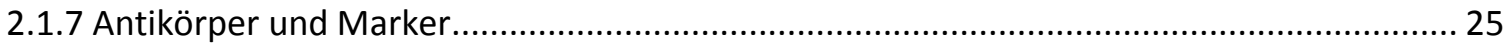

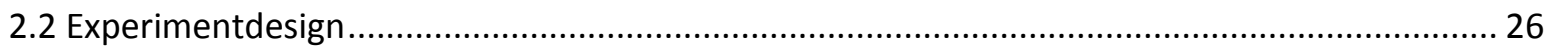

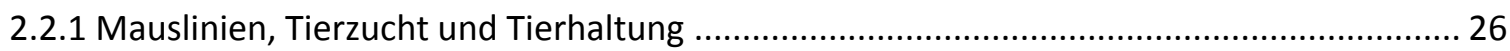

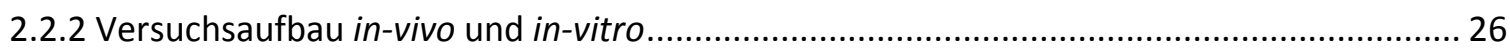

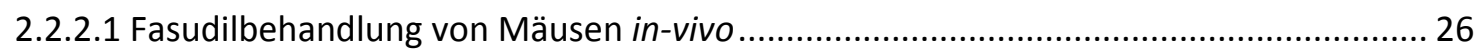

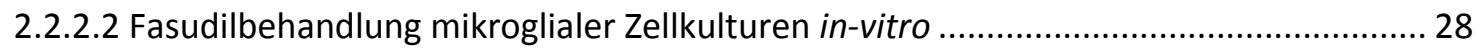

2.3. Immunhistochemische Analyse des Rückenmarks........................................................... 28

2.3.1 Anfertigung von Cryoschnitten des Rückenmarks .......................................................... 28

2.3.2 Immunhistochemische Färbungen von Rückenmarksquerschnitten.................................. 29 
2.3.3 Mikroskopie von Rückenmarksquerschnitten und quantitative Auswertung 30

2.3.3.1 Quantifikation der Mikrogliainfiltration des Rückenmarks .................................... 30

2.3.3.2 Morphologische Auswertung mikroglialer Zellen im Rückenmark .......................... 31

2.4 In-vitro-Analyse von Mikrogliazellkulturen .............................................................. 31

2.4.1 Generierung von Mikrogliazellkulturen ............................................................ 31

2.4.2 Genotypisierung SOD1-G93A-transgener Mäuse...................................................... 32

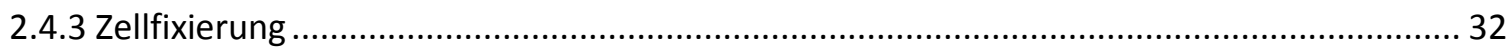

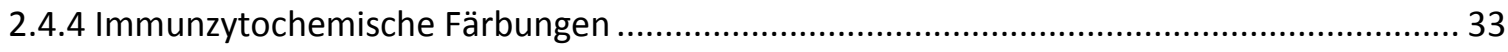

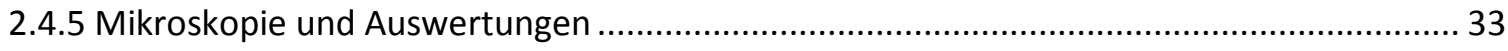

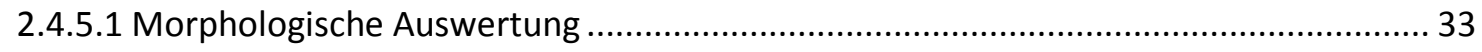

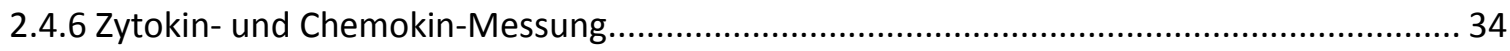

2.5 Statistische Auswertung der erhobenen Daten ........................................................ 34

3. Ergebnisse

3.1. Verhalten mikroglialer Zellen im Rückenmark des SOD1-G93A-Mausmodells nach Behandlung

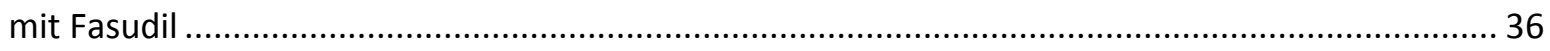

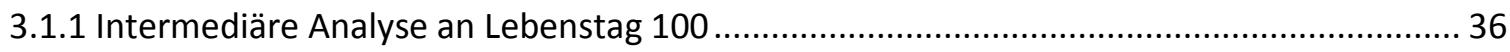

3.1.1.1 Fasudilbehandlung erhöht die Gesamtzahl mikroglialer Zellen im Rückenmark......... 37

3.1.1.2 Mikrogliazellmorphologie im Rückenmark nach Fasudil-Behandlung ....................... 39

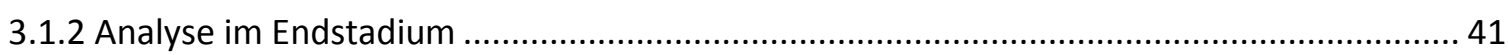

3.1.2.1 Im Endstadium bestehen keine mikroglialen Zellzahlveränderungen nach Behandlung

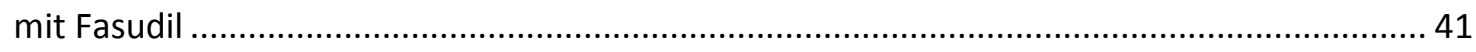

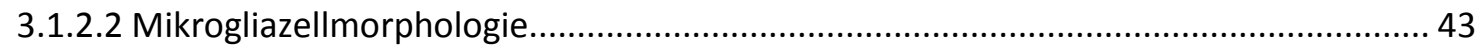

3.1.3 Mikroglia-Quantifizierung bei Analyse intermediär und Endstadium im Vergleich........... 44

3.2 Analyse stimulierter SOD1-G93A-transgener mikroglialer Zellen nach Behandlung mit Fasudil 45

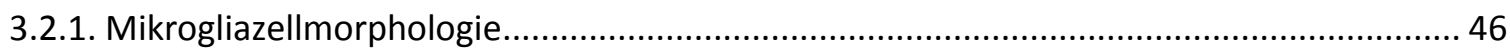

3.2.1.1 Gesamtzahl der Fortsätze pro Mikrogliazelle...................................................... 46

3.2.1.2 Fortsatzlängen pro Mikrogliazelle .................................................................. 48

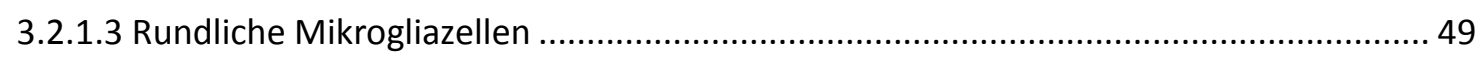

3.2.2 Mikrogliales Profil der Zytokine und Chemokine ..................................................... 50

3.2.2.1 Freisetzung von Zytokinen und Chemokinen nach Stimulation mit LPS ....................50

3.2.2.2 Kombinierte Behandlung mit LPS und Fasudil ............................................. 51

4. Diskussion............................................................................................................... 55

4.1 Proliferation mikroglialer Zellen unter Rock-Inhibition .................................................... 55

4.2 Veränderungen des morphologischen Phänotyps ..................................................... 57

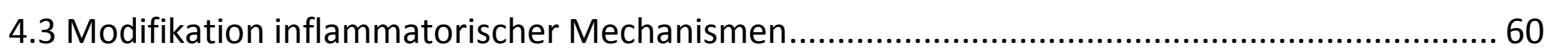


4.4 Neuroprotektion und Therapiepotential von Fasudil bei ALS .................................................. 63

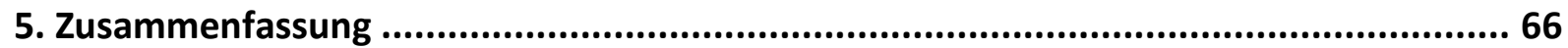

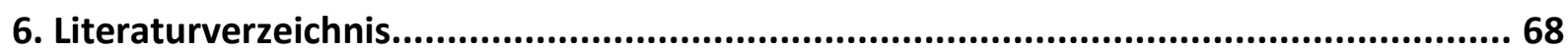

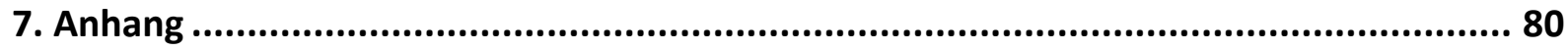

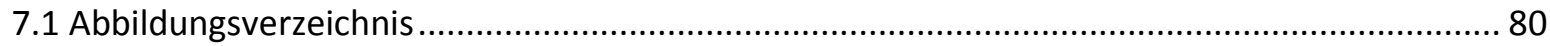

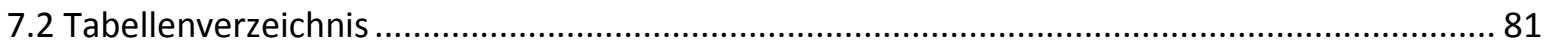

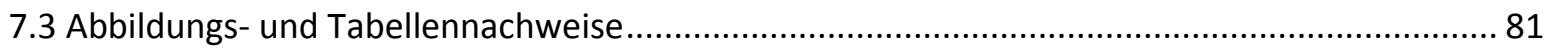

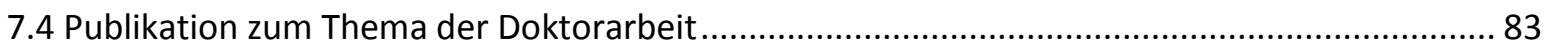




\section{Abkürzungsverzeichnis}

\begin{tabular}{|c|c|}
\hline ALS & Amyotrophe Lateralsklerose \\
\hline$A G$ & Arbeitsgruppe \\
\hline ATP & Adenosintriphosphat \\
\hline BSA & Bovines Serum-Albumin \\
\hline $\mathrm{Ca}^{2+}$ & Kalzium \\
\hline $\mathrm{CCL}$ & Chemokin-Ligand \\
\hline$C D$ & cluster of differentiation (Unterscheidungsgruppen) \\
\hline CRMP-2 & Collapsin response mediator protein-2 \\
\hline CSF & $\begin{array}{l}\text { Macrophage colony-stimulating factor (Makrophagen-Kolonie stimulierender } \\
\text { Faktor) }\end{array}$ \\
\hline CSF1R & $\begin{array}{l}\text { Macrophage colony-stimulating factor receptor (Makrophagen-Kolonie- } \\
\text { stimulierender Faktor-Rezeptor) }\end{array}$ \\
\hline$d$ & Tag \\
\hline DAPI & Diaminophenylindol \\
\hline dest. & destilliert \\
\hline DNA & desoxyribonucleic acid (Desoxyribonukleinsäure) \\
\hline EAE & experimentelle autoimmune Enzephalomyelitis \\
\hline ELISA & enzyme linked immunosorbent assay (antikörperbasiertes Nachweisverfahren) \\
\hline EMG & Elektromyographie \\
\hline fALS & familiäre Amyotrophe Lateralsklerose \\
\hline Fas & Fasudil \\
\hline FTD & frontotemporale Demenz \\
\hline FUS & fused in sarcoma \\
\hline GPX & Glutathionperoxidase \\
\hline $\mathrm{h}$ & Stunde \\
\hline $\mathrm{H}_{2} \mathrm{O}$ & Wasser \\
\hline $\mathrm{HCl}$ & Chlorwasserstoffsäure \\
\hline ॥ & Interleukin \\
\hline INF & Interferon \\
\hline kDa & Kilodalton \\
\hline
\end{tabular}




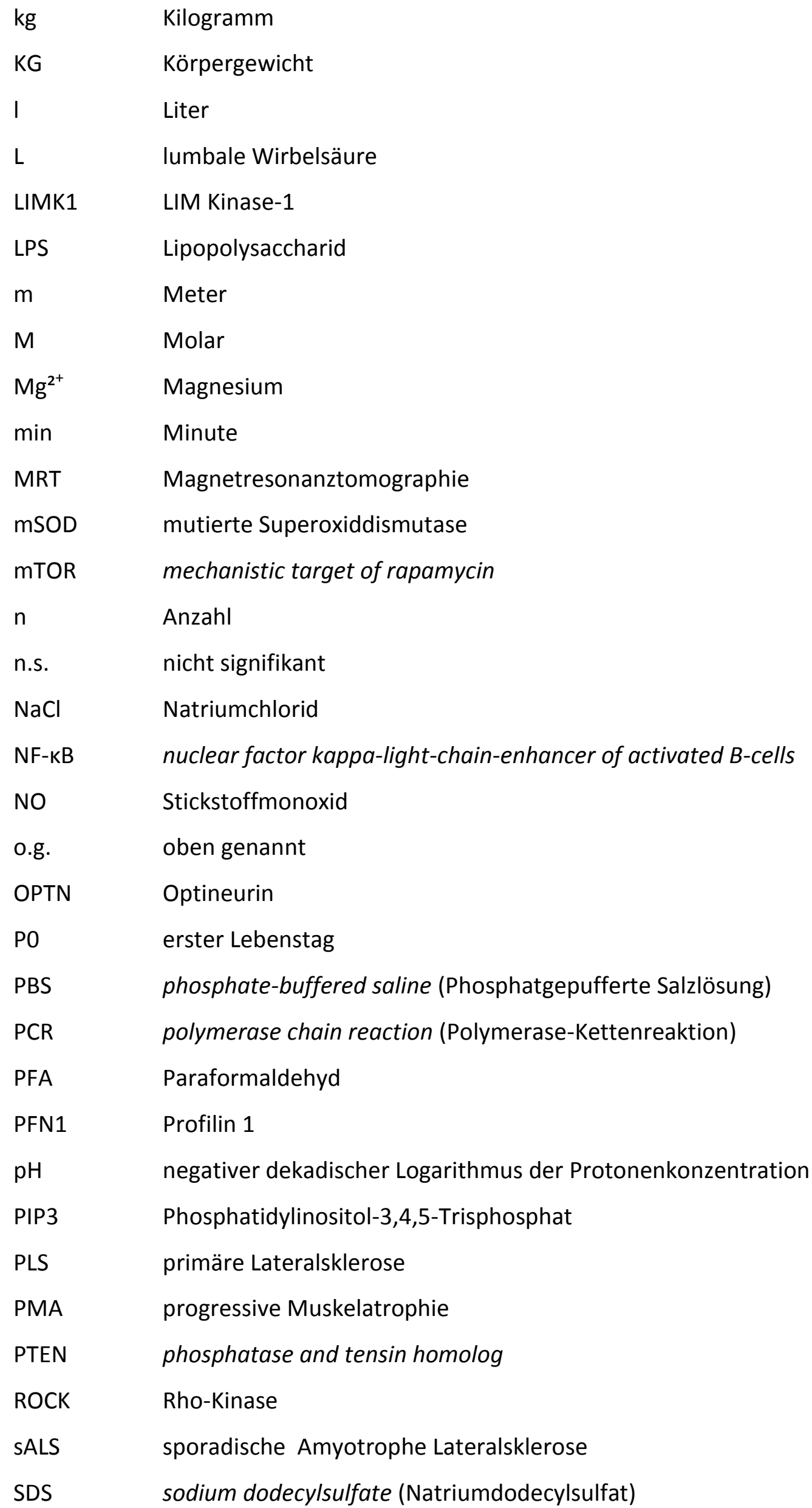




$\begin{array}{ll}\text { Sec } & \text { Sekunde } \\ \text { SEM } & \text { standard error of the mean (Standardfehler des Mittelwerts) } \\ \text { SOD } & \text { Superoxiddismutase } \\ \text { TARDB } & \text { TAR DNA-binding protein (TAR DNA bindendes Protein) } \\ \text { TBE } & \text { Tris-Borat-EDTA } \\ \text { TBS } & \text { Tris (hydroxymethyl)-aminomethan, gepuffert } \\ \text { TG } & \text { transgen } \\ \text { TGF } & \text { Transforming growth factor (Transformierender Wachstumsfaktor) } \\ \text { TLR } & \text { toll-like receptor (Toll-ähnlicher Rezeptor) } \\ \text { TNF } & \text { Tumornekrosefaktor } \\ \text { Tris } & \text { Tris (hydroxymethyl)-aminomethan } \\ \text { U } & \text { unified atomic mass unit (atomare Masseneinheit) } \\ \text { UBQLN2 } & \text { Ubiquilin 2 } \\ \text { UMG } & \text { Universitätsmedizin Göttingen } \\ \text { Veh } & \text { Vehikelbehandlung } \\ \text { WT } & \text { Wildtyp } \\ \text { ZNS } & \text { zentrales Nervensystem } \\ \text { ZTE } & \text { Zentrale Tiereinheit }\end{array}$




\section{Einleitung}

\subsection{Amyotrophe Lateralsklerose}

\subsubsection{Historie}

Der Begriff Amyotrophe Lateralsklerose (ALS) beschreibt eine unaufhaltsame neurodegenerative Erkrankung, die erstmals von dem französischen Neurologen JeanMartin Charcot wissenschaftlich ausführlich beschrieben wurde (Charcot und Joffroy 1869). Die ALS wurde daher zunächst unter dem Namen Charcotsche Sklerose bekannt. In den USA kennt man sie heute auch als Lou-Gehrings-Erkrankung, benannt nach einem bekannten Baseballspieler, der in den 1930er Jahren erkrankte (Cleveland und Rothstein 2001). „Amyotroph“ bezieht sich auf die Atrophie und Schwäche der Muskulatur. „Lateralsklerose“ bezeichnet die palpatorische Festigkeit der lateralen Abschnitte des Rückenmarks, wie sie in humanem Autopsiematerial gefunden wurde (Rowland und Shneider 2001).

\subsubsection{Epidemiologie}

Die ALS gehört zu der Gruppe der Motoneuronenerkrankungen (motor neuron diseases, MDN). Diese Erkrankungen sind charakterisiert durch eine Degeneration der motorischen Neurone mit konsekutivem Muskelschwund und Schwäche. Die motoneuronale Degeneration resultiert in einer Degeneration des kortikospinalen Traktes mit Beteiligung des ersten und oberen Motoneurons im motorischen Kortex, sowie des zweiten und unteren im Rückenmarksvorderhorn (Holloway und Emery 1982). Die ALS ist die häufigste Motoneuron Erkrankung des Erwachsenenalters. Die weltweite Prävalenz schwankt in verschiedenen Quellen zwischen 2-6 Erkrankten pro 100.000 Menschen. Die Inzidenz wird angegeben zwischen 0,4-2,7 pro 100.000. Die epidemiologischen Daten der ALS sind weltweit bis auf wenige Ausnahmen relativ vergleichbar (Chancellor und Warlow 1992; Tandan und Bradley 1985; Cleveland und Rothstein 2001; Chiò et al. 2013). In Süddeutschland liegt die Inzidenz zum Beispiel bei 2,5 pro 100.000 (Uenal et al. 2014). Man unterscheidet prinzipiell die sporadisch entstehende ALS (SALS) und die genetisch bedingte familiäre ALS (fALS) (Details in Kapitel 1.1.4). 90-95 \% aller ALS-Fälle sind sporadisch. Sie scheinen in der Bevölkerung zufällig aufzutreten. Es wird davon ausgegangen, dass der sporadischen Form ein Zusammenspiel von Umwelteinflüssen und genetischen Faktoren zugrunde liegt (Rothstein 2009; Renton et al. 2014). Mehrere epidemiologische Studien zeigen, dass das mittlere Erkrankungsalter von sporadischer ALS in den USA und Europa ca. 
56 Jahre beträgt. Das mittlere Todesalter liegt bei 59 Jahren. Die Erkrankungsdauer vom Beginn der Symptome bis zum Tod beträgt durchschnittlich 2,5 Jahre und das Verhältnis von männlichen zu weiblichen Erkrankten ist 2:1. Bei 5-10 \% aller ALS-Fälle handelt es sich um die familiäre Form der ALS mit einer positiven Familienanamnese (Cleveland und Rothstein 2001). In den meisten Fällen zeigen sporadische und familiäre ALS ein ähnliches klinisches Erkrankungsbild (Rosen et al. 1993). Bei der familiären ALS ist das mittlere Erkrankungsalter mit 45,1 Jahren jedoch früher und die mittlere Erkrankungsdauer mit 1,5 Jahren kürzer. Das Verhältnis von männlichen zu weiblichen Erkrankten ist bei der familiären ALS 1,2:1. Allgemein beträgt die 5-Jahres-Überlebenswahrscheinlichkeit nach Diagnosestellung nur ca. 7 \% (Tandan und Bradley 1985; del Aguila et al. 2003).

\subsubsection{Neuropathologie}

Neuropathologisch liegt der ALS eine kombinierte Degeneration des ersten und zweiten Motoneurons zugrunde. Das erste Motoneuron liegt im Motokortex, dem Teil der Großhirnrinde, der für Bewegungsabläufe verantwortlich ist. Dessen Axone bilden größtenteils den Tractus corticospinalis (Pyramidenbahn), der die Motoneurone des Rückenmarksvorderhorns (zweites Motoneuron) innerviert (Trepel 2012). Je nach Lokalisation einer Läsion oder Degeneration entwickelt sich eine spastische oder schlaffe Parese. Passend zu den Symptomen der ALS-Patienten sind neuropathologische Korrelate nachweisbar. In Autopsieproben von ALS-Patienten können der Verlust und die Degeneration der großen Zellen des Rückenmarksvorderhorns und der motorischen Hirnnervenkerne nachgewiesen werden. Der neuronale Verlust geht mit muskulärer Atrophie sowie einer Verringerung von Synaptophysin, einem Bestandteil der Membran der präsynaptischen Vesikel, im Vorderhorn einher. Weiterhin ist histopathologisch eine Akkumulation von phosphorylierten Neurofilamenten, Ubiquitin-positive Zelleinschlüsse, sowie Bunina Körperchen in den Zellsomata der Vorderhornzellen zu beobachten. Letztgenannte stellen eosinophile Proteineinschlüsse dar, in denen die Proteine Cystatin C und Transferrin nachgewiesen werden konnten (Hirano 1996; Okamoto et al. 2008). Auch in Mausmodellen der ALS konnten Zeichen neuronaler Degeneration wie Vakuolen und der Verlust von Motoneuronen nachgewiesen werden (Brandt 2001; Dal Canto und Gurney 1994). Ebenso kommt es zu einem Verlust der Myelinscheiden von Motoneuronen. Im Endstadium der Erkrankung sind bis zu 50 \% der Motoneurone des Hirnstamms und Rückenmarks der Tiere zugrunde gegangen (Chiu et al. 1995). Weiterhin sind eine begleitende Gliose und intrazytoplasmatische Proteinaggregate zu beobachten (Soto 2003). 


\subsubsection{Genetik}

Genetische Veränderungen spielen sowohl bei der familiären als auch bei der sporadischen ALS eine bedeutende Rolle. In den letzten Jahren gab es in diesem Bereich einen enorm schnellen Wissensfortschritt, und es wurden viele neue Gene entdeckt, deren Mutation mit $\operatorname{der}$ ALS in Zusammenhang stehen. Heute ist die genetische Ätiologie von ca. zwei Dritteln der familiären und ca. $11 \%$ der sporadischen Fälle bekannt (Renton et al. 2014). Die familiäre ALS wird typischerweise autosomal dominant vererbt und zeigt eine sehr variable Penetranz. Das SOD1-Gen, das für das Enzym Superoxiddismutase (SOD) kodiert, war das erste, bei dem ein Zusammenhang zur fALS identifiziert wurde.

Das SOD1-Gen, das auf Chromosom 21 liegt, kodiert für die Kupfer-Zink-Superoxiddismutase (SOD1) (Rosen et al. 1993). Die SOD1 ist ein homodimeres Protein aus 153 Aminosäuren mit einem Molekulargewicht von $32 \mathrm{kDa}$, das ubiquitär exprimiert wird (Bruijn et al. 2004). Das Enzym katalysiert die Umwandlung freier Superoxidradikale zu Sauerstoff und Wasserstoffperoxid. Superoxidradikale sind zelltoxisch, da sie anderen Molekülen Ionen entziehen können. Durch das Enzym werden sie enttoxifiziert. Das anfallende Wasserstoffperoxid wird durch die Katalase und die Glutathionperoxidase weiter abgebaut (Berlit 2006).

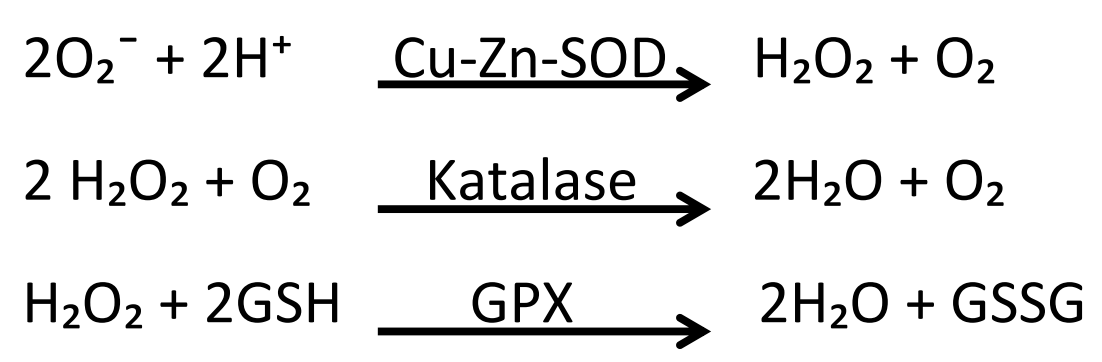

GPX: Glutathionperoxidase

Abbildung 1: Abbau von Superoxidradikalen (verändert nach Berlit 2006).

Die krankheitsauslösenden Mutationen des Gens sind Punktmutationen, von denen zum Zeitpunkt des Verfassens der vorliegenden Arbeit mehr als 150 bekannt sind. Die häufigsten sind der Austausch der Aminosäure Valin für Alanin in Kodon 4 (A4V), bei 50 \% der Patienten mit einer SOD1-Mutation (mSOD1) nachweisbar, und der Austausch von Alanin für Glycin in Position 93 der Proteinsequenz (G93A) (Cudkowicz et al. 1997). Es gibt eine erhebliche Heterogenität des klinischen Bildes wie der Beginn der Symptome, der Schweregrad, die Progression und die Dauer, zwischen verschiedenen Mutationen des Gens (Chen et al. 2013). So ist zum Beispiel die AV4-Mutation mit einem besonders kurzen Überleben von im Durchschnitt nur einem Jahr und einer hohen Penetranz von $91 \%$ assoziiert. Es wird 
berichtet, dass eine Mutation des SOD1-Gens für ca. $20 \%$ der familiären und ca. $1 \%$ der sporadischen Fälle verantwortlich ist (Pasinelli und Brown 2006). Als die SOD1-Mutation erstmals identifiziert wurde ist man von einer loss of function-Mutation ausgegangen, bei der das Genprodukt verminderte oder keine Funktion hat. Neue Untersuchungen zeigen allerdings, dass es sich eher um eine gain of function-Mutation handelt (Saccon et al. 2013). Dabei ändert sich das Genprodukt so, dass es eine andere Funktion erhält. Die Entwicklung der Toxizität durch die Mutation ist dabei immer noch nicht gänzlich geklärt. Es werden in diesem Zusammenhang viele Hypothesen diskutiert (Details in Kapitel 1.1.5). Die Entdeckung der SOD1-Mutation führte zu der Entwicklung zahlreicher SOD1-transgener Mausmodelle, von denen sich das SOD1-G93A-Mausmodell, das für die vorliegende Arbeit benutzt wurde, sehr gut etablierte (Details in Kapitel 1.1.9). Weitere Gene, deren Mutation mit fALS in Verbindung gebracht werden, sind zum Beispiel TARDBP (TAR DNA-binding protein), C9ORF72, FUS (fused in sarcoma), OPTN (Optineurin), VCP (Valosin-containing protein), UBQLN2 (Ubiquilin 2), SQSTM1 (Sequestosome 1), PFN1 (Profilin 1) und viele andere mehr. Das TARDBP-Gen kodiert für das TDP43-Protein, das Hauptbestandteil der Ubiquitinpositiven intraneuronalen Einschlüsse ist, die typischerweise bei ALS, aber auch bei mehr als der Hälfte der Patienten mit frontotemporaler Demenz (FTD) zu finden sind. Diese Entdeckung deutet darauf hin, dass diese beiden Leiden weniger als getrennte klinische Entitäten, sondern als Erkrankungsspektrum anzusehen sind (Renton et al. 2014; van Damme und Robberecht 2013). Mutationen des FUS-Gens und des TARDBP-Gens erklären jeweils ca. 4 \% der fALS Fälle (Renton et al. 2014). Die Verlängerung des C9ORF72-Gens durch Hexanukleotidwiederholungen ist die am häufigsten nachweisbare Mutation bei familiärer ALS (Pamphlett et al. 2013). Diese Mutation tritt bei $40-50 \%$ aller fALS-Fälle auf und wurde nun auch bei einigen Fällen von sALS gefunden. Diese Entdeckung stellt die traditionelle Trennung von sporadischer und familiärer ALS somit in Frage (van Damme und Robberecht 2013; Turner et al. 2013). Insgesamt besteht im genetischen Spektrum der fALS und SALS eine große Heterogenität. Viele der ALS-Gene sind bekannt dafür auch andere neurodegenerative Erkrankungen hervorzurufen, und es gibt eine Überlappung zur FTD (Chen et al. 2013).

\subsection{5 Ätiologie und Pathogenese}

Axonale Degeneration ist die primär ätiologische und pathologische Eigenschaft der ALS. Hierfür werden mannigfaltige Gründe angeführt (Orrell 2007). Nach heutigem Wissensstand besteht eine große Heterogenität in den pathogenetischen und pathophysiologischen Mechanismen der ALS. Neben Proteinfehlbildung, toxischen Proteinaggregaten und oxidativem Stress werden auch andere Mechanismen wie beeinträchtigter Proteinabbau und Autophagie, Störungen im RNA-Metabolismus, Toxizität von RNA, RNA-Translation, mitochondriale Dysfunktion, fehlerhafter axonaler Transport und exogene Faktoren wie 
Expositionen in Umwelt oder Arbeit, diskutiert (Mitchell und Borasio 2007). Es wird vermutet, dass der Erkrankung somit sehr wahrscheinlich eine multifaktorielle Genese zugrunde liegt. Eine vereinheitlichende Hypothese wie diese Mechanismen in einem gemeinsamen Weg zusammenlaufen gibt es bisher nicht. Die Heterogenität auf verschiedenen Ebenen hat dazu geführt, dass einige Autoren die ALS als Teil eines Spektrums neurodegenerativer Erkrankungen betrachten, anstatt von einer für sich stehenden Erkrankung auszugehen (van Damme und Robberecht 2013; Goodall und Morrison 2006).

Im Folgenden sollen die wichtigsten in der Literatur diskutierten pathogenetischen Hypothesen besprochen werden.

Oxidativer Stress ist sehr wahrscheinlich ein zentraler Bestandteil der Pathogenese der ALS und kann durch Modifizierung von DNA, Lipiden und Proteinen zu zellulärem Schaden und Degeneration durch freie Sauerstoffradikale führen (Simpson et al. 2003). Hierfür sprechen zum einen erhöhte Werte von biochemischen Markern oxidativen Schadens in ALS-Patienten (Bogdanov et al. 2000) und zum anderen die positive Wirkung einer antioxidativen Therapie auf das Überleben in transgenen Mausmodellen (Wu et al. 2003). Die Toxizität entsteht dabei wahrscheinlich nicht nur durch eine mangelnde Detoxifizierung der freien Radikale, sondern auch durch eine mitochondriale Dysfunktion (Goodall und Morrison 2006; Menzies et al. 2002). Fehlfunktionen der Mitochondrien sind schon früh in die Pathogenese der ALS involviert und tragen zur Erkrankungsprogression bei. Es wird im Zusammenhang mit diesem Organell über viele mögliche Einbindungen in die Pathogenese der Erkrankung diskutiert (Shi et al. 2010b). Relevant ist dabei unter anderem die Generation von intrazellulärem Adenosintriphosphat (ATP) und Spezies freier Radikale sowie die Calcium-Homöostase (Menzies et al. 2002). Eine Rolle in der Pathogenese spielt wahrscheinlich auch Glutamat. Der Neurotransmitter wirkt bei der ALS durch einen verminderten astrozytären Transport oder durch gesteigerte Freisetzung in verstärktem Maße exzitotoxisch und kann zur Degeneration von Neuronen beitragen (Milanese et al. 2011). Neben Astrozyten scheinen auch Mikrogliazellen einen starken Beitrag an der Pathophysiologie der ALS zu haben. Sie sind in engem Kontakt mit Motoneuronen und in die Entwicklung der chronischen Entzündungsreaktion des ZNS involviert. Dieser Prozess ist ein pathologisches Kennzeichen der ALS und wird von Mikrogliazellen, den ansässigen Immunzellen im ZNS, moduliert (Details in Kapitel 1.3.1) (Philips und Robberecht 2011; Appel et al. 2011).

Es wird in der Literatur weiterhin diskutiert, ob exogene Faktoren wie Toxine, Virusinfektionen, Metallexposition oder auch sportliche Aktivität, Arbeit in der Textil- oder Kunststoffindustrie, Landarbeit, mechanische Traumata und Belastung durch Schweißarbeiten zur Erkrankung beitragen (Goodall und Morrison 2006). Dies ist wie die These, dass professionelle Fußballspieler ein erhöhtes Risiko besitzen, allerdings umstritten (Chiò et al. 2005). In der jüngeren Literatur wird viel über die RNA-, DNA- und Proteinhomöostase als mögliche Ursachen der ALS diskutiert. Dieser Ansatz wird besonders seit der Entdeckung von Mutationen der Gene TARDBP und FUS in ALS-Patienten, die für die RNA-bindenden Proteine TDP43 und FUS kodieren, verfolgt. Seitdem wird dem RNA- und 
DNA-Metabolismus eine große Bedeutung in der Pathogenese der ALS zugesprochen (Mackenzie et al. 2010; Dion et al. 2009).

Viele Rückschlüsse auf die möglich Pathogenese der ALS wurden durch Forschung mit Mausmodellen erzielt. Sehr weit verbreitet ist das SOD1-transgene Mausmodell, im speziellen das SOD1-G93A-Mausmodell (Details in Kapitel 1.1.9), das auch für die vorliegende Arbeit genutzt wurde. Die Mechanismen der Toxizitätsentwicklung durch die Mutation des Enzyms SOD1 sind noch nicht vollständig geklärt. So wird in der Literatur zum Beispiel diskutiert, ob eine Aggregation des Enzyms ursächlich für die Erkrankung ist. Dafür spricht, dass bei ALS-Patienten SOD1-positve Zelleinschlüsse zu finden sein können (Chen et al. 2013). Diese Einschlüsse entstehen durch fehlgefaltete SOD1-Enzyme, die daraufhin Proteinaggregate bilden. Der Mechanismus der Fehlfaltung des Proteins ist bisher nicht bekannt. Ebenso ist unklar, ob die Aggregate die Erkrankung bedingen, oder als Folge der Erkrankung auftreten. Es scheint allerdings einen Zusammenhang der Proteinaggregation mit dem Calciumhaushalt zu geben. So zeigte Leal et al. (2013), dass SOD1-Aggregation durch Calcium unterstützt und moduliert wird. Dafür spricht auch, dass durch eine gesteigerte Pufferkapazität der Mitochondrien für Calcium eine verminderte Aggregation von SOD1 zu beobachten ist (Parone et al. 2013).

In den letzten Jahren hat die Hypothese der distalen Axonopathie viel Aufmerksamkeit erhalten. Diese geht davon aus, dass sich pathologische Veränderungen zuerst distal an der neuromuskulären Endplatte zeigen und sich dann nach proximal, in Richtung des Zellkörpers ausbreiten. Unterstützt wird diese These durch Studien die zeigen, dass neuromuskuläre Synapsen vor der Degeneration der Motoneurone und auch vor dem Einsetzen klinischer Defizite selektiv zugrunde gehen (Frey et al. 2000; Moloney et al. 2014). In der präsymptomatischen Phase der Erkrankung kommt es so durch eine Veränderung des distalen Zytoskeletts zu einem Verlust der synaptischen Integrität. Ein Auslöser könnten das verminderte Vorhandensein neurotropher Faktoren wie glial cell line derived neurotrophic factor (GDNF), insulin-like growth factor (IGF-1), ciliary neurotrophic factor (CNTF) und vascular endothelial growth factor (VEGF), im Verlauf der Erkrankung sein. Studien konnten auch zeigen, dass die andauernde Bereitstellung der neurotrophen Faktoren die Erkrankungsprogression verlangsamt (Moloney et al. 2014). Ebenfalls zur Degeneration der distalen Axone beitragen soll eine Verlangsamung des axonalen Transports (Krakora et al. 2012). Dabei ist vor allem der retrograde Transport durch Interaktion der mSOD1 mit dem Motorprotein Dynein betroffen. Da gezeigt werden konnte, dass eine Mutation im DyneinGen Symptome einer Motoneuronenerkrankung auslösen kann (Puls et al. 2003), wird angenommen, dass die Beeinträchtigung des axonalen Transports zur Ätiologie der ALS beitragen könnte (Shi et al. 2010a; Shi et al. 2010b). 


\subsubsection{Klinische Symptome}

Die ALS ist charakterisiert durch das Vorliegen von zentralen und peripheren Paresen, die durch die Degeneration der Motoneurone im Kortex (erstes Motoneuron) und ihrer Axone in der Pyramidenbahn sowie der zweiten Motoneurone im Rückenmarksvorderhorn bedingt sind (Körner et al. 2011). Durch Degeneration des ersten Motoneurons kommt es klinisch zu Spastiken und gesteigerten Reflexen, die Schädigung des zweiten Motoneurons führt zu Muskelatrophie, Schwäche und Faszikulationen (Rowland und Shneider 2001). Die Patienten erleiden dabei meist keine Einschränkungen der Sensibilität (Kiernan et al. 2011). Eine Schwäche der Muskeln des Atemapparats und des Diaphragmas sind oft mit Todesfolge verbunden (Cheah et al. 2009).

Klinisch unterschieden werden: Die klassische ALS mit Defiziten des oberen und unteren Motoneurons, die primäre Lateralsklerose (PLS) als reines Syndrom des oberen Motoneurons, die progressive Muskelatrophie (PMA) mit ausschließlicher Affektion des zweiten Motoneurons und das Vulpain-Bernhard Syndrom, bei dem es oft initial zu einer Parese der oberen Extremitäten ohne Reflexsteigerung kommt (DGN 2015)

Klinische Bilder der ALS:

- Klassische ALS

- Primäre Lateralsklerose (PLS)

- Progressive Muskelatrophie (PMA)

- Vulpian-Bernhard Syndrom (fail arm syndrom)

Grundsätzlich kann zwischen einem bulbären und einem spinalen Beginn der ALS unterschieden werden (Hardiman et al. 2011). Die Mehrzahl der Patienten (60 \%) zeigt einen spinalen Beginn, der durch erste Symptome an den Extremitäten charakterisiert ist. Hier sind Muskelkrämpfe, Schwäche und Faszikulationen oft an der kleinen Handmuskulatur oder Fußmuskulatur (pseudopolyneuritische Form) zu beobachten. Später entstehen Paresen der Beine oder Arme. Die Patienten berichten anamnestisch über Ungeschicklichkeit der Hände, häufige Stürze, Schwierigkeiten beim Aufstehen oder Treppensteigen. In der Regel breiten sich die Paresen an den Extremitäten von distal nach proximal aus. Trotz des Vorliegens von peripheren Paresen und Atrophien sind Muskeleigenreflexe meist lebhaft bis gesteigert auslösbar. Beim bulbären Beginn, der bei 30 \% der Patienten auftritt, zeigen sich initial Symptome an der Kau- und Schluckmuskulatur (progressive Bulbärparalyse), also an der Muskulatur, die von den motorischen Hirnnervenkernen innerviert wird. Hier Kommt es zu Artikulationsstörungen, sowie Problemen bei der Nahrungsaufnahme durch Atrophie der Zungen- Mundboden- und Gaumenmuskulatur. Das Entweichen von Speichel ist dabei für die Patienten besonders belastend. Später münden die Symptome in Anarthrie und Unfähigkeit den Schluckakt durchzuführen (Hardiman et al. 2011; Berlit 2006). Der 
Krankheitsbeginn mit bulbären Symptomen zeigt einen aggressiveren Verlauf und hat eine schlechtere Prognose als die ALS mit spinalem Beginn (Wijesekera et al. 2009).

Bei der ALS handelt es sich auch um eine Erkrankung, die als Multisystemdegeneration eingestuft wird und nicht ausschließlich motorische Symptome hervorruft, d.h. auch extramotorische Hirnregionen sind in den Krankheitsprozess involviert. So werden zum Beispiel Organbeteiligungen, wie die Störungen der gastrointestinalen Motilität, Hautveränderungen und Pankreasfunktionsstörungen bei gestörter Glukosetoleranz durch endokrine Funktionsstörungen beschrieben (Ikeda et al. 1995). Zum Bild der ALS kann auch eine Affektlabilität mit pathologischem Lachen oder Weinen sowie ungewollte Gesichtsbewegungen gehören (Olney et al. 2011). Sowohl bei sporadischer als auch bei familiärer ALS können Symptome auftreten, die das Frontalhirn betreffen. So sind Veränderungen der Persönlichkeit, des Benehmens, der Fähigkeit zu planen oder organisieren und sprachliche Dysfunktionen zu beobachten. Diese Symptome waren jeher bekannt für Erkrankungen, die mit einer Degeneration des Frontalhirns einhergehen, wie der frontotemporalen Demenz (Lomen-Hoerth et al. 2003).

\subsubsection{Diagnosestellung}

Da es bei der ALS derzeit keine sicheren biologischen Marker und keine sicheren spezifischen neuroradiologischen- und neurophysiologischen Merkmale gibt, stützt sich die Diagnose hauptsächlich auf das klinische Bild (Zoccolella et al. 2005; Li et al. 1991). Insbesondere die Elektromyographhie (EMG) ist eine wichtige Zusatzuntersuchung (Kiernan et al. 2011). Die Basisdiagnostik sollte auch zur Abgrenzung von Differentialdiagnosen eine klinischneurologische Untersuchung, eine klinisch-neuropsychologischen Befunderhebung, Elektromyographie und -neurographie, MRT-Bildgebung, Vitalkapazität und gegebenenfalls Blutgasanalyse, Körpergewicht und Body-Mass-Index sowie Basislabordiagnostik enthalten (DGN 2015). Zur erleichterten Diagnosestellung wurden 1994 die El Escorial-Kriterien durch die World Federation of Neurology erstellt und 1998 revidiert um ihre Sensitivität für die Diagnose einer ALS zu erhöhen (Brooks et al. 2000). Sie zeigen die klinischen Voraussetzungen für eine Diagnose einer ALS durch charakteristische Bilder der Läsion des ersten und zweiten Motoneurons und geben Wahrscheinlichkeiten für die Diagnose anhand der Anzahl betroffener Körperregionen an (Berlit 2006). 


\begin{tabular}{|l|l|}
\hline & Klinische Voraussetzungen für die Diagnose einer ALS \\
\hline A & Anwesenheit von: \\
\hline A1. & $\begin{array}{l}\text { Zeichen der Läsion des zweiten Motoneurons durch klinische, } \\
\text { elektrophysiologische, oder neuropathologische Untersuchungen. }\end{array}$ \\
\hline A2. & Zeichen der Läsion des ersten Motoneurons durch klinische Untersuchung \\
\hline A3. & Progredienz der Symptome in einer, oder mehreren Regionen \\
\hline B & Abwesenheit von: \\
\hline B1. & $\begin{array}{l}\text { Elektrophysiologischen, oder pathologischen Zeichen anderer } \\
\text { Krankheitsprozesse, die die Zeichen der Läsion des ersten oder zweiten } \\
\text { Motoneurons erklären. }\end{array}$ \\
\hline B2. & $\begin{array}{l}\text { Bildgebenden Zeichen anderer Krankheitsprozesse, die die klinisch- und } \\
\text { elektrophysiologisch beobachteten Zeichen erklären. }\end{array}$ \\
\hline
\end{tabular}

\begin{tabular}{|l|l|}
\hline & Diagnostische Kategorien der ALS-Diagnose \\
\hline Klinisch sichere ALS & $\begin{array}{l}\text { Zeichen der Läsion des ersten und zweiten Motoneurons in } \\
\text { mindestens 3 von 4 Regionen (bulbär, zervikal, thorakal, } \\
\text { lumbosakral) }\end{array}$ \\
\hline $\begin{array}{l}\text { Klinisch } \\
\text { wahrscheinliche ALS }\end{array}$ & $\begin{array}{l}\text { Zeichen der Läsion des ersten und zweiten Motoneurons in 2 } \\
\text { von 4 Regionen (Zeichen des ersten Motoneurons rostral zu den } \\
\text { Zeichen des zweiten Motoneurons) }\end{array}$ \\
\hline $\begin{array}{l}\text { Klinisch } \\
\text { wahrscheinliche } \\
\text { laborunterstützte ALS }\end{array}$ & $\begin{array}{l}\text { Zeichen der Läsion des ersten und zweiten Motoneurons in 1 } \\
\text { von 4 Regionen (oder nur Zeichen des ersten Motoneurons in } \\
\text { einer Region) und Denervierungszeichen des zweiten } \\
\text { Motoneurons in der Elektromyographie (EMG) in mindestens } \\
\text { zwei Regionen. }\end{array}$ \\
\hline Klinisch mögliche ALS & $\begin{array}{l}\text { Zeichen der Läsion des ersten und zweiten Motoneurons in 1 } \\
\text { von 4 Regionen oder nur Zeichen der Läsion des ersten } \\
\text { Motoneurons in mehr als zwei Regionen oder Zeichen der Läsion } \\
\text { des zweiten Motoneurons rostral zu Zeichen der Läsion des } \\
\text { ersten Motoneurons und kein Beweis für klinisch } \\
\text { wahrscheinliche -laborunterstützte- ALS }\end{array}$ \\
\hline
\end{tabular}

Tabelle 1: El Escorial-Kriterien (verändert nach Brooks et al. 2000).

Laut der Leitlinie für die ALS der Deutschen Gesellschaft für Neurologie (2015) sollen die El Escorial-Kriterien allerdings nur als wissenschaftliches Hilfsmittel angesehen werden, da sie für den klinischen Gebrauch zu eng gefasst seien und einer frühen Diagnose der ALS im Wege stünden. Im Jahr 2008 wurden neue Kriterien für die neurophysiologische Diagnose der ALS veröffentlicht. Diese Awaji-Shima-Kriterien unterscheiden sich von den anerkannten El Escorail-Kriterien durch eine stärkere Beachtung der EMG-Untersuchung und erhöhen nach aktuellen Studien die Sensitivität der Diagnose ohne die Spezifität zu verschlechtern (Douglass et al. 2010). Diagnostisch können bei ALS-Patienten im EMG Muskelfaszikulationen, sowie Fibrillationspotentiale und positive scharfe Wellen als Zeichen aktiver oder chronischer Denervierung des zweiten Neurons festgestellt werden. Dabei sind Faszikulationen in der Muskulatur sensitiver zu diagnostizieren als in der klinischen 
Untersuchung (Dengler und Petri 2012). Die Elektroneurographie dient zur Beurteilung der Nervenleitgeschwindigkeit des peripheren Nervs. Diese ist bei ALS, durch den Verlust von großen, schnell leitenden motorischen Fasern, meist erst in späten Stadien festzustellen. Differentialdiagnostisch kommen bei verminderter Leitungsgeschwindigkeit auch demyelinisierende Neuropathien in Frage (Feinberg et al. 1999). Genetische Testungen sind bei positiver Familienanamnese sinnvoll um Genmutationen identifizieren zu könne (Hübers et al. 2013). Weitere Untersuchungen dienen vornehmlich dem Ausschluss möglicher Differentialdiagnosen. Mittels zusätzlicher Bildgebung können strukturelle Läsionen wie Spinalkanalstenosen, zervikale Myelopathien, Syringomyelie, spinale Tumoren oder Zysten ausgeschlossen werden. Erweiterte Blutuntersuchungen können infektiologische Erkrankungen sowie metabolische Störungen auszuschließen. Differenzialdiagnosen wie Vaskulitiden oder seltene Muskelerkrankungen, wie die Einschlusskörperchenmyositis, können eine Nerven- oder Muskelbiopsie notwendig werden lassen (Körner et al. 2011). Vor allem in frühen Phasen der Erkrankung kann die ALS aufgrund hoher klinischer Heterogenität leicht fehldiagnostiziert werden und sich dadurch eine adäquate Behandlung verzögern (Chiò 1999). Eine frühe Diagnose der ALS ist jedoch aufgrund der fatalen Prognose und der eingeschränkten Wirksamkeit der Therapie anzustreben. Um negative Auswirkungen auf das Outcome der Patienten zu vermeiden, sollten mögliche Differentialdiagnosen zeitnah ausgeschlossen werden (Ross et al. 1998). In der aktuellen Literatur werden Biomarker für die ALS postuliert, die möglicherweise in Zukunft helfen könnten, eine frühere Diagnose zu stellen und die Progression der Erkrankung besser einschätzen zu können (Bowser et al. 2011; Robelin und Gonzalez De Aguilar 2014). Diskutiert werden dabei körpereigene Proteine und Hormone, die aus dem Blut oder Liquor gewonnen werden können, wie zum Beispiel pNFH (Phosphorylated neurofilament heavy protein), CD14, S100ß, Cystatin C, Transthyretin, a2 Glykoprotein, Komplementfaktor C3, Fetuin-A (Bowser et al. 2011).

\subsubsection{Therapie}

Bei der Therapie der ALS ist prinzipiell zwischen einer kausal orientierten, pharmakologischen Therapie und einer symptomatischen bzw. palliativen Therapie zu unterscheiden. Die einzig zugelassene kausal orientierte Pharmakotherapie ist derzeit das Medikament Riluzol. Bensimon et al. zeigte (1994) erstmals in einer doppelt verblindeten, Plazebo kontrollierten, retrospektiven Studie, dass Riluzol einen positiven, stabilisierenden Effekt auf die Progression der ALS hat. Riluzol (6-(Trifluormethoxy)-1,3-benzothiazol-2-amin) bewirkt eine verminderte Freisetzung des exzitatorischen Neurotransmitters Glutamat durch Blockierung des Glutamatrezeptors (Martin et al. 1993). Eine Dosis von 100mg Riluzol pro Tag kann das Leben von ALS-Patienten um 6 bis 20 Monate verlängern (DGN 2015; Lacomblez et al. 1996). Andere pharmakologische Ansätze befinden sich noch in der experimentellen Phase. Dabei erschwert die noch nicht vollständig geklärte Ätiologie der ALS 
die Entwicklung einer effektiven Therapie. Dennoch gibt es immer wieder neue Therapieansätze um die Progression der ALS zu verlangsamen (Van den Berg, Leonard H 2014). Ein vielversprechender Ansatz ist der in dieser Arbeit verwendete Rho-Kinase (ROCK) Inhibitor Fasudil (Details in Kapitel 1.2).

Das Ziel der symptomatischen Therapie ist es, Beschwerden der Patienten zu lindern und Lebensqualität so lange wie möglich zu erhalten (DGN 2015). ALS-Patienten profitieren von einer Behandlung durch ein multidisziplinäres Team von Neurologen, erfahrenen Schwestern, Physiotherapeuten, Logopäden, Pulmonologen, Psychologen, Ernährungsberatern und Sozialarbeitern (Traynor et al. 2003). Krankengymnastik und Ergotherapie ist sinnvoll um Restfunktionen bei Paresen zu fördern und Immobilitätsfolgen zu vermeiden. Eine Thromboseprophylaxe sollten Patienten mit Paresen erhalten, die ein erhöhtes Thromboserisiko aufweisen. Muskelfaszikulationen und Spastiken können mit Magnesium oder Antispastika behandelt werden. In beiden Fällen sind auch physiotherapeutische Anwendungen und Krankengymnastik zu empfehlen (DGN 2015). Dyspnoe bis hin zur respiratorischen Insuffizienz sollte symptomatisch behandelt werden. Hier ist eine Pneumonie-Prophylaxe durch Atemgymnastik, unterstützende Medikation, gegebenenfalls antibiotische Therapie bei Pneumonie oder nicht invasive Heimbeatmung zu erwägen. Besonders bulbäre Symptome wie Hypersalivation, Dysarthrie, Laryngospasmen und Dysphagie sind therapiebedürftig, da diese für die Patienten sehr belastend sind und das Pneumonierisiko erhöhen (Kühnlein et al. 2008). Nicht selten entwickeln ALS-Patienten Symptome einer depressiven Stimmungslage. Daher kann der Einsatz von Antidepressiva und eine psychosoziale Betreuung erwogen werden (Lulé et al. 2008). Eine Schmerztherapie sollte sich an dem Stufenschema der WHO orientieren (DGN 2015).

\subsubsection{Tiermodelle der ALS}

Um die Mechanismen der ALS zu untersuchen und Rückschlüsse auf die Pathogenese ziehen zu können, wurden transgene Mausmodelle entwickelt, bei denen die Tiere durch Genmutationen eine selektive Motoneuron Degeneration zeigen (Cleveland et al. 1996). Das erste Mausmodell wurde nach der Entdeckung des SOD1-Gens 1993 entwickelt und entsprechend stammen viele Erkenntnisse der Ätiologie und Pathogenese von Studien, die dieses Mausmodell nutzen (Vinsant et al. 2013). Obwohl nur ca. 20\% aller familiären ALSFälle durch eine Mutation im Cu/Zn-Superoxiddismutase (SOD1)-Gen verursacht werden, ist das SOD1-Mausmodell aufgrund seiner guten klinischen und neuropathologischen Charakterisierung das derzeit meist genutzte Tiermodell der ALS. Von verschiedenen Modellen mit transgener Expression der SOD1-Mutation, wie zum Beispiel G93A, G85R, G37R und G86R, hat sich das SOD1-G93A-Mausmodell am besten etabliert (Turner und Talbot 2008). Die vorliegende Arbeit basiert auf dem Letztgenannten, bei dem die genutzten 
Tiere die Punktmutation Alanin für Glycin in Position 93 (SOD $1^{\mathrm{G} 93 \mathrm{~A}}$ ) besitzen. Diese Tiere entwickeln fokale periphere Paresen, sterben an einer respiratorischen Insuffizienz und imitieren so die humane ALS sehr nah (DGN 2015; Gurney et al. 1994). Erste Zeichen der Erkrankung, ein feines Zittern oder Tremor in den Extremitäten, entwickeln sich durchschnittlich am 91. Lebenstag. Die Tiere zeigen Spastiken und Hyperreflexibilität. Mit weiterer Progression der Erkrankung entwickelt sich eine Schwäche und Atrophie. Diese beginnt um den Tag 125 und ist meist in den Hinterbeinen stärker ausgeprägt als in den Vorderbeinen. Die Schwäche wird im weiteren Verlauf ausgeprägter, während Spastiken und Hyperreflexie zurückgehen. An Tag 80 sind 60 Prozent der Endplatten denerviert, der Motoneuronenverlust beginnt um den 80. bis 90. Lebenstag (Fischer et al. 2004). Im Endstadium der Erkrankung zeigen sich schwere Lähmungen. Die Tiere liegen auf der Seite und sind unfähig sich aufzurichten. Lähmung und Tod treten durchschnittlich um den 136. Lebenstag ein. Das Gewicht ist bis ungefähr zum 75. Lebenstag normal und stagniert dann. In den letzten beiden Wochen der Erkrankung verlieren die Mäuse 10 \% ihres Körpergewichts (Chiu et al. 1995; Turner und Talbot 2008). Sowohl die histopathologischen Veränderungen als auch die klinische Erscheinung sind dabei vergleichbar mit der humanen ALS, sodass das SOD1-Tiermodell für die Erforschung der Pathogenese, aber auch der Entwicklung therapeutischer Strategien, sehr gut etabliert ist (DGN 2015).

In jüngerer Vergangenheit wurden Mutationen in weiteren Genen gefunden, die ursächlich für die ALS sind. Hierzu zählen zum Beispiel TARDBP, FUS und C9ORF72. Diese Entdeckungen führten zur Generierung weiterer Mausmodelle. Das TARDBP-Gen kodiert für das TDP-43 Protein, dass eine Rolle in der Prozessierung der RNA, Genexpression, Embryogenese und neuronaler Entwicklung spielt, dessen exakte Funktion aber wenig verstanden ist (Wang et al. 2008; Sephton et al. 2012). Die auf dem TARDBP-Gen basierenden Mausmodelle können bisher allerdings keinen ALS ähnlichen Phänotyp erzeugen (McGoldrick et al. 2013). TDP-43 und FUS sind strukturell und funktional ähnliche Proteine. Es konnte gezeigt werden, dass Mäuse, die transgenes FUS überexprimieren an neuronaler Degeneration und Muskeldenervation leiden (Huang et al. 2011). Allerdings gibt es in der Literatur bisher nur wenige Studien zu diesem Mausmodell (McGoldrick et al. 2013). Die Verlängerung durch Nukleotidwiederholungen des C9ORF72-Gens ist die am häufigsten nachweisbare Mutation bei ALS-Patienten. Über die Toxizitätsentwicklung gibt es viele Hypothesen wie zum Beispiel die Entwicklung von RNA-Toxizität oder die Akkumulation von RNA-bindenden Proteinen (Stepto et al. 2014). Aufgrund der Aktualität der Entdeckung existieren bisher nur sehr wenige Tiermodelle zu dieser Mutation. Es konnten jedoch kürzlich Motoneurondefekte in einem Zebrafisch-Modell nachgewiesen werden (Ciura et al. 2013). 


\subsection{Rho-Kinase als therapeutisches Ziel bei ALS}

In den letzten Jahren wurden viele mögliche Ursachen von neurodegenerativen Erkrankungen untersucht und viele translational therapeutische Ansätze bei der ALS verfolgt (Takata et al. 2013). Dennoch ist Riluzol immer noch das einzige für die ALS zugelassene Medikament. Dabei verlängert es das Leben der Patienten um nur wenige Monate und ist somit in seiner Wirkung deutlich limitiert (Martin et al. 1993; Bellingham 2011), sodass neue therapeutische Targets untersucht werden sollten.

Die Rho-Kinase (ROCK) ist eine Serin/Threonin-Kinase, die durch Phosphorylierung zahlreicher Zielproteine in die Modulation des Zytoskeletts involviert ist und damit Zellform, Beweglichkeit, Regeneration und zelluläres Überleben beeinflusst. LIM-Kinase-1 (LIMK1), Myosin-leichte-Ketten-Phosphatase, die Phosphatase PTEN (Phosphatase and Tensin homolog) sowie Ezrin, Radixin und Moesin sind Substrate der aktiven ROCK. Es wurde gezeigt, dass ROCK ein Schlüsselmediator in der Hemmung von axonalem Wachstum ist und eine negative Rolle bei dem zellulären Überleben spielt (Tönges et al. 2014; Tönges et al. 2011; Lingor et al. 2008). ROCK besitzt eine Molekülmasse von 160 kDa und zeigt eine große Homologie zur Familie der AGC-Kinasen (Mueller et al. 2005). Strukturell besteht sie aus einer Kinase Domäne am N-Terminus, gefolgt von einer coiled-coil-Formation, die eine RhoBindungsstelle beinhaltet, und anderen funktionellen Strukturen am C-Terminus, darunter auch eine Pleckstrin-Homologie (PH) Domäne, die autoinhibitorische Funktion hat (Riento und Ridley 2003). Es existieren zwei Isoformen: ROCK 1 und ROCK 2. Sie zeigen eine große Ähnlichkeit auf dem Level der Aminosäurensequenz, jedoch Unterschiede in der Verteilung in verschiedenen Geweben. Während die ROCK2 vor allem im Gehirn exprimiert wird, findet sich die ROCK1 vornehmlich in nicht neuronalem Gewebe wie Lunge, Herz und Skelettmuskel (Mueller et al. 2005).

Fasudil, eine Substanz aus der chemischen Gruppe der Isoquinoline, ist der meistgenutzte Rho-Kinase-Inhibitor und wurde in vielen Tiermodellen getestet. Neben Fasudil und vielen anderen wurde als pharmakologischer ROCK-Inhibitor zudem Y-27632 entwickelt. Beide hemmen die Rho-Kinase kompetitiv. Fasudil wirkt dabei auf die Rho-Kinase 1000-mal potenter als auf die Protein Kinase $\mathrm{C}$ und die Myosin-leichte-Ketten-Kinase. Der Hauptmetabolit von Fasudil ist Hydroxyfasudil, welches eine gute Bioverfügbarkeit nach oraler Gabe zeigt (Mueller et al. 2005; Shimokawa et al. 1999; Shimokawa 2002; Wang et al. 2005). Neben dem Nutzen in neurodegenerativen Erkrankungen werden in der Literatur viele weitere mögliche Indikationen wie kardiovaskuläre Erkrankungen, onkologische Erkrankungen, Asthma bronchiale, pulmonale Hypertension, Glaukom, vorzeitige Wehen, erektile Dysfunktion und renale Erkrankungen, für die ROCK-Inhibition untersucht (Mueller et al. 2005). Wegen seiner starken vasodilatativen Wirkung wurde Fasudil zudem bei Patienten mit zerebralen Vasospasmen und assoziierten ischämischen Symptomen getestet und in Japan und China zur Therapie bei Schlaganfallpatienten zugelassen (Zhao et al. 2006a). 
Unsere Arbeitsgruppe und andere haben in Vorarbeiten im SOD1-G93A-Mausmodell gezeigt, dass eine Inhibition von ROCK nach oraler Applikation das neuronale Überleben fördert (Tönges et al. 2014; Günther et al. 2014). Interessanterweise steht ROCK upstream des PTEN/Akt/mTOR-Signalweges, der negativen Einfluss auf den zellulären Metabolismus und das Zellwachstum hat. Das durch Phosphorylierung von ROCK aktivierte PTEN reguliert die Aktivität der Akt Proteinkinasen negativ, wodurch mTOR (mammalian Target of Rapamycin) gehemmt wird (Tönges et al. 2011). In Studien konnte gezeigt werden, dass dieser Signalweg auch die Regulation des Zelltodes und das zelluläre Überleben moduliert (Takata et al. 2013; Tönges et al. 2011; Kirby et al. 2011). Zusätzlich konnte gezeigt werden, dass durch eine ROCK-Inhibition das axonale Wachstum gesteigert bzw. der axonale Verlust vermindert werden kann (Bermel et al. 2009; Lingor et al. 2007; Tönges et al. 2012). Die Serin/ThreoninKinase ROCK ist somit ein Schlüsselmediator in der Hemmung des axonalen Wachstums. Dafür aktiviert ROCK die LIM-Kinase1, die wiederum Cofilin phosphoryliert und so inaktiviert. Als ein Regulator des Auf- und Abbaus von Aktinfilamenten wird durch eine Inaktivierung von Cofilin das axonale Wachstum gehemmt (Yang et al. 1998). Es scheint, als könne eine Inhibition von ROCK diese Kaskade unterbrechen. Die in Vorarbeiten und in der Literatur beobachteten positiven Effekte der ROCK-Inhibition könnten auf o.g. Wirkmechanismen von ROCK und dessen Einbindung in diese Signalkaskaden beruhen.

Axonale Degeneration spielt in der Pathogenese der ALS eine wichtige Rolle und beginnt, schon bevor erste Symptome auftreten (Fischer und Glass 2007). Die Regeneration der Neurone ist dabei durch neuronale Apoptose und hemmende Einflüsse der Umgebung auf die axonale Elongation limitiert. Fasudil als Inhibitor von ROCK, einem Schlüsselmediator der axonalen Wachstumshemmung, könnte daher eine pharmakologische Behandlungsstrategie darstellen (Lingor et al. 2008). Weiterhin weisen andere Veröffentlichungen darauf hin, dass allein der Schutz von Motoneuronen nur geringen Einfluss auf den Beginn und die Progression von ALS haben könnte. Vielmehr scheinen es viele verschiedene Faktoren zu sein, die zur axonalen Degeneration führen (Gould et al. 2006; Fischer und Glass 2007). Dieser entgegenzuwirken scheint deshalb eines der wichtigsten therapeutischen Ziele zu sein (Coleman 2005). Sowohl das zelluläre Überleben als auch die axonale Regeneration werden bei neurodegenerativen Erkrankungen prinzipiell durch inflammatorische Reaktionen beeinflusst. Daher soll dieser Aspekt im Folgenden genauer dargestellt werden.

\subsection{Mikroglia}

Im zentralen Nervensystem sind Mikrogliazellen die ansässigen immunkompetenten Zellen. Hier überwachen sie das Gewebe auf pathologische Veränderungen (Graeber 2010). Mikrogliazellen haben einen mesodermalen Ursprung. Vorläuferzellen wandern während der frühen Embryogenese aus der Peripherie in das ZNS ein (Kierdorf und Prinz 2013). Die 
einwandernden Zellen zeigen zunächst eine amöboide Erscheinung, im Gehirngewebe weisen die Mikrogliazellen dann eher einen ramifizierten Phänotyp auf. Diese ramifizierte Erscheinung mit schmalen Zellsomata und dünnen, verzweigten Zellfortsätzen wird assoziiert mit dem „beobachtenden Zustand“ im gesunden ZNS (Kettenmann et al. 2011). Die Mikrogliafortsätze sind extrem mobil und suchen ihre Umgebung unentwegt ab. Die Zellen kontrollieren so ihre Mikroumgebung, beseitigen akkumulierte metabolische Produkte oder Gewebskomponenten und interagieren mit Astrozyten, Neuronen und Blutgefäßen (Nimmerjahn et al. 2005). Infektionen, Trauma, neurodegenerative Erkrankungen, Ischämie, veränderte neuronale Aktivität oder andere Veränderungen der Homöostase im Gehirn rufen einen Wechsel der Zellmorphologie, der Genexpression und des funktionellen Verhaltens der Zellen hervor. Dieser Prozess kann eine mikrogliale Aktivitätsänderung hervorrufen (Kettenmann et al. 2011). Erkennen die Mikrogliazellen pathologische Veränderungen sind sie in der Lage mit den Fortsätzen gezielte Bewegungen zum Beispiel in Richtung einer Läsion auszuführen (Hanisch und Kettenmann 2007). Eine Mikrogliose ist in der Literatur bei neurodegenerativen Erkrankungen wie beispielsweise ALS, Morbus Parkinson, oder Morbus Alzheimer gut dokumentiert. Diese Erkrankungen haben gemeinsam, dass es zu einer abnormen Ablagerung von Proteinaggregaten kommt. Charakteristischerweise beta-Amyloid $(A B)$ und Tau-Protein bei Morbus Alzheimer, alphaSynuclein bei Morbus Parkinson. Diese Ablagerungen können zu einer mikroglialen Aktivierung und Mikrogliose führen (Nayak et al. 2014). Die Erkennung von Pathogenen wird dabei unter anderem über Toll-like Rezeptoren (TLR) vermittelt, die mit pathogen associated molecular patterns (PAMPs) und demage associated molecular patterns (DAMPs) in der Umgebung interagieren (Colton 2009). Auf die Aktivitätsänderung folgt die akute Antwort der Mikrogliazellen, die Neuroinflammation. Diese beinhaltet die Freisetzung verschiedener Mediatoren, wie Zytokine und Chemokine. Die Zellen wechseln schließlich von einer überwachenden in eine protektive und reparierende Rolle (Frank-Cannon et al. 2009). Die Mikrogliazellen sezernieren Zytokine mit der Absicht, vor Pathogenen zu schützen. Chemokine führen dazu, dass weitere inflammatorische Zellen rekrutiert werden (Garden und La Spada 2012). Bei der beschriebenen mikroglialen Aktivitätsänderung wandelt sich zudem der morphologische Phänotyp der Zellen. Die Fortsätze der Zellen werden dicker und kürzer, das Zellsoma erscheint prominenter. Eine Änderung der Mikrogliamorphologie kann folglich Einblicke in die Zellfunktion und Aktivität der Zellen geben, da der morphologische Status eng mit der Funktion der Zelle verknüpft ist (Beynon und Walker 2012). Die Freisetzung von bestimmten Faktoren kann, abhängig von der Pathologie, der sich die Zellen ausgesetzt sehen, auch begleitet sein von Phagozytose (Hanisch und Kettenmann 2007). Phagozytotisch aktive Mikrogliazellen erscheinen rundlich, in einer amöboiden Form und besitzen keine Fortsätze (Graeber 2010). 


\subsubsection{Rolle von Mikrogliazellen und Neuroinflammation in ALS}

Die oben beschriebene Neuroinflammation ist eine der wesentlichen pathologischen Merkmale neurodegenerativer Erkrankungen wie der ALS (Appel et al. 2011). Im Gegensatz zu einer akuten Entzündungsreaktion besteht bei degenerativen Erkrankungen über einen langen Zeitraum eine mikrogliale Aktivierung, gesteigerte Freisetzung von Inflammationsmediatoren und erhöhter zellulärer Stress im Sinne einer chronischen Neuroinflammation (Frank-Cannon et al. 2009). Akute Neuroinflammation ist eher eine protektive Antwort auf pathogene Stimuli im ZNS. Ohne sie wäre das Abtragen von angreifendem Material, das Reparieren von ZNS-Schäden sowie eine Gewebehomöostase im ZNS nicht denkbar. Chronische Neuroinflammation hingegen ist nicht kontrolliert, wird durch sich selbst stimulierende Zyklen aus pro-inflammatorischen Stimuli aufrechterhalten und kann die Progression neurodegenerativer Erkrankungen beschleunigen (Gao und Hong 2008). In der Literatur wird die mikrogliale Aktivitätsänderung deshalb als eine Art zweischneidiges Schwert betrachtet. Es gibt mehrere Belege, dass die Interaktion zwischen Motoneuronen und Mikrogliazellen initial neuroprotektiv und inflammatorisch hemmend ist, jedoch wechseln mit fortschreitender Erkrankung Mikrogliazellen von einem eher antiinflammatorisch und neuroprotektiven Phänotyp zu einem pro-inflammatorisch und neurotoxischen Phänotyp (Appel et al. 2011). Man unterscheidet daher vereinfachend zwei Mikrogliazelltypen: M1 und M2. Neuroprotektive Mikrogliazellen werden M2 genannt, neurotoxische M1 (Liao et al. 2012; Appel et al. 2011; Colton 2009). M1 Mikrogliazellen sezernieren typischerweise pro-inflammatorische Zytokine wie Tumornekrosefaktor alpha (TNF $\alpha$ ), Interleukin 1 beta (II $)$, Interleukin 6 (II6), Interleukin 12 (II12), Interleukin 23 (II23), sowie erhöhte Mengen an Stickstoffmonoxid (NO) und reaktiven Sauerstoffradikalen. Außerdem werden Chemokine wie der CC-Chemokin-Ligand-2 (CCL2), der CC-ChemokinLigand-3 (CCL3), der CC-Chemokin-Ligand-5 (CCL5) und der Chemokin (C-X-C Motif)-Ligand 1 (CXCL1) freigesetzt. M2 Mikrogliazellen setzten dagegen typischerweise Interleukin 10 (Il10), Interleukin 4 (II4), Interleukin 13 (II13) und Transforming growth factor beta (TGF $\beta$ ) frei (Lewis et al. 2012). Die Aktivierung der M1 Mikrogliazellen wird als „klassisch“ bezeichnet und hauptsächlich über Interferon-gamma (INF- $\gamma$ ), Tumornekrosefaktor alpha (TNF $\alpha$ ) und Lipopolysaccharid (LPS) vermittelt. Letztgenanntes wird in der Literatur, und auch in der vorliegenden Arbeit, genutzt um einen mikroglialen M1 Phänotyp zu provozieren. LPS täuscht dabei eine Infektion mit gramnegativen Bakterien vor und ruft eine massive Abwehrreaktion durch pro-inflammatorische und neurotoxische Mikrogliazellen hervor (Hanisch und Kettenmann 2007). Bei M2 Mikroglia wird die Aktivierung, die durch Interleukin 4 (IL4) und Interleukin 13 (IL13) vermittelt wird, als „alternativ“ bezeichnet (Gordon 2003). In-vivo ist die Funktion der Mikrogliazellen nicht schwarz oder weiß, sondern als ein Spektrum zwischen beiden Extremen anzusehen. Es konnte gezeigt werden, dass in der frühen Phase der ALS größtenteils Zytokin- und Chemokin Marker der M2 Mikroglia zu finden sind, während im fortgeschrittenen Verlauf vornehmlich M1 Marker vorliegen (Liao et al. 2012). 
Mikrogliazellen nehmen eine zentrale Stelle in der Neuroinflammation und damit auch in der Progression der ALS ein. So zeigten beispielsweise Hall et al. (1998) bei SOD1-G93Atransgenen Mäusen einen signifikanten Anstieg der Anzahl an aktivierten Astrozyten und Mikrogliazellen im Vergleich zu Wildtyp-Tieren (Henkel et al. 2009). Dass die SOD1-Mutation in Mikrogliazellen eine der hauptverantwortlichen Faktoren in der Progression der Erkrankung ist, unterstrichen unter anderem Beers et al. (2006). Hier wurde an chimären Mäusen gezeigt, dass Wildtyp-Mikrogliazellen in SOD1-G93A-transgenen Mäusen die Progression der Erkrankung verlangsamen und die Degeneration der Motoneurone verzögern (Clement et al. 2003). SOD1-G93A-transgene Mikrogliazellen scheinen dagegen eine reduzierte Kapazität als Sensor für eine gestörte Homöostase des Gewebes und eine reduzierte neuroprotektive Wirkung zu haben (Sargsyan et al. 2011). SOD1-G93A-transgene Mikrogliazellen setzen mehr proinflammatorische Mediatoren frei und induzierten so den Untergang von mehr Neuronen, verglichen mit Wildtyp-Mikroglia. Ferner entwickeln SOD1G93A-transgene Tiere, die aber auch Wildtyp-Motoneurone besitzen, Symptome der ALS (Clement et al. 2003). Zudem wurde beobachtet, dass die frühe Phase der Erkrankung mit dem Schaden der Motoneurone und die spätere Phase, die Progression der ALS bis zur kompletten Paralyse, mehr mit der inflammatorischen Antwort der transgenen Mikrogliazellen verbunden zu sein scheint (Boillée et al. 2006). Andere Studien zeigten, dass ein einzelner Zelltyp, Mikrogliazellen oder Neuron, der das mutierte SOD1-Gen exprimiert nicht ausreicht, um dieselbe Motoneuronenerkrankung auszulösen wie in transgenen Mäusen, die ubiquitär das mutierte SOD1-Gen exprimieren (Beers et al. 2006). Nachgewiesen ist, dass es bei der ALS zu einer Mikrogliose kommt. So zeigten beispielhaft Graber et al. (2010) im SOD1-G93A-Mausmodell durch immunhistochemische Färbungen eine Akkumulation von Mikrogliazellen im Rückenmarksvorderhorn und im peripheren Nerven noch vor dem klinischen Beginn der ALS. Mit weiterer Progression der Erkrankung nahm die Anzahl an Mikrogliazellen weiter zu. Eine Astrogliose ist erst in symptomatischen Stadien der Erkrankung zu erkennen (Hall et al. 1998). In der jüngeren Literatur werden Astrozyten-ähnliche Gliazellen mit abweichendem Phänotyp (AbA Zellen) beschrieben, die nach dem Symptombeginn von SOD1-G93A transgenen Mäusen benachbart zu Motoneuronen auftreten. Diese Zellen tragen zum Absterben von Motoneuronen bei und scheinen von proliferierenden Mikrogliazellen abzustammen (Trias et al. 2013; Díaz-Amarilla et al. 2011). Die Infiltration von Mikrogliazellen beschreibt eine immunologische Reaktion unter dem Fortschreiten der Erkrankung und lässt vermuten, dass besonders diese Zellen entscheidend an der Pathogenese beteiligt sind (Alexianu et al. 2001). Dennoch ist in der aktuellen wissenschaftlichen Diskussion unklar ob die gliale Antwort protektive oder toxische Wirkung hat (Colton 2009; Liao et al. 2012). Daraus lässt sich insgesamt schließen, dass die Progression der ALS nicht auf einen Zelltyp zurückzuführen ist und sowohl Neurone als auch Mikrogliazellen involviert sind (Henkel et al. 2009).

Die Rho-Kinase spielt neben den bereits in 1.2 genannten Prozessen auch in der Entwicklung einer Entzündungsreaktion durch Beeinflussung von Mikrogliazellen und einer Vielzahl weiterer Zelltypen eine wichtige Rolle (Zhao et al. 2014). So konnte gezeigt werden, dass 
nach einer ZNS Verletzung und bei der experimentellen autoimmunen Enzephalomyelitis (EAE), einem Mausmodell der Multiplen Sklerose, die Expression und die Aktivität von ROCK erhöht ist (Niederöst et al. 2002; Liu et al. 2013). Die bisherige Forschung zeigt, dass der ROCK-Inhibitor Fasudil eine inflammationshemmende Wirkung im ZNS ausüben kann. In der EAE konnte gezeigt werden, dass die Behandlung mit Fasudil zu einer Senkung der proinflammatorischen Zytokine führt. Dies könnte daran liegen, dass Fasudil einen Transfer der M1 Mikrogliazellen zu M2 Zellen bewirkt und sich so, wie oben beschrieben, das mikrogliale Verhalten ändert (Liu et al. 2013; Zhao et al. 2014). Die Minderung der Inflammation mit Fasudil könnte aber auch durch dessen hemmende Wirkung auf die Migration von Entzündungszellen durch die Blut-Hirn Schranke vermittelt werden (Sun et al. 2006). Andere Autoren vermuten, dass der therapeutische Effekt einer Rho-Kinase-Hemmung über eine Blockierung des Toll-like-Rezeptor-Signalweges und einer damit einhergehenden verminderten Entzündungsreaktion vermittelt sein könnte (Zhao et al. 2014). An Retinazellen von Mäusen konnte gezeigt werden, dass eine ROCK-Inhibition Parameter einer Inflammation wie reaktive Mikrogliazellen, Astrozyten und pro-inflammatorische Zytokine reduziert (Tura et al. 2009). Ein Einfluss der ROCK-Inhibition ist ebenfalls bei T-Lymphozyten zu beobachten. Tharaux et al. (2003) konnte beispielsweise zeigen, dass eine Behandlung mit dem Rho-Kinase-Inhibitor Y-27632 zu einer verminderten T-Zell Proliferation und Rezeptoraktivität führt.

\subsection{Zusammenfassung der vorausgegangenen Studien und Ziele der Arbeit}

Der vorliegenden Arbeit gingen Studien voraus, die entworfen wurden, um das therapeutische Potential einer oralen ROCK-Inhibition im SOD1-G93A-Mausmodell zu beurteilen (Details zum Experimentdesign in Kapitel 2.2). Die Wirkung von Y-27632 und Fasudil jenseits der Blut-Hirn-Schranke nach oraler Applikation wurde sowohl von anderen, als auch durch unsere Arbeitsgruppe nachgewiesen (Li et al. 2009; Tönges et al. 2014). Im Rahmen der Experimente wurden die Krankheitsprogression, die motorische Funktion, das Überleben, eine Gewichtsanalyse sowie histomorphologische und elektroneurographische Analysen durchgeführt. In einer vorangegangenen Studie wurden SOD1-G93A-transgene Mäuse ab dem 50. Lebenstag präsymptomatisch mit Fasudil behandelt. Hier zeigten sich deutlich positive Effekte durch die ROCK-Inhibition mit signifikant verbesserter motorische Fähigkeit und signifikant erhöhtem Überleben gegenüber unbehandelten SOD1-G93A transgenen Tieren (Tönges et al. 2014). 


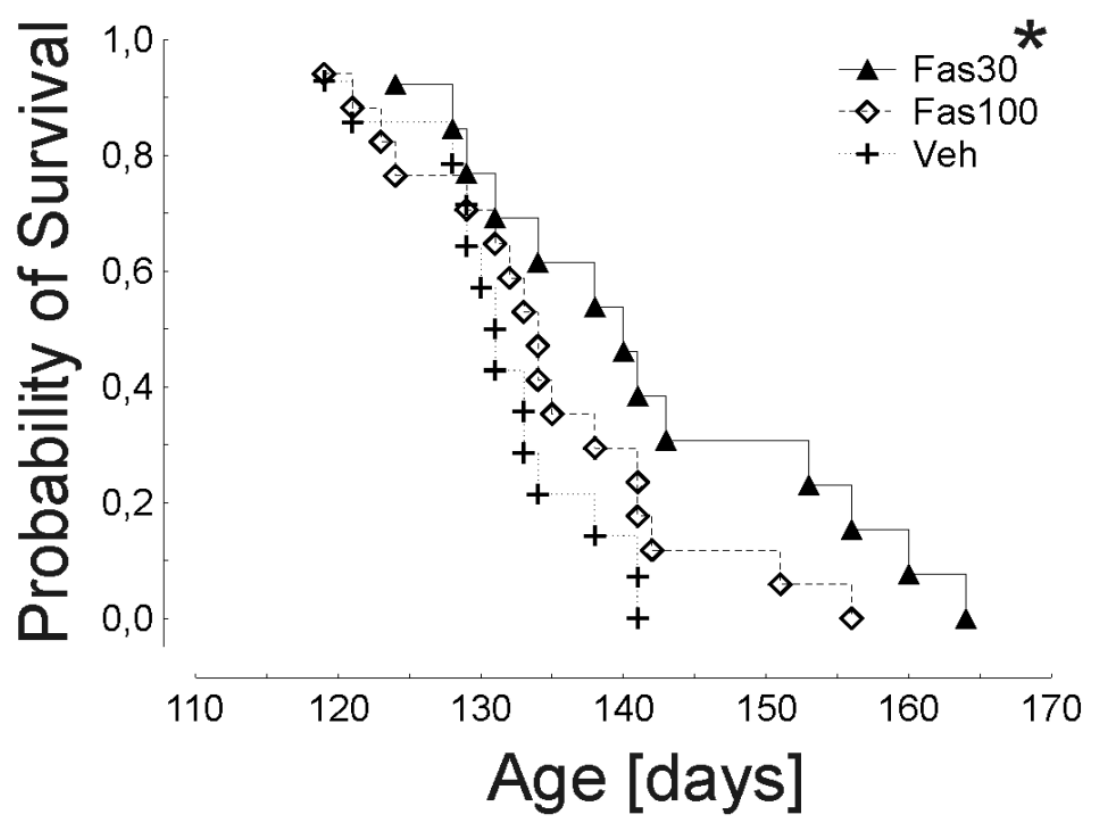

Abbildung 2: Präsymptomatische ROCK-Inhibition mit Fasudil verbessert das Überleben bei weiblichen SOD1-G93A-Mäusen (übernommen aus Tönges et al. 2014). Dargestellt ist eine Kaplan-Meier-Kurve für die Überlebenswahrscheinlichkeit (Probability of survival) in Abhängigkeit vom Alter in Tagen (Age [days]) von SOD1-G93A-transgenen unbehandelten (SOD1 TG Veh; $n=14$ ), mit Fasudil30mg/kg KG (Fas30; $n=13$ ) und mit Fasudil 100mg/kg KG (Fas100; $n=17$ ) behandelten Tieren. ${ }^{*}<<0,05$ im Vergleich zu Veh.

Aufgrund der Behandlungserfolge von Fasudil wurden zur Analyse der Rolle der mikroglialen Zellen in dieser Arbeit histologische Gewebeproben der oben beschriebenen Studie mit präsymptomatischer Fasudil-Behandlung näher untersucht. Ziel dieser Arbeit war es insbesondere den Einfluss der ROCK-Inhibition durch Fasudil auf Mikrogliazellen im SOD1G93A-Mausmodell zu entschlüsseln. Ergänzend wurden in-vitro-Experimente durchgeführt, die zum einen den Einfluss von Fasudil auf die Zellmorphologie und zum anderen auf die Zytokin- und Chemokinfreisetzung analysieren sollen. 


\section{Material und Methoden}

\subsection{Materialien}

In den nachfolgenden Tabellen sind die Materialien aufgelistet, die für die beschriebenen Experimente zum Einsatz kamen.

\subsubsection{Geräte}

\begin{tabular}{|c|c|c|}
\hline Gerät & Modell & Hersteller \\
\hline 40fach Objektiv & Plan-Neofluar 40x/0,75 & $\begin{array}{l}\text { Carl Zeiss Microscopy GmbH, } \\
\text { Jena, Deutschland }\end{array}$ \\
\hline 63fach Öl-Objektiv & $\begin{array}{l}\text { Plan-Apochromat } 63 x / 1.40 \\
\text { Oil DIC }\end{array}$ & $\begin{array}{l}\text { Carl Zeiss Microscopy GmbH, } \\
\text { Jena, Deutschland }\end{array}$ \\
\hline Absauger & $\begin{array}{l}\text { EcoVac Vakuumpumpe } \\
3350101\end{array}$ & $\begin{array}{l}\text { Schuett-biotec } \mathrm{GmbH} \text {, } \\
\text { Göttingen, } \\
\text { Deutschland }\end{array}$ \\
\hline Axiovision software & 4.8 & $\begin{array}{l}\text { Carl Zeiss Microscopy GmbH, } \\
\text { Jena, Deutschland }\end{array}$ \\
\hline Blocking Stift & Dako Pen & $\begin{array}{l}\text { Dako GmbH, Hamburg, } \\
\text { Deutschland }\end{array}$ \\
\hline Eismaschine & AF 100 & $\begin{array}{l}\text { Scotsman Ice Systems, } \\
\text { Mailand, Italien }\end{array}$ \\
\hline Feinwaage & BL210S & $\begin{array}{l}\text { Sartorius AG, Göttingen, } \\
\text { Deutschland }\end{array}$ \\
\hline Gefrierschrank & $-20^{\circ} \mathrm{C}$ & $\begin{array}{l}\text { Robert Bosch Hausgeräte } \\
\text { GmbH, München } \\
\text { Deutschland }\end{array}$ \\
\hline Gefrierschrank & $-80^{\circ} \mathrm{C}$ & Forma, ThermoQuest \\
\hline
\end{tabular}




\begin{tabular}{|c|c|c|}
\hline & & $\begin{array}{l}\text { Analytische Systeme GmbH, } \\
\text { Egelsbach, Deutschland }\end{array}$ \\
\hline ImageJ & $1.46 r$ & $\begin{array}{l}\text { Wayne Rasband, National } \\
\text { Institutes of Health, USA } \\
\text { (gemeinfrei) }\end{array}$ \\
\hline Inkubator/Brutschrank & B20 & $\begin{array}{l}\text { Heraeus, KendroLaboratory } \\
\text { Products GmbH, } \\
\text { Langenselbold, Deutschland }\end{array}$ \\
\hline Kamera & CCD Axiokamera & $\begin{array}{l}\text { Carl Zeiss Microscopy GmbH, } \\
\text { Jena, Deutschland }\end{array}$ \\
\hline Kühlschrank & $5^{\circ} \mathrm{C}$ & $\begin{array}{l}\text { Liebherr-Hausgeräte } \\
\text { Ochsenhausen } \mathrm{GmbH} \text {, } \\
\text { Ochsenhausen, Deutschland }\end{array}$ \\
\hline Ky Plot & $4.01 \mathrm{~g}$ & $\begin{array}{l}\text { KyensLab Incorporated, } \\
\text { Tokyo, Japan }\end{array}$ \\
\hline Mikroskop & $\begin{array}{l}\text { Axioplan-2 } \\
\text { Fluoreszenzmikroskop }\end{array}$ & $\begin{array}{l}\text { Carl Zeiss Microscopy GmbH, } \\
\text { Jena, Deutschland }\end{array}$ \\
\hline PCR-Gerät & Cyclone 25 & $\begin{array}{l}\text { Pealab Biotechnology } \mathrm{GmbH} \text {, } \\
\text { Erlangen, Deutschland }\end{array}$ \\
\hline pH-Meter & PD-20 & $\begin{array}{l}\text { Sartorius AG, Göttingen, } \\
\text { Deutschland }\end{array}$ \\
\hline Pipetten & $\begin{array}{l}\text { P2, P10, P20, P100, P200, } \\
\text { P1000 }\end{array}$ & $\begin{array}{l}\text { Gilson Inc., Middleton, } \\
\text { Wisconsin, USA }\end{array}$ \\
\hline Reinstwasseranlage & Arium pro VIVAH2Opro-DI-D & $\begin{array}{l}\text { Sartorius AG, Göttingen } \\
\text { Deutschland }\end{array}$ \\
\hline Schüttler & $\begin{array}{l}\text { Stuart 3D gyratory shaker } \\
\text { SSM3 }\end{array}$ & Bibby Scientific, Stone, UK \\
\hline Thermoblock & Thermomixer comfort & Eppendorf AG, Hamburg, D \\
\hline Vortex Reagenzglasmischer & $7-2020$ & $\begin{array}{l}\text { neoLab Migge Laborbedarf- } \\
\text { Vertriebs GmbH, Heidelberg, } \\
\text { D }\end{array}$ \\
\hline Waage & MR3000 & Heidolph, Schwabach, D \\
\hline
\end{tabular}




\begin{tabular}{|l|l|l|}
\hline Wasserbad & 3043 & $\begin{array}{l}\text { Köttermann GmbH \& Co KG, } \\
\text { Hänigsen, Deutschland }\end{array}$ \\
\hline
\end{tabular}

Tabelle 2: Geräte

\subsubsection{Verbrauchsmaterialien}

\begin{tabular}{|l|l|}
\hline Verbrauchsmaterial & Hersteller \\
\hline Objektträger 76×26 mm & $\begin{array}{l}\text { Gerhard Menzel Glasbearbeitungswerk } \\
\text { GmbH \& Co KG, Braunschweig, Deutschland }\end{array}$ \\
\hline Deckgläser 55×24 mm & $\begin{array}{l}\text { Gerhard Menzel Glasbearbeitungswerk } \\
\text { GmbH \& Co KG, Braunschweig, Deutschland }\end{array}$ \\
\hline 24-Well Platten & Corning Incorporated, Corning, USA \\
\hline
\end{tabular}

Tabelle 3: Verbrauchsmaterial

\subsubsection{Chemikalien und Reagenzien}

\begin{tabular}{|l|l|}
\hline Chemikalie/Reagenz & Hersteller \\
\hline Aceton & AppliChem, Darmstadt, D \\
\hline Agarose & AppliChem, Darmstadt, D \\
\hline Ampuva Wasser & Fresenius Kabi, Homburg, D \\
\hline Beta-Mercaptoethanol & Sigma-Aldrich, München, D \\
\hline BSA (Bovines Serum-Albumin) & Sigma-Aldrich, München, D \\
\hline Dako (Antibody diluent with background & Dako, Hamburg, D \\
\hline reducing components) & $\begin{array}{l}\text { Biomol Research Laboratories, Plymouth } \\
\text { DAPI (4',6-Diamidino-2-Phenylindole) }\end{array}$ \\
\hline EDTA & Sigma-Aldrich, München, D \\
\hline EGTA & AppliChem, Darmstadt, D \\
\hline
\end{tabular}




\begin{tabular}{|l|l|}
\hline Ethidiumbromid & Carl Roth, Karlsruhe, D \\
\hline Fasudil (Mono-Hydrochlorid Salz, >99 \%) & LC Laboratories, Woburn, USA \\
\hline $\begin{array}{l}\text { LPS (E.coli R515, TLR ligand set 1, APO.54N- } \\
\text { Mowiol 4-88 }\end{array}$ & Axxora/Appotech, Lörrach, D \\
\hline Paraformaldehyd (PFA) 4 \% & Carl Roth, Karlsruhe, D \\
\hline Phosphostop tablets & Sigma-Aldrich, München, D \\
\hline Protease-Inhibitor Tablette & Roche Diagnostocs, Mannheim, D \\
\hline Tris & Roche, Penzberg, D \\
\hline Triton X-100, 0,5 \% & AppliChem, Darmstadt, D \\
\hline
\end{tabular}

Tabelle 4: Chemikalien und Reagenzien

\subsubsection{Substanzen für Polymerasekettenreaktion}

\begin{tabular}{|l|l|}
\hline Substanz & Hersteller \\
\hline dNTPs & New England Bio Lab \\
\hline Primer Interleukin-Gen & Sigma-Aldrich, München, D. \\
\hline Primer SOD1-Gen & Sigma-Aldrich, München, D. \\
\hline Proteinase K & AppliChem, Darmstadt, D. \\
\hline Taq DNA-Polymerase & Life technologies, Darmstadt, D. \\
\hline
\end{tabular}

Tabelle 5: Substanzen für Polymerasekettenreaktion

\subsubsection{Verwendete Lösungen}

\begin{tabular}{|l|l|}
\hline Lösung & Zusammensetzung \\
\hline Lysereagenz & $0.2 \mathrm{mg} / \mathrm{ml}$ Proteinase $\mathrm{K}$, \\
& $0.2 \% \mathrm{SDS}$, \\
\hline
\end{tabular}




\begin{tabular}{|l|l|}
\hline & $\begin{array}{l}5 \mathrm{mM} \text { EDTA, in PBS } \\
\text { (Peqlab Biotechnologie GmbH, Erlangen, } \\
\text { Deutschland) }\end{array}$ \\
\hline Paraformaldehyd (PFA) & $4 \%$ in PBS, $\mathrm{pH} 7,4$ \\
\hline
\end{tabular}

Tabelle 6: Lösungen

\subsubsection{Verwendete Puffer}

\begin{tabular}{|c|c|}
\hline Puffer & Zusammensetzung \\
\hline Ladepuffer & $\begin{array}{l}10 \text { mM Tris-HCL (pH7.6), } \\
00.03 \text { \% Bromphenolblau, } \\
0.03 \% \text { Xylencyanol, } \\
60 \% \text { Glycerin, } \\
60 \text { mM EDTA } \\
\text { (Direct PCR Lysis Reagent (Tail), Paqlab, } \\
\text { Erlangen, D.) }\end{array}$ \\
\hline PBS & $\begin{array}{l}\text { Kaliumchlorid 0,20 g/l, } \\
\text { Kalium Dihydrogenphosphat 0,20 g/l, } \\
\text { Natriumchlorid 8,00 g/l, } \\
\text { Dinatrium-Dihydrogenphosphat 1,15 g/l, } \\
\text { Wasserfrei, ohne } \mathrm{Ca}^{2+}, \mathrm{Mg}^{2+} \\
\text { (AppliChem, Darmstadt, D.) }\end{array}$ \\
\hline TBE Puffer & $\begin{array}{l}\text { Borsäure } 55,03 \mathrm{~g} / \mathrm{l} \\
\text { EDTA-Na } 27,44 \mathrm{~g} / \mathrm{l} \\
\text { Tris } 107,81 \mathrm{~g} / \mathrm{l} \\
\text { (AppliChem, Darmstadt, D.) }\end{array}$ \\
\hline TBS & $\begin{array}{l}24,2 \mathrm{~g} \text { Tris, } \\
80 \mathrm{~g} \mathrm{NaCl} \\
\mathrm{pH} \mathrm{8,98,} \\
\text { auf } 1000 \mathrm{ml} \text { aqua dest. }\end{array}$ \\
\hline
\end{tabular}




\begin{tabular}{|l|l|}
\hline Zelllysepuffer & 50 mM Tris, \\
& $0,1 \%$ Triton X-100, \\
1 mM EDTA, \\
1 mM EGTA, \\
10 mM beta-Mercaptoethanol, \\
1 Tablette Phosphostop, \\
2 Tabletten Protease-Inhibitor, \\
pH 8, \\
auf 100ml Aqua dest.
\end{tabular}

Tabelle 7: Puffer

\subsubsection{Antikörper und Marker}

\begin{tabular}{|c|c|c|c|}
\hline $\begin{array}{l}\text { Antikörper und } \\
\text { Marker }\end{array}$ & Spezies & Verdünnung & Hersteller \\
\hline Anti-Iba1 & Kaninchen & 1:500 in Dako & $\begin{array}{l}\text { Katalognummer: } \\
\text { 19-19741 Wako Pure } \\
\text { Chemical Industries, } \\
\text { Osaka, Japan }\end{array}$ \\
\hline $\begin{array}{l}\text { Cy3 konjugiert, Anti } \\
\text { Kaninchen }\end{array}$ & Esel & 1:250 in Dako & $\begin{array}{l}\text { Katalognummer: } \\
\text { 711-165-152, } \\
\text { Jackson Immuno } \\
\text { Research, West } \\
\text { Grove, USA }\end{array}$ \\
\hline Rhodamin Phalloidin & Amanita phalloides & $1: 500$ in PBS & $\begin{array}{l}\text { Katalognummer: } \\
\text { R415, Molecular } \\
\text { Probes, Eugene, USA }\end{array}$ \\
\hline
\end{tabular}

Tabelle 8: Antikörper und Marker 


\subsection{Experimentdesign}

Die vorliegende Arbeit gliedert sich in zwei Teile. Einen ersten mit immunhistochemischer Mikrogliaanalyse von in-vivo mit Fasudil behandelten SOD1-G93A-Mäusen sowie einen zweiten Teil mit Fasudil behandelten, stimulierten Mikrogliazellkulturen.

\subsubsection{Mauslinien, Tierzucht und Tierhaltung}

Das SOD1-G93A-Mausmodell gilt als Goldstandard für präklinische Studien der ALS (Ludolph et al. 2010). Es wurden Mäuse des Typs High-copy B6SJL Tg(SOD1-G93A)1Gur/J (Jackson Labs, Bar Harbor, USA) (Gurney et al. 1994) und B6SJL SOD1 WT (Jackson Labs, Bar Harbor, USA) benutzt. Zur Aufrechterhaltung der Kolonie wurden SOD1-transgene Männchen mit weiblichen SOD1-Wildtyptieren verpaart. Da bei der Verpaarung von heterozygoten und Wildtyp-Tieren unterschiedliche Genotypen der Nachkommen zu erwarten sind, wurde eine Genotypisierung notwendig. Dazu wurden Schwanzspitzenbiopsien der Jungtiere entnommen, der SOD1-Genabschnitt durch die Polymerasekettenreaktion amplifiziert und in der Gelelektrophorese genotypisiert (Details in Kapitel 2.4.2). Die Tiere wurden in der Zentralen Tiereinheit (ZTE) der Universitätsmedizin Göttingen (UMG) entsprechend der Empfehlungen und Richtlinien des Tierschutzes gehalten (Tierversuchsantrag: Aktenzeichen 33.14.42502-04-092/09 und 33.9-42502-04-12/0938).

\subsubsection{Versuchsaufbau in-vivo und in-vitro}

\subsubsection{Fasudilbehandlung von Mäusen in-vivo}

Die Tiere der Versuchsgruppe „Präsymptomatische Studie mit Fasudil am Lebensende“ sind männliche und weibliche SOD1-G93A transgene Mäuse, die ab dem 50. Lebenstag behandelt wurden. Die Tiere wurden in drei Behandlungsgruppen unterteilt: Eine mit Wasser 
behandelte Gruppe (SOD1 H2O; n=3), eine mit $30 \mathrm{mg} / \mathrm{kg}$ Körpergewicht/Tag Fasudil behandelte Gruppe (SOD1 Fas30; n=3) und eine mit 100 mg/kg Körpergewicht/Tag Fasudil behandelte Gruppe (SOD1 Fas100; $n=3$ ). Sämtliche Behandlungen wurden verblindet durchgeführt. Die Tiere wurden im Endstadium der Erkrankung nach Tierversuchsabbruchkriterien getötet (Endstadium Tiere). Ob sich ein Tier im Endstadium der Erkrankung befindet, wurde mit Hilfe eines motorischen Bewertungssystems definiert, dass auf Weydt et al. (2003) basiert. Tiere ohne motorische Dysfunktion und keinerlei neurologischen Defiziten, die eine Wildtyp-ähnliche Verhaltensweise zeigen, erhalten demnach 4 Punkte. Ist bei einer Maus ein Tremor der Hinterbeine zu erkennen wenn sie am Schwanz gehalten wird, erhält sie 3 Punkte. Bei Gangstörungen wird die Maus mit 2 Punkten bewertet. 1 Punkt erhält ein Tier, wenn mindestens ein Hinterbein beim Gehen hinterhergezogen wird. Im Endstadium, 0 Punkte, befindet sich eine Maus, wenn sie sich unfähig zeigt, sich innerhalb von 30 Sekunden aus Bauch- oder Rückenlage zu drehen, sichtbare Lähmungserscheinungen in zwei oder mehr Extremitäten aufweist, nicht mehr selbstständig in der Lage ist Wasser oder Futter zu sich zu nehmen, oder ein Verlust des Körpergewichts von mehr als $25 \%$ des Maximalgewichts, bzw. über 48 Stunden ein Gewichtsverlust von mehr als 20 \% des Maximalgewichts vorliegt. Mit 0 Punkten bewertete Tiere wurden durch Kohlenstoff-Insufflation euthanasiert.

Die Tiere der Versuchsgruppe „Präsymptomatische Studie mit Fasudil an Lebenstag 100“ sind weibliche SOD1-G93A transgene Mäuse, die ab dem 50. Lebenstag behandelt wurden und bereits an Lebenstag 100 analysiert wurden. Hier wurden zwei Behandlungsgruppen untersucht: Eine mit Wasser behandelte Gruppe (SOD1 TgVeh; $n=5$ ) und eine mit $30 \mathrm{mg} / \mathrm{kg}$ Körpergewicht/Tag Fasudil (SOD1 TgFas30; $n=5$ ) behandelte Gruppe. Zusätzlich gibt es hier eine Gruppe aus SOD1 Wildtyp-Mäusen (SOD1 WT; $n=3$ ), ohne Fasudil-Behandlung, als Kontrollgruppe. Die Tiere mit präsymptomatischer Behandlung wurden am 100. Lebenstag durch Kohlendioxid-Insufflation getötet (Tag100 Tiere). Alle oben beschriebenen Behandlungen der Tiere erfolgten oral mit Trinkwasser. 


\subsubsection{Fasudilbehandlung mikroglialer Zellkulturen in-vitro}

Für die In-vitro-Analysen wurden die Gehirne von Jungtieren aus der Verpaarung von SOD $1^{\text {wt }}$ - und SOD $1^{\text {G93A }}$-Mäusen am ersten Lebenstag (PO) präpariert und Mikrogliazellkulturen angelegt. Diese durchliefen folgende Behandlungen: 1 . Keine Behandlung (Kontrolle), 2. Stimulation mit LPS (10 ng/ml) für 18 Stunden (finale Konzentration $10 \mathrm{ng} / \mathrm{ml}$ ), 3. Behandlung mit Fasudil (2, 10 oder $50 \mu \mathrm{M})$ für 18 Stunden, 4. Stimulation mit LPS und Behandlung mit Fasudil in verschiedenen Konzentrationen, wie oben beschrieben, 5. (nur für Zytokin ELISA) Präinkubation mit Fasudil (50 $\mu \mathrm{M}$ ) für 1, 4 oder 12 Stunden vor der LPS-Stimulation (während fortgesetztem Vorhandensein von Fasudil). Es wurden zwei separate Präparationen durchgeführt, denen jeweils eine Zucht vorausging.

\subsection{Immunhistochemische Analyse des Rückenmarks}

Die immunhistochemische Analyse der Gewebeschnitte wurde an den oben beschriebenen Versuchsgruppen an Tag 100 bzw. im Endstadium durchgeführt. Sämtliche Analysen wurden verblindet durchgeführt.

\subsubsection{Anfertigung von Cryoschnitten des Rückenmarks}

Bei den Gewebeschnitten, die für diese Arbeit benutzt wurden, handelt es sich um transversale Cryoschnitte von Rückenmärkern oben genannter Mäuse. Die Gewebeschnitte wurden mit dem Kryostat CM-3050-S (Leica, Biosystems) angefertigt. Es sind Schnitte des lumbalen Bereichs (L3-L6) mit einer Schichtdicke von $20 \mu \mathrm{m}$. Die Schnitte wurden auf nummerierte Objektträger gezogen, sodass auf jedem Objektträger 5 Gewebeschnitte eines Rückenmarks mit einem Abstand von jeweils $100 \mu \mathrm{m}$ zu finden sind. Die Gewebsschnitte lagen zu Beginn dieser Arbeit eingebettet in Shandon Cryomatrix (Thermo Fisher, Scientific Inc Kalamazoo, Michigan USA), gelagert bei $-20{ }^{\circ} \mathrm{C}$ vor. Um bei den Tieren vergleichbare 
Höhen des Rückenmarks zu untersuchen, wurden stets Objektträger mit ähnlicher Nummer benutzt.

\subsubsection{Immunhistochemische Färbungen von Rückenmarksquerschnitten}

Die immunhistochemischen Färbungen wurden durchgeführt, um eine quantitative und histomorphologische Evaluation der Mikrogliazellen in den Rückenmarksvorderhörnern möglich zu machen. Hierzu wurden der Mikrogliazellmarker Anti-lba1-Antikörper und der Zellkernmarker DAPI verwendet.

Die Objektträger mit den fixierten Cryoschnitten wurden im ersten Schritt im Inkubator bei $37^{\circ} \mathrm{C}$ für 30 Minuten aufgetaut. Anschließend wurden die Objektträger auf dem Schüttler in PBS für 30 Minuten gewaschen. Um mögliche Proteinverbindungen zu brechen, die Bindungsstellen des Antikörpers verdecken können, wurden die Objektträger mit den Gewebeschnitten dann in TBS, $\mathrm{pH} 8,98$, in einem auf $60{ }^{\circ} \mathrm{C}$ vorgeheizten Wasserbad gewaschen. Danach wurden die Schnitte 2x5 Minuten auf dem Schüttler in PBS gewaschen. Um ein Verlaufen des Antikörpers zu verhindern, wurden die Rückenmarksschnitte dann mit einem Fettstift, dem Blocking-Stift, umrandet. Anschließend wurde Dako auf die Schnitte gegeben und dort 1 Stunde (h) bei Raumtemperatur belassen. Dieses Produkt führt zu einer Blockierung unspezifischer Bindungsstellen und reduziert so die Hintergrundfärbung. Im nächsten Schritt erfolgte die Inkubation mit dem primären Antikörper. Hierzu wurden die Schnitte für 12 bis 24 Stunden bei $4{ }^{\circ} \mathrm{C}$ mit dem Anti-lba1-Antikörper, 1:500 verdünnt in Dako, behandelt. Nach einem weiteren Waschen für 3×10-15 min auf dem Schüttler in PBS wurden die Schnitte dann mit dem fluoreszierenden, sekundären Cy3-gekoppelten Antikörper, Anti-Kaninchen, 1:250 verdünnt in Dako, für eine Stunde inkubiert. Von diesem Zeitpunkt an wurde lichtgeschützt gearbeitet, um ein Verblassen der Fluoreszenz zu vermeiden. Anschließend wurden die Schnitte auf dem Schüttler in PBS für 3×10-15 min gewaschen und dann mit DAPI für 10 min bei Raumtemperatur behandelt. Zum Abschluss wurden die Gewebeschnitte ein weiteres Mal für 3x15 min auf dem Schüttler in PBS gewaschen. Daraufhin folgte das Eindeckeln der Schnitte mit Mowiol Harz, welches vorher im Inkubator auf $37^{\circ} \mathrm{C}$ erwärmt wurde. 


\subsubsection{Mikroskopie von Rückenmarksquerschnitten und quantitative Auswertung}

Die Gewebeschnitte wurden mit Hilfe eines Zeiss Axioplan-2-Fluoreszenzmikroskops, ausgestattet mit einer CCD Kamera und AxioVision Software, aufgenommen.

\subsubsection{Quantifikation der Mikrogliainfiltration des Rückenmarks}

Für die quantitative Auswertung der Iba1-positiven Zellen wurden Bilder von jedem Vorderhorn eines Rückenmarks in 10facher Vergrößerung angefertigt. Mit Hilfe des gemeinfreien Softwareprogramms ImageJ (http://rsb.info.nih.gov/ij/index.html) wurde auf den Bildern der Vorderhornbereich definiert und umrandet. Innerhalb dieses Bereiches wurden dann die Iba1-positiven Mikrogliazellen manuell ausgezählt. Die Anzahl der Zellen wurde für eine Fläche von $0,5 \mathrm{~mm}^{2}$ berechnet.

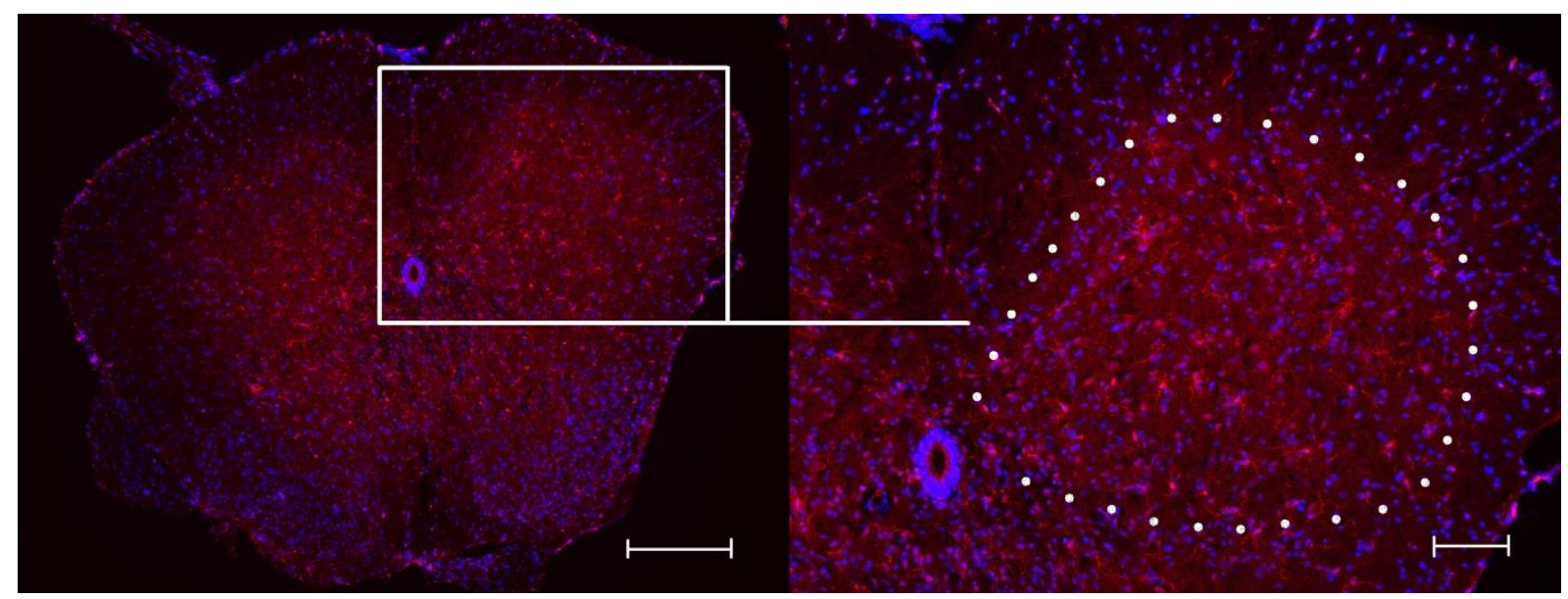

Abbildung 3: Repräsentatives Bild der Immunofluoreszenz-Färbung der Iba1-positiven Mikrogliazellen des Rückenmarks. Iba1/Cy3 (rot), DAPI (blau). Die gepunktete Linie deutet die Region des Vorderhorns an. Links: Übersicht des Rückenmarksquerschnitts in 5facher Vergrößerung. Rechts: Rechtes Rückenmarksvorderhorn in $10 f a c h e r$ Vergrößerung mit umrandetem Vorderhorn. Maßstabbalken links $250 \mu \mathrm{m}$, rechts $100 \mu \mathrm{m}$. 


\subsubsection{Morphologische Auswertung mikroglialer Zellen im Rückenmark}

Für die morphologische Auswertung wurden mindestens 10 zufällig ausgewählte Zellen pro Vorderhorn bei einer 63fachen Vergrößerung klassifiziert. Die Zellen wurden in drei Gruppen eingeteilt: Dünn ramifiziert, dick ramifiziert, rund. Ramifizierte Zellen wurden definiert als Zellen, die mindestens 2 Fortsätze besitzen, welche mindestens die doppelte Länge des Durchmessers ihres Zellkörpers besitzen. Dünn ramifizierte Zellen haben einen geringen Fortsatzdurchmesser $(<0,5 \mu \mathrm{m})$ und einen schmalen Zellkörper $(<5 \mu \mathrm{m})$. Dicker ramifizierte Zellen hingegen haben breitere Fortsätze $(>0,5 \mu \mathrm{m})$ und größere Zellsomadurchmesser (>5 $\mu \mathrm{m})$. Runde Zellen haben keine Fortsätze und eine runde Erscheinung.

\subsection{In-vitro-Analyse von Mikrogliazellkulturen}

Anhand von Mikrogliazellkulturen wurde eine immunzytochemische Analyse sowie eine Zytokin- und Chemokin Messung nach Stimulation und Behandlung mit Fasudil durchgeführt. Sämtliche Analysen wurden verblindet durchgeführt.

\subsubsection{Generierung von Mikrogliazellkulturen}

Primäre Mikrogliazellkulturen wurden von P0 B6/SJL SOD1-G93A und B6/SJL SOD1 ${ }^{\text {wt }}$ Mäusen hergestellt und in Dulbecco's Modified Eagle's Medium (DMEM) (Invitrogen/Gibco, Karlsruhe, Deutschland) kultiviert (Regen et al. 2011). Das Medium wurde ergänzt durch $10 \%$ fetales Kälber Serum (FKS) (Invitrogen/Gibco, Karlsruhe, Deutschland), 100 U/ml Penicillin (Biochrom, Berlin, Deutschland) und $100 \mu \mathrm{g} / \mathrm{ml}$ Streptomycin (Biochrom, Berlin, Deutschland). Die Zellen wurden dann entweder in 96-Well Platten mit 100.000 Zellen $/ \mathrm{cm}^{2}$ für Zytokin-Chemokin ELISA, oder auf Poly L-Lysin (PLL) beschichtete Deckgläser in 24-Well Platten mit 100.000 Zellen/cm² für immunzytochemische Analysen gegeben. Die Zellkultur durchlief folgende Behandlungen: 1. Vehikel Behandlung (Kontrolle), 2. Stimulation mit LPS 
für 18 Stunden (finale Konzentration $10 \mathrm{ng} / \mathrm{ml}$ ), 3. Behandlung mit Fasudil (2, 10 oder $50 \mu \mathrm{M})$ für 18 Stunden, 4. Stimulation mit LPS und Behandlung mit Fasudil in verschiedenen Konzentrationen, wie in 3. Sowohl die Präparation der Gehirne, als auch die Kultivierung wurde von der Abteilung Neuropathologie der UMG (AG Hanisch) übernommen.

\subsubsection{Genotypisierung SOD1-G93A-transgener Mäuse}

Da zur Erhaltung der Kolonie SOD1-G93A transgene Männchen mit SOD1 Wildtyp-Weibchen verpaart wurden, war eine Genotypisierung der Nachkommen nötig. Am ersten Lebenstag (P0) wurden daher circa 0,4 cm lange Schwanzbiopsien der Mäuse entnommen, in Lyse Reagenz, bestehend aus $0,2 \mathrm{mg} / \mathrm{ml}$ Proteinase $\mathrm{K}, 0.2 \%$ SDS und $5 \mathrm{mM}$ EDTA in PBS, gegeben und für 10 bis 15 Stunden bei $55{ }^{\circ} \mathrm{C}$ im Thermoblock inkubiert. Danach wurde durch eine Temperaturerhöhung auf $85{ }^{\circ} \mathrm{C}$ für $45 \mathrm{~min}$ die Proteinkinase gestoppt. In $200 \mu$ dieser Lösung wurden dann die spezifischen Primer für das humane SOD1-Gen und zur Kontrolle für das Interleukin Gen gegeben (hSOD1-vorwärts, CAATGTGACTGCTGACAAAG; hSOD1rückwärts, GTGCGGCCAATGATGCAAT; IL vorwärts 5'-CTAGGCCACAGAATTGAAAGATCT, IL rückwärts 5'- GTAGGTGGAAATTCTAGCATCATCC), sowie $200 \mu \mathrm{l}$ dNTPs, $1 \mu \mathrm{l}$ Taq-Polymerase und $1290 \mu$ Ampuva Wasser. Die PCR wurde in folgenden Zyklen durchgeführt: 1 Zyklus bei $94{ }^{\circ} \mathrm{C}, 5 \mathrm{~min}$; 35 Zyklen bei $94^{\circ} \mathrm{C}, 30 \mathrm{sec}, 58^{\circ} \mathrm{C} 30 \mathrm{sec}, 72{ }^{\circ} \mathrm{C} 60 \mathrm{sec}, 1$ Zyklus bei $72{ }^{\circ} \mathrm{C}, 5 \mathrm{~min}$. Danach erfolgte die Agarose-Gel-Analyse (1,5\% Agarose Gel). Das humane SOD1Genprodukt, falls vorhanden, war zu sehen bei 236 Basenpaaren, das Interleukin Genprodukt bei 324 Basenpaaren. Die Mikrogliazellkulturen wurden anhand der Ergebnisse der Genotypisierung aufbereitet.

\subsubsection{Zellfixierung}

Die kultivierten Mikrogliazellen wurden zur immunzytochemischen Analyse auf Coverslips vorbereitet. Nach dem Waschen durch Aufpipettieren von PBS wurden die Zellen in PFA $4 \%$ 
für 10 min fixiert und anschließend mit 0,5 \% Triton x 100 für 10 min bei Raumtemperatur, sowie $100 \%$ Aceton für $10 \mathrm{~min}$ bei $-20^{\circ} \mathrm{C}$ permeabilisiert.

\subsubsection{Immunzytochemische Färbungen}

Für die immunzytochemischen Färbungen wurden die Zellen zu Beginn $2 x$ durch Aufpipettieren von PBS gewaschen. Daraufhin fand das Blocken mit Dako sowie das Inkubieren des primären Antikörpers anti-Iba1 und des dazu passenden sekundären Antikörpers wie bei der vorher beschriebenen immunhistochemischen Färbung statt. Nach einer Waschung mit PBS wurde dann Rhodamin Phalloidin, 1:500 in PBS verdünnt, für 30 min bei Raumtemperatur auf die Zellen gegeben. Danach folgten, wie bei der immunhistochemischen Färbung die Behandlung mit DAPI und das Eindeckeln mit Hilfe von Mowiol Harz.

\subsubsection{Mikroskopie und Auswertungen}

Die Mikrogliazellen wurden mit Hilfe eines Zeiss Axioplan-2-Fluoreszenzmikroskops, ausgestattet mit einer CCD Kamera und AxioVision Software, aufgenommen.

\subsubsection{Morphologische Auswertung}

Für die Evaluation der Mikrogliazellmorphologie wurden Bilder von mindestens 25 zufällig ausgewählten Zellen pro Kondition mit dem 63X Objektiv angefertigt. Da die Mikrogliazellen in-vitro einen anderen Phänotyp zeigen als die Zellen in-vivo, wurden für die morphologische Analyse die Parameter Anzahl an Fortsätzen, Länge der Fortsätze, Zellgröße und Zellform 
ausgewählt. Die Fortsätze der ausgewählten Zellen wurden gezählt und mit Hilfe von ImageJ (http://rsb.info.nih.gov/ij/index.html) vermessen. Ein Fortsatz wurde definiert als Zellerweiterung von mindestens 1/3 des Durchmessers des Zellkerns. Außerdem wurde jede Zelle als rund oder nicht rund klassifiziert. Für jeden morphologischen Parameter wurden pro Behandlungsgruppe mindestens 25 Zellen ausgewertet.

\subsubsection{Zytokin- und Chemokin-Messung}

Die Überstände der Mikrogliazellkulturen wurden für eine Zytokin- und Chemokin-Messung genutzt. Wie unter Kapitel 2.4 .1 beschrieben, durchliefen die Zellen dabei verschiedene Behandlungen. Folgende von den Mikrogliazellen freigesetzten Zytokine und Chemokine wurden im Überstand der Zellkultur mit DuoSet ELISA Development Kits (R\&D Systems) quantifiziert: IL6 (Interleukin 6), CCL2 (monocyte chemotactic protein, MCP1), CCL3 (macrophage inflammatory protein, MIP-1 $\alpha$ ), CCL5 (regulated upon activation normal T-cell expressed and presumably secreted, RANTES), und CXCL1 (KC, equivalent of the human GRO $\alpha$ ). TNFa (tumor necrosis factor alpha) wurde mit dem MAX ${ }^{\mathrm{TM}}$ ELISA kit (Biolegend) nachgewiesen. Die Experimente wurden mindestens in vierfachem Ansatz und mit mindestens zwei separaten Präparationen durchgeführt. Die Durchführung der Zytokin- und Chemokin-Messung wurde freundlicherweise von der Abteilung Neuropathologie (AG Hanisch) der UMG übernommen.

\subsection{Statistische Auswertung der erhobenen Daten}

Bei den Daten der In-vitro-Experimente wurde für den Vergleich zweier Gruppen ein ungepaarter Student's t-Test benutzt. Für Unterschiede zwischen mehreren Gruppen wurde ein multifaktorieller ANOVA, gefolgt von einem Tukey's post hoc-Test, verwendet. Vergleiche von histologischen Parametern zwischen zwei Tiergruppen wurden mit Hilfe eines 
ungepaarten Student's t-Test vollzogen. Für Vergleiche mehrerer Gruppen bei Tierexperimenten wurde ein einfaktorieller ANOVA, gefolgt von einem Tukey's post hocTest, benutzt. Die statistischen Analysen wurden mit KyPlot (http://www.kyenslab.com/en/index.html) durchgeführt. 


\section{Ergebnisse}

\subsection{Verhalten mikroglialer Zellen im Rückenmark des SOD1-G93A- Mausmodells nach Behandlung mit Fasudil}

Das Ziel der Analyse der Mikrogliazellen im Rückenmark bestand darin, quantitative und morphologische Veränderungen von Mikrogliazellen in SOD1-G93A-transgenen (SOD1 TG) und Wildtyp-Tieren (SOD1 WT) zu unterschiedlichen Zeitpunkten im Verlauf der Erkrankung unter Behandlung mit Fasudil in einer Dosierung von $30 \mathrm{mg} / \mathrm{kg} \mathrm{KG}$ oder $100 \mathrm{mg} / \mathrm{kg} \mathrm{KG} \mathrm{zu}$ evaluieren. Dazu wurden Gewebsschnitte von Mausrückenmärkern mit Hilfe von immunhistochemischen Färbungen verblindet analysiert. Das Material stammt aus den Versuchsgruppen „Präsymptomatische Studie an Lebenstag 100“ und „Präsymptomatische Studie am Lebensende" eines dieser Arbeit vorausgegangenen Experiments (siehe Kapitel 1.4). Die vorliegende Arbeit ist ein Teilprojekt, das sich mit der Analyse der Mikrogliazellen in den Rückenmarksvorderhörnern beschäftigt.

\subsubsection{Intermediäre Analyse an Lebenstag 100}

Die Tiere der „Präsymptomatischen Studie an Lebenstag 100“ wurden ab dem 50. Lebenstag behandelt und in verschiedene Gruppen eingeteilt. Eine SOD1-G93A-transgene Versuchsgruppe erhielt den Rho-Kinase-Inhibitor Fasudil in der Konzentration 30 mg/kg KG (SOD1 TG Fas30) in Trinkwasser gelöst zur oralen Aufnahme. Die andere transgene Gruppe wurde nur mit der Trägersubstanz Trinkwasser als Vehikel behandelt (SOD1 TG Veh). Zusätzlich wurde eine nicht transgene Wildtyp-Kontrollgruppe (SOD1 WT Veh) untersucht, die mit Trinkwasser als Vehikel behandelt wurde. Es fand eine intermediäre Analyse der Gewebsschnitte an Lebenstag 100 (d100) statt. Die präsymptomatische Studie an Lebenstag 100 beinhaltet ausschließlich weibliche Tiere, da diese im Rahmen einer Vorstudie bzgl. des verbesserten Überlebens am deutlichsten von der Behandlung mit Fasudil profitiert hatten. Von der anderen Kohorte am Tag des Todeseintritts (endstage), wurden ebenfalls weibliche Mäuse analysiert. 


\subsubsection{Fasudilbehandlung erhöht die Gesamtzahl mikroglialer Zellen im Rückenmark}

Die quantitative Analyse der Iba1-positiven Mikrogliazellen im Vorderhorn des lumbalen Rückenmarks an d100 zeigte einen signifikanten Anstieg der mittleren Mikrogliaanzahl pro 0,5 $\mathrm{mm}^{2}$ in der SOD1 TG Fas30-Gruppe $(39,54 \pm 3,89$ Mikrogliazellen) im Vergleich zu der SOD1 TG Veh-Gruppe (27,80 \pm 4,73 Mikrogliazellen). In der SOD1 Wildtyp-Gruppe wurde die geringste Anzahl von Iba1-positiven Zellen $(14,04 \pm 2,82)$ gefunden. Zwischen der SOD1 TG Veh- und der SOD1 WT Veh-Gruppe zeigte sich ein Anstieg der Zellzahl von Wildtyp- zu transgenen Tieren, der jedoch nicht das Signifikanz-Niveau erreichte. 
A

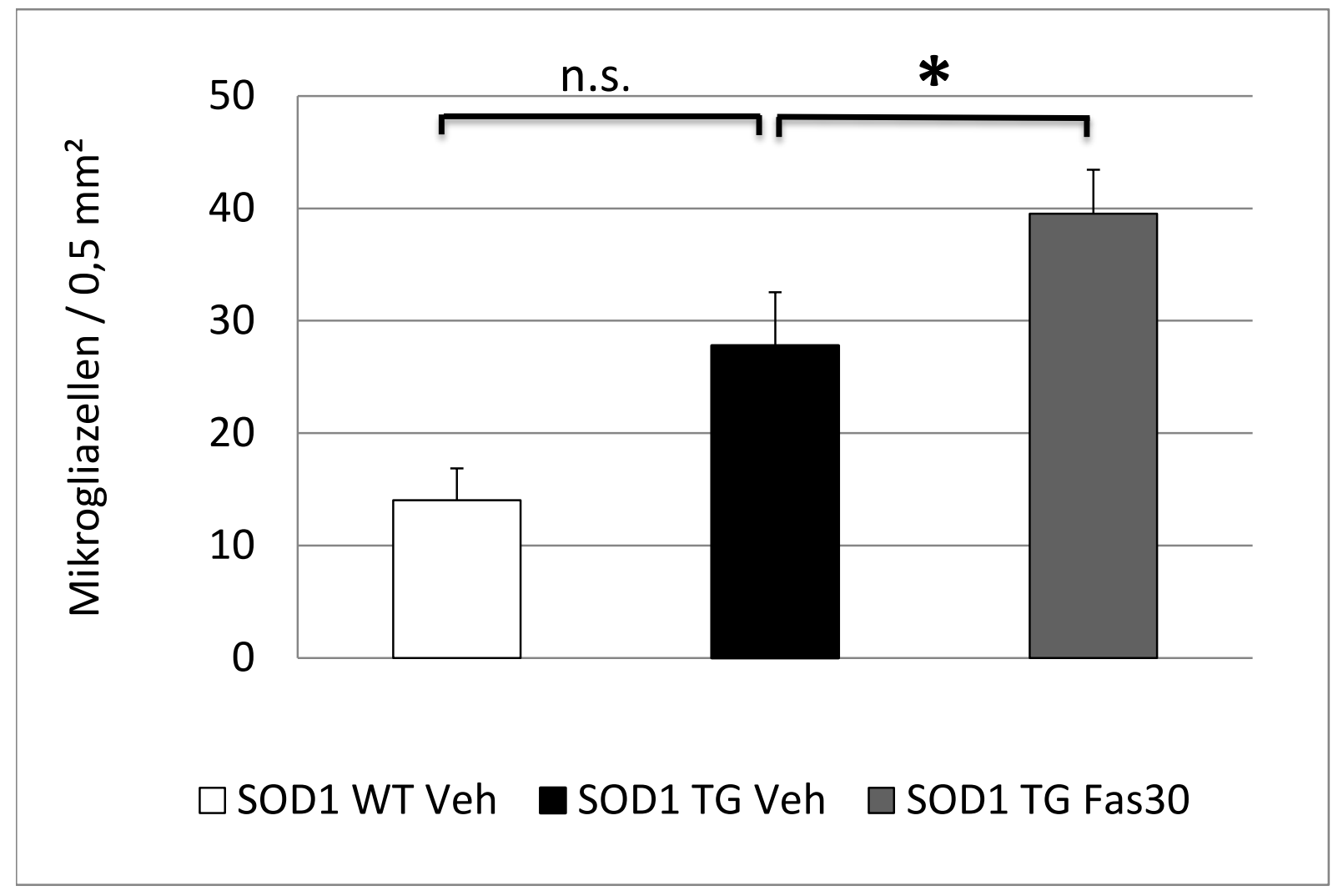

B

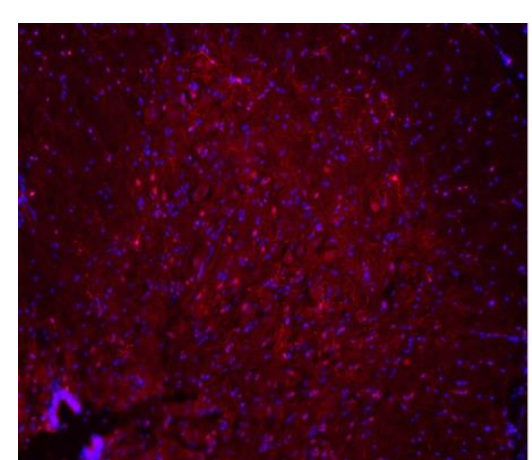

SOD1 WT

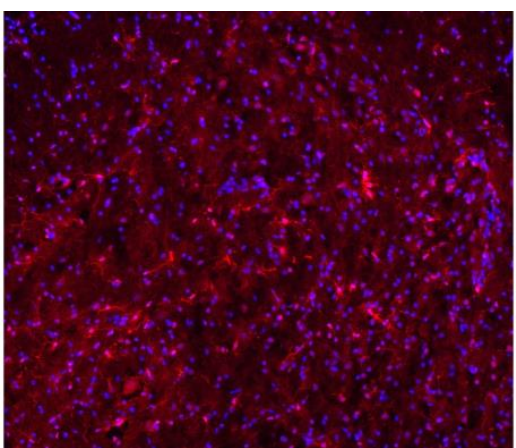

SOD1 TG Veh

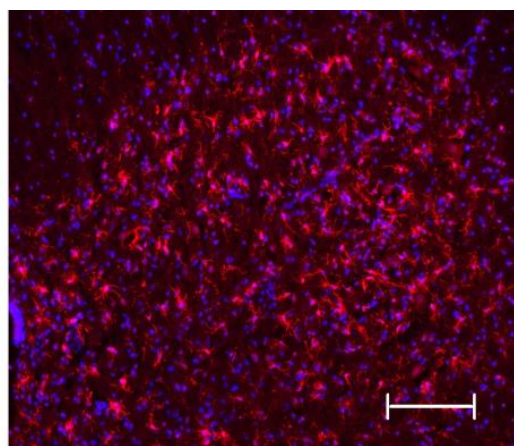

SOD1 TG Fas30

Abbildung 4: Infiltration Iba1-positiver Mikrogliazellen im Vorderhorn des lumbalen Rückenmarks an d100. A Durchschnittliche Anzahl Iba1-positiver Mikrogliazellen pro 0,5 $\mathrm{mm}^{2}$ im Vorderhorn des lumbalen Rückenmarks bei Vehikel behandelten Wildtyp-Tieren (SOD1 WT Veh; n=3) und bei SOD1-G93A-transgenen Vehikel-behandelten (SOD1 TG Veh; $n=5$ ), oder mit Fasudil30 mg/kg KG (SOD1 TG Fas30; $n=4$ ) behandelten Tieren. B Repräsentative Bilder der Immunofluoreszenz-Färbung Iba1-positiver Zellen im Rückenmarksvorderhorn in 10facher Vergrößerung [Iba1/Cy3: rot, DAPI: blau]. Fehlerindikatoren zeigen SEM; n.s.= nicht signifikant; ${ }^{*} p<0,05$. Maßstabbalken $100 \mu \mathrm{m}$. 


\subsubsection{Mikrogliazellmorphologie im Rückenmark nach Fasudil-Behandlung}

Um eine morphologische Aussage über die Iba1-positiven Mikrogliazellen treffen zu können, wurden sie nach Graeber (2010) in drei Gruppen eingeteilt; dünn ramifizierte-, dick ramifizierte- und runde Erscheinung. Es zeigte sich, dass dünn ramifizierte Mikrogliazellen in der Wildtyp-Gruppe (SOD1 WT Veh) signifikant relativ häufiger $(95,02 \% \pm 0,69 \%)$ vorkommen als in den transgenen Tieren, SOD1 TG Veh $(52,59 \% \pm 6,02 \%)$ oder SOD1 TG Fas30 $(28,70 \% \pm 5,01 \%)$. Weiterhin sieht man einen signifikanten Abfall in der relativen Zahl der dünn ramifizierten Zellen von transgenen Vehikel-behandelten Tieren $(52,59 \% \pm 6,02$ \%) zu transgenen Fasudil $30 \mathrm{mg} / \mathrm{kg} \mathrm{KG}$-behandelten Tieren $(28,70 \% \pm 5,01 \%)$. Dick ramifizierte Zellen sind bei Tieren, die mit 30mg Fasudil/kg KG behandelt wurden am häufigsten zu finden $(70,82 \% \pm 5,02 \%)$. Es besteht hier ein signifikanter Unterschied zu den beiden anderen Gruppen (46,67 \% $\pm 5,96 \%$ SOD1 TG Veh; 4,98 \% 0,69 \% SOD1 WT Veh). Ein Unterschied in der Anzahl dick ramifizierter Mikrogliazellen in ähnlicher Signifikanz ist auch zwischen den SOD1 WT Veh $(4,98 \% \pm 0,69 \%)$ und SOD1 TG Veh-Tieren $(46,67 \% \pm$ $5,96 \%)$ zu sehen. Runde Zellen kommen in allen drei Behandlungsgruppen sehr selten vor (0 \% SOD1 WT Veh; 0,74 \% \pm 0,20\% SOD1 TG Veh; 0,48 \% \pm 0,13\% SOD1 TG Fas30). Insgesamt ist zu erkennen, dass bei den Vehikel-behandelten Wildtyp-Tieren vornehmlich dünn ramifizierte Mikroglia vorliegt. In der transgenen Vehikel-Gruppe gibt es ähnlich viele dünn ramifizierte wie dick ramifizierte Mikrogliazellen. Bei den mit Fasudil behandelten Tieren liegen dick ramifizierte und dünn ramifizierte Zellen in einem Verhältnis von ca. 70:30 vor. 
A

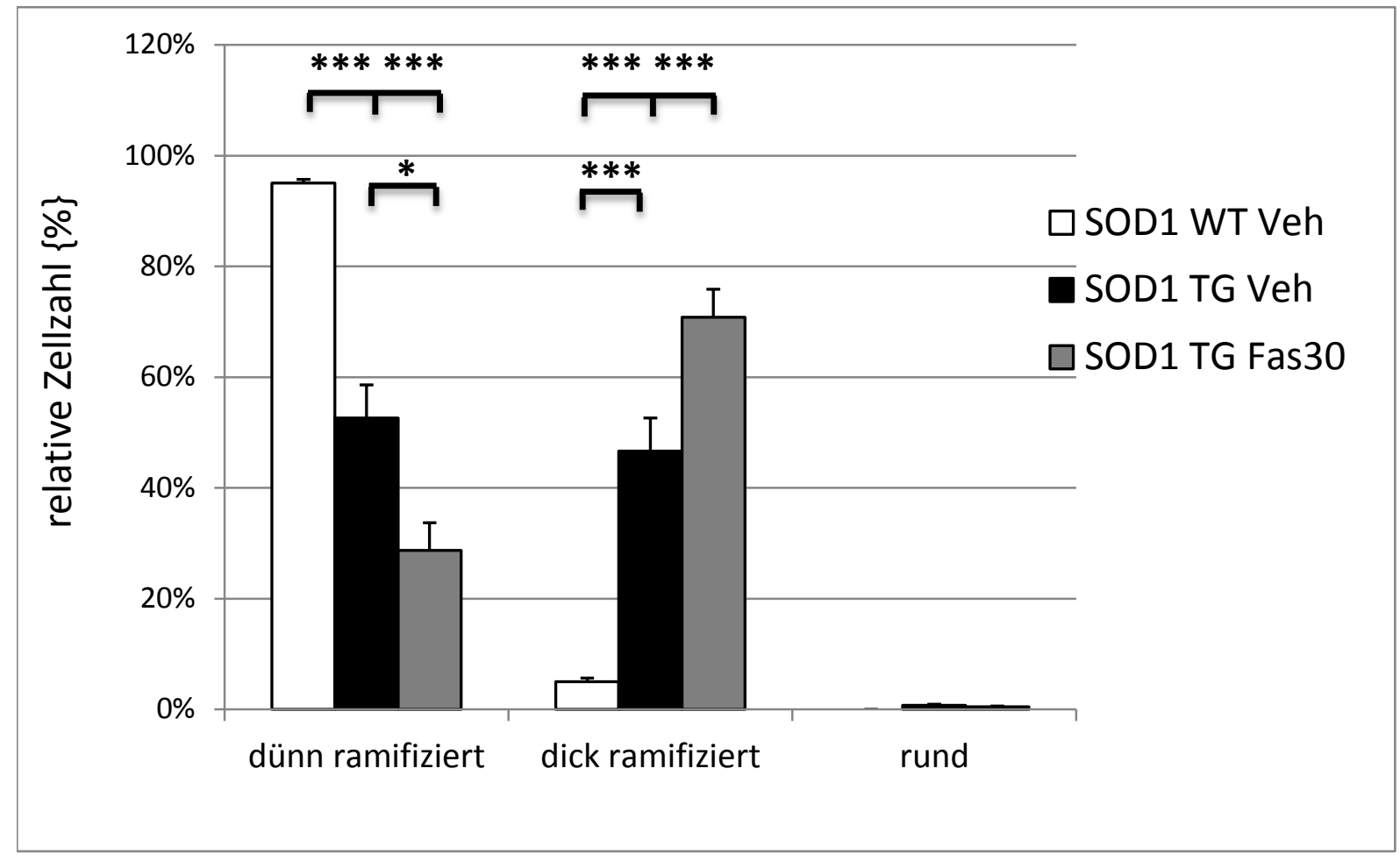

B

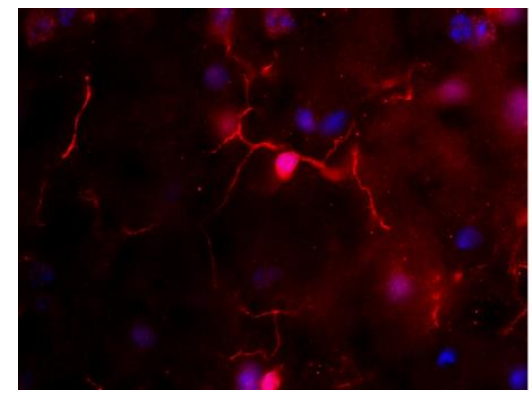

dünn ramifiziert

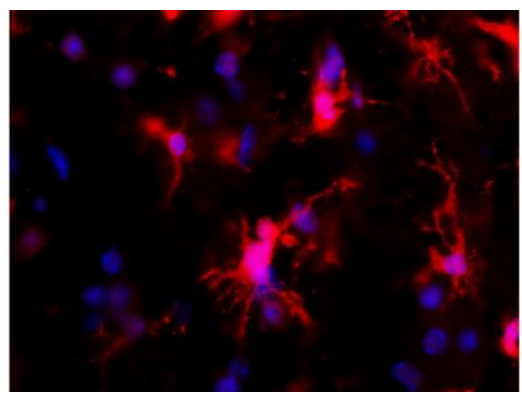

dick ramifiziert

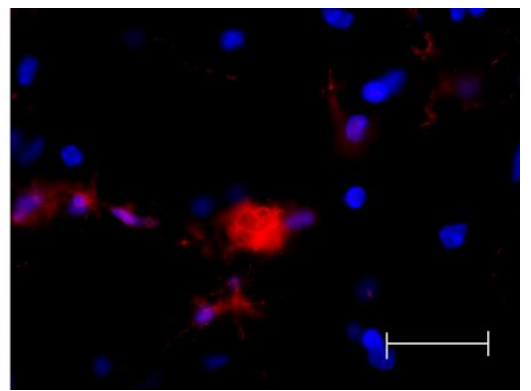

rund

Abbildung 5: Morphologie Iba1-positiver Mikrogliazellen im lumbalen Rückenmarksvorderhorn an d100.

A Quantitative Analyse der relativen Zellzahlen dreier unterschiedlicher morphologischer Typen (dünn ramifiziert, dick ramifiziert, rund) Iba1-positiver Mikrogliazellen von Vehikel-behandelten Wildtyp-Tieren (SOD1 WT Veh; $n=3$ ) und SOD1-G93A-transgenen, Vehikel- (SOD1 TG Veh; $n=5$ ) oder mit Fasudil 30 mg/kg KG behandelten (SOD1 TG Fas30; $n=4$ ) Mäusen. B Repräsentative Bilder der drei Zelltypen in 63facher Vergrößerung [Iba1/Cy3: rot, DAPI: blau]. Fehlerindikatoren zeigen SEM; n.s.= nicht signifikant; ${ }^{*} p<0,05$; $* * * p<0,001$. Maßstabbalken $50 \mu \mathrm{m}$. 


\subsubsection{Analyse im Endstadium}

Bei den Tieren der „Präsymptomatische Studie am Lebensende“ wurden eine separate Kohorte ab dem 50. Lebenstag behandelt und am Tag des Todeseintritts (endstage) analysiert. Die drei Untersuchungsgruppen bestanden aus Vehikel (SOD1 TG Veh)-, Fasudil 30 mg/kg KG (SOD1 TG Fas30)- und Fasudil 100 mg/kg KG (SOD1 TG Fas100)-behandelten Mäusen.

\subsubsection{Im Endstadium bestehen keine mikroglialen Zellzahlveränderungen nach Behandlung mit Fasudil}

Die quantitative Analyse der Iba1-positiven Mikrogliazellen im Vorderhorn des lumbalen Rückenmarks zum Zeitpunkt endstage zeigt einen insignifikanten Trend mit Anstieg der Mikrogliazellzahl in den mit Fasudil behandelten Gruppen SOD1 TG Fas30 $(48,81 \pm 3,28)$ und SOD1 TG Fas100 $(50,17 \pm 4,71)$ an. In der SOD1 TG Veh-Gruppe fand sich die geringste Anzahl Iba1-positiver Zellen im Rückenmarksvorderhorn $(43,15 \pm 4,24)$. 
A

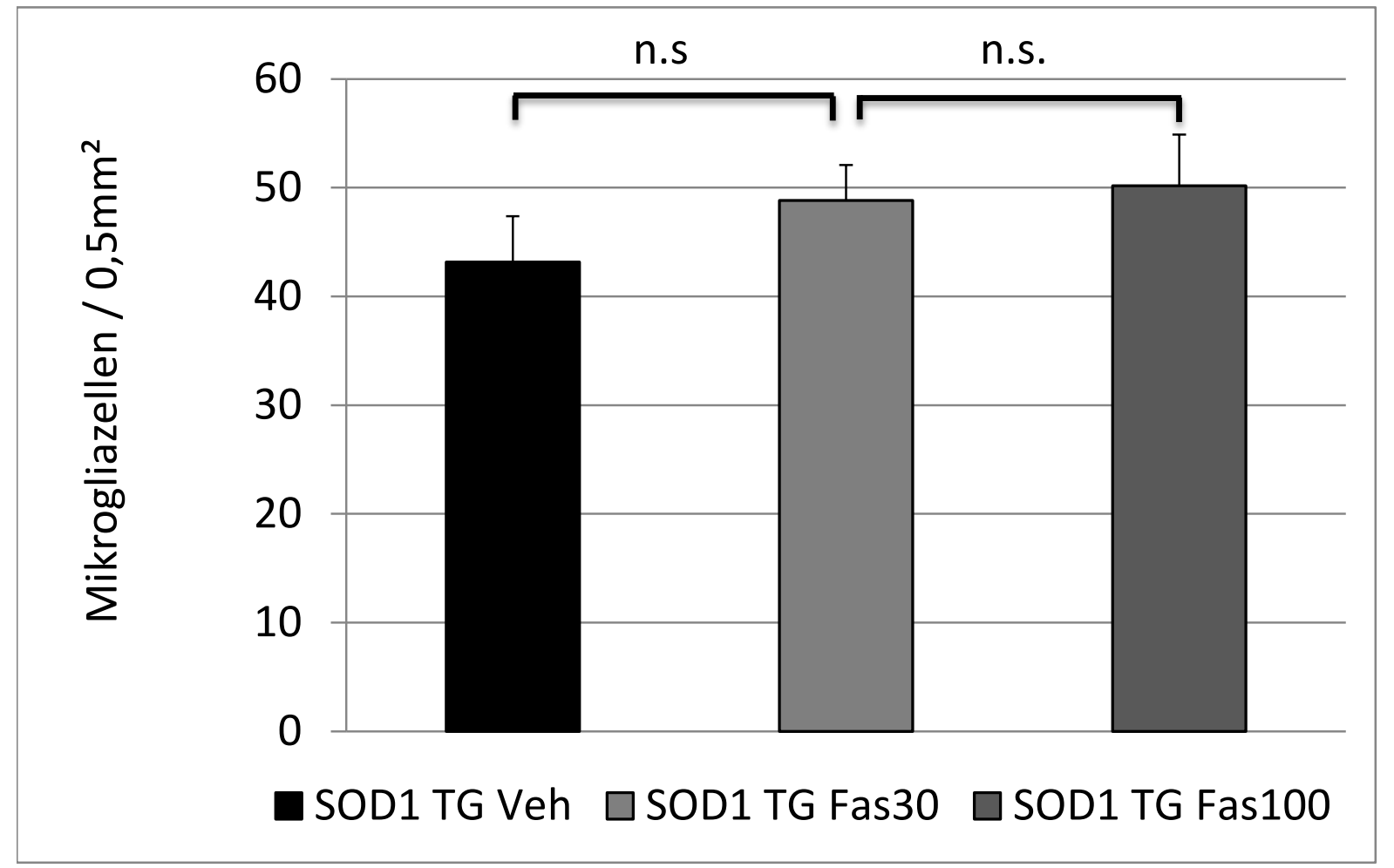

B

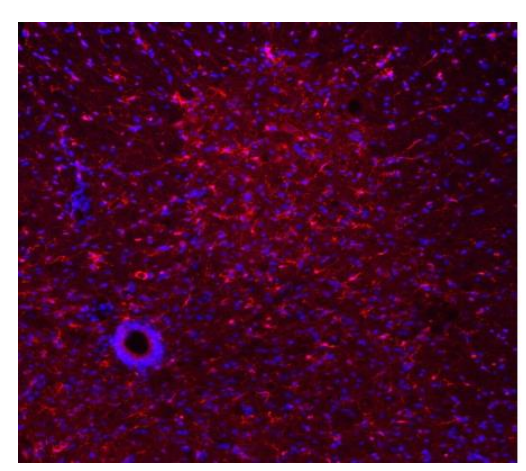

SOD1 TG Veh

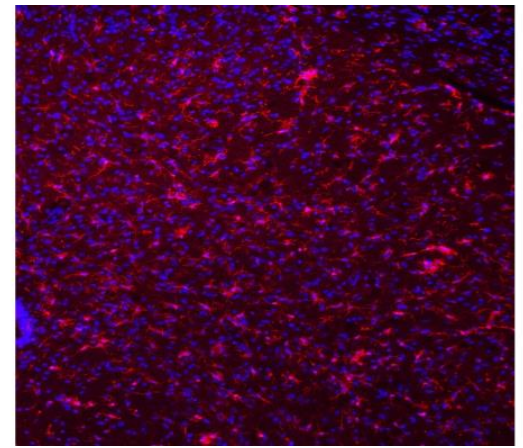

SOD1 TG Fas30

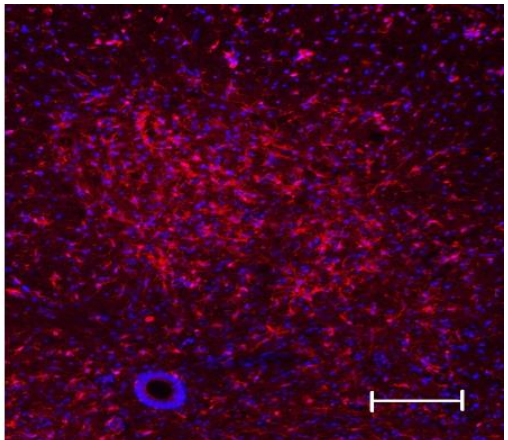

SOD1 TG Fas100

Abbildung 6: Infiltration Iba1-positiver Mikrogliazellen im Vorderhorn des lumbalen Rückenmarks zum Zeitpunkt Endstadium. A Durchschnittliche Anzahl Iba1-positiver Mikrogliazellen pro 0,5 $\mathrm{mm}^{2} \mathrm{im}$ Vorderhorn des lumbalen Rückenmarks bei SOD1-G93A-transgenen Vehikel (SOD1 TG Veh; n=3), mit Fasudil 30 mg/kg KG (SOD1 TG Fas30; n=3) oder mit Fasudil 100 mg/kg KG (SOD1 TG Fas100; $n=3$ ) behandelten Tieren. B Repräsentative Bilder der Immunofluoreszenz-Färbung Iba1-positiver Zellen im Rückenmarksvorderhorn in 10facher Vergrößerung [Iba1/Cy3: rot, DAPI: blau]. Fehlerindikatoren zeigen SEM; n.s.= nicht signifikant. Maßstabbalken $100 \mu \mathrm{m}$. 


\subsubsection{Mikrogliazellmorphologie}

Bei der morphologischen Analyse der Mikrogliazellen des Rückenmarksvorderhorns zeigt sich, dass es bei Tieren im Endstadium der Erkrankung keine signifikanten Unterschiede in der Verteilung der Zellmorphologie zwischen den Behandlungsgruppen gibt. In allen drei Gruppen ist die Mehrzahl der Zellen dick ramifiziert (SOD1 TG Veh 71,77 \% $\pm 1,52 \%$; SOD1 TG Fas30 73,88 \% 0,58 \%; SOD1 TG Fas100 76,12 \% \pm 1,87 \%). Dünn ramifizierte (SOD1 TG Veh 15,48 \% \pm 0,14 \%; SOD1 TG Fas30 15,64 \% \pm 0,34 \%; SOD1 TG Fas100 13,90 \% \pm 1,43 \%) und runde Zellen (SOD1 TG Veh 12,75 \% \pm 1,42 \%; SOD1 TG Fas30 10,48 \% \pm 0,63 \%; SOD1 TG Fas100 9,98 \% \pm 0,52 \%) liegen jeweils nur zu unter $20 \%$ vor. 


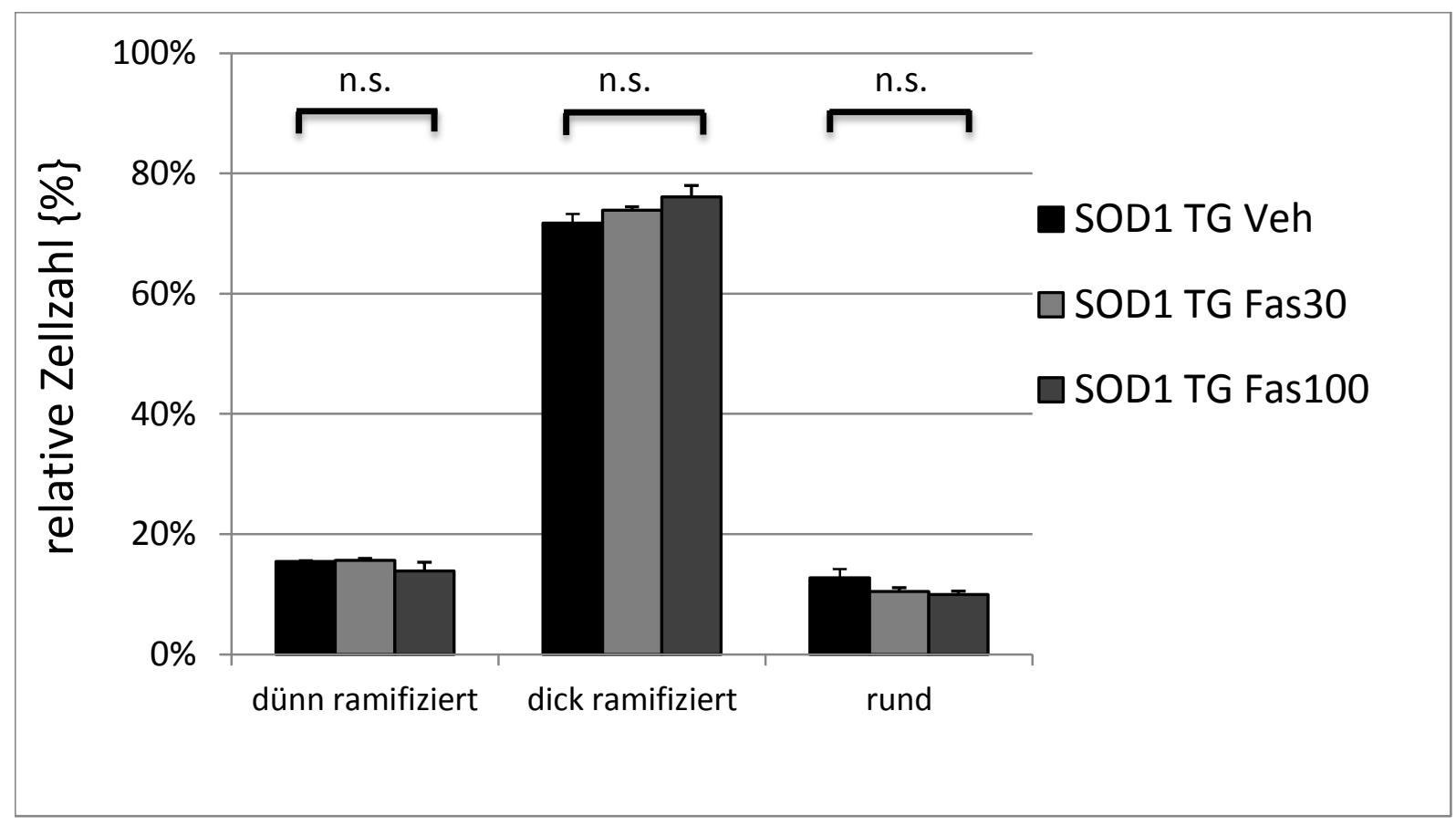

Abbildung 7: Morphologische Erscheinung Iba1-positiver Mikrogliazellen im lumbalen Rückenmarksvorderhorn zum Zeitpunkt Endstadium. Quantitative Analyse der relativen Zellzahlen dreier unterschiedlicher morphologischer Typen (dünn ramifiziert, dick ramifiziert, rund) Iba1-positiver Mikrogliazellen von SOD1-G93A-transgenen Vehikel (SOD1 TG Veh; n=3), mit 30 mg/kg KG (SOD1 TG Fas30; $\mathrm{n}=3$ ) oder 100 mg/kg KG (SOD1 TG Fas100; n=3) behandelten Tieren. Fehlerindikatoren zeigen SEM; n.s.= nicht signifikant.

\subsubsection{Mikroglia-Quantifizierung bei Analyse intermediär und Endstadium im Vergleich}

Ein Vergleich der quantitativen Analyse der Tiere mit präsymptomatischer Behandlung zum Zeitpunkt Tag100 und der Tiere mit präsymptomatischer Behandlung zum Zeitpunkt Endstadium zeigt, im Trend, einen Anstieg in der Anzahl Iba1-positiver Mikrogliazellen des lumbalen Rückenmarksvorderhorns mit Fortschreiten der Erkrankung. Dieser Trend ist sowohl bei SOD1-G93A-transgenen Vehikel-behandelten Tieren (Tag100 27,80 \pm 4,23; Endstadium 43,15 \pm 6,30 Mikrogliazellen), als auch bei Fasudil $30 \mathrm{mg} / \mathrm{kg} \mathrm{KG}$ behandelten Tieren (Tag100 39,54 \pm 3,37; Endstadium 48,81 \pm 2,92 Mikrogliazellen) zu erkennen, weist allerdings keine Signifikanz auf. 


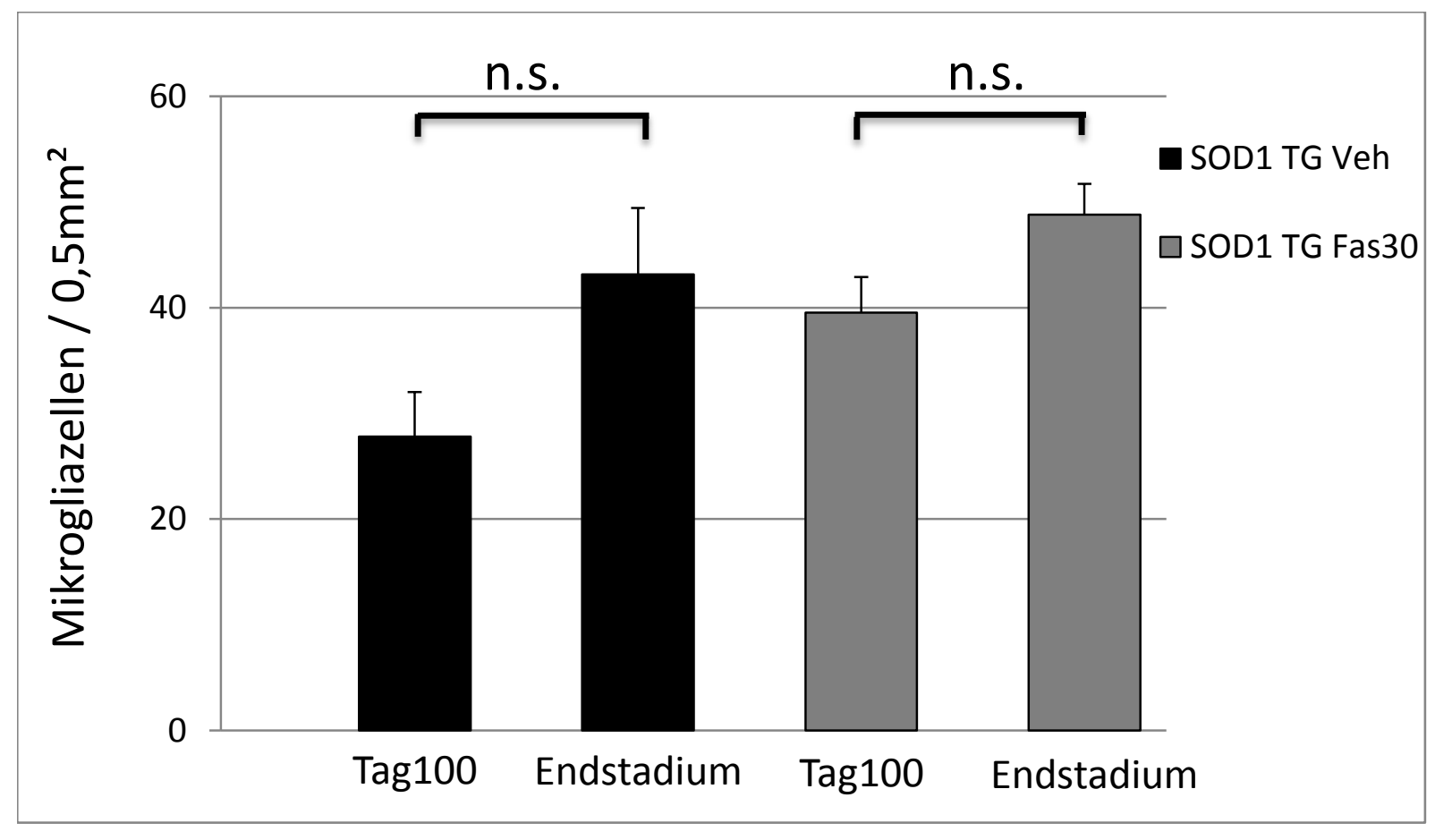

Abbildung 8: Infiltration Iba1-positiver Mikrogliazellen im Vorderhorn des lumbalen Rückenmarks zu den Zeitpunkten Tag100 und Endstadium. Durchschnittliche Anzahl Iba1-positiver Mikrogliazellen pro 0,5 $\mathrm{mm}^{2} \mathrm{im}$ Vorderhorn des lumbalen Rückenmarks bei SOD1-G93A-transgenen Vehikel (SOD1 TG Veh; Tag100 n=5, Endstadium n=3) und mit Fasudil 30 mg/kg KG (SOD1 TG Fas30; Tag100 n=4, Endstadium n=3) behandelten Tieren. Fehlerindikatoren zeigen SEM; n.s.= nicht signifikant.

\subsection{Analyse stimulierter SOD1-G93A-transgener mikroglialer Zellen nach Behandlung mit Fasudil}

Nach der quantitativen und morphologischen Auswertung der Mikrogliazellen im Rückenmarksvorderhorn von SOD1-wildtyp und transgenen Mäusen wurden die Experimente auf Zellen von Mikrogliazellkulturen ausgeweitet, um den in-vivo beobachteten Einfluss der Fasudil-Behandlung in einem mikroglialen Modell in-vitro weiter zu präzisieren.

Die Behandlungsgruppen setzten sich wie folgt zusammen:

- SOD1 WT Vehikel (SOD1 WT Veh) \pm LPS (SOD1 WT LPS)

- SOD1 WT $2 \mu$ M Fasudil (SOD1 WT Fas2) \pm LPS (SOD1 WT LPS+Fas2)

- SOD1 WT $10 \mu \mathrm{M}$ Fasudil (SOD1 WT Fas10) \pm LPS (SOD1 WT LPS+Fas10) 
- $\quad$ SOD1 WT $50 \mu \mathrm{M}$ Fasudil (SOD1 WT Fas50) \pm LPS (SOD1 WT LPS+Fas50)

- SOD1-G93A TG Vehikel (SOD1 TG Veh) \pm LPS (SOD1 TG LPS)

- SOD1-G93A TG $2 \mu$ M Fasudil (SOD1 TG Fas2) \pm LPS (SOD1 TG LPS+Fas2)

- SOD1-G93A TG $10 \mu \mathrm{M}$ Fasudil (SOD1 TG Fas10) \pm LPS (SOD1 TG LPS+Fas10)

- SOD1-G93A TG $50 \mu$ M Fasudil (SOD1 TG Fas50) \pm LPS (SOD1 TG LPS+Fas50)

\subsubsection{Mikrogliazellmorphologie}

Da die Mikrogliazellen in-vitro einen anderen Phänotyp zeigen als die Zellen im Rückenmark, wurden für die morphologische Analyse die Parameter Anzahl und Länge der Fortsätze sowie Zellform (rundlich oder nicht rundlich) ausgewählt.

\subsubsection{Gesamtzahl der Fortsätze pro Mikrogliazelle}

Es zeigte sich, dass sowohl bei SOD1-wildtyp als auch bei transgenen Zellen durch die Stimulation mit LPS die Anzahl der Fortsätze signifikant steigt. So wächst die Anzahl der Fortsätze pro Mikrogliazelle bei SOD1-wildtyp Zellen in der Vehikel-Gruppe von $6,13 \pm 1,31$ Fortsätzen zur LPS-Gruppe auf 25,80 $\pm 2,41$ und bei SOD1-G93A-transgenen Zellen in der Vehikel-Gruppe von 7,25 \pm 0,97 Fortsätzen zur LPS-Gruppe auf 19,00 $\pm 1,86$ an. Weiterhin kann man bei den durch LPS stimulierten Wildtyp-Zellen eine Abnahme der Anzahl an Fortsätzen mit der Behandlung durch Fasudil beobachten. So sinkt die Anzahl von der SOD1wildtyp LPS-Gruppe $(25,80 \pm 2,41$ Fortsätze) zur wildtyp LPS+Fas50-Gruppe $(12,42 \pm 1,55$ Fortsätze) signifikant. Ebenso kann man eine Verringerung in der Anzahl der Fortsätze pro Zelle von der wildtyp LPS-Gruppe $(25,80 \pm 2,41)$ zur wildtyp LPS+Fas10-Gruppe $(18,70 \pm 2,34)$ und von der wildtyp LPS+Fas2-Gruppe $(20,75 \pm 1,75)$ zur wildtyp LPS+Fas50-Gruppe $(12,42 \pm$ 1,55) sehen. Bei den SOD1-G93A-transgenen Zellen zeigen sich keine signifikanten Unterschiede zwischen den Behandlungsgruppen mit unterschiedlichen Konzentrationen von Fasudil. 
A

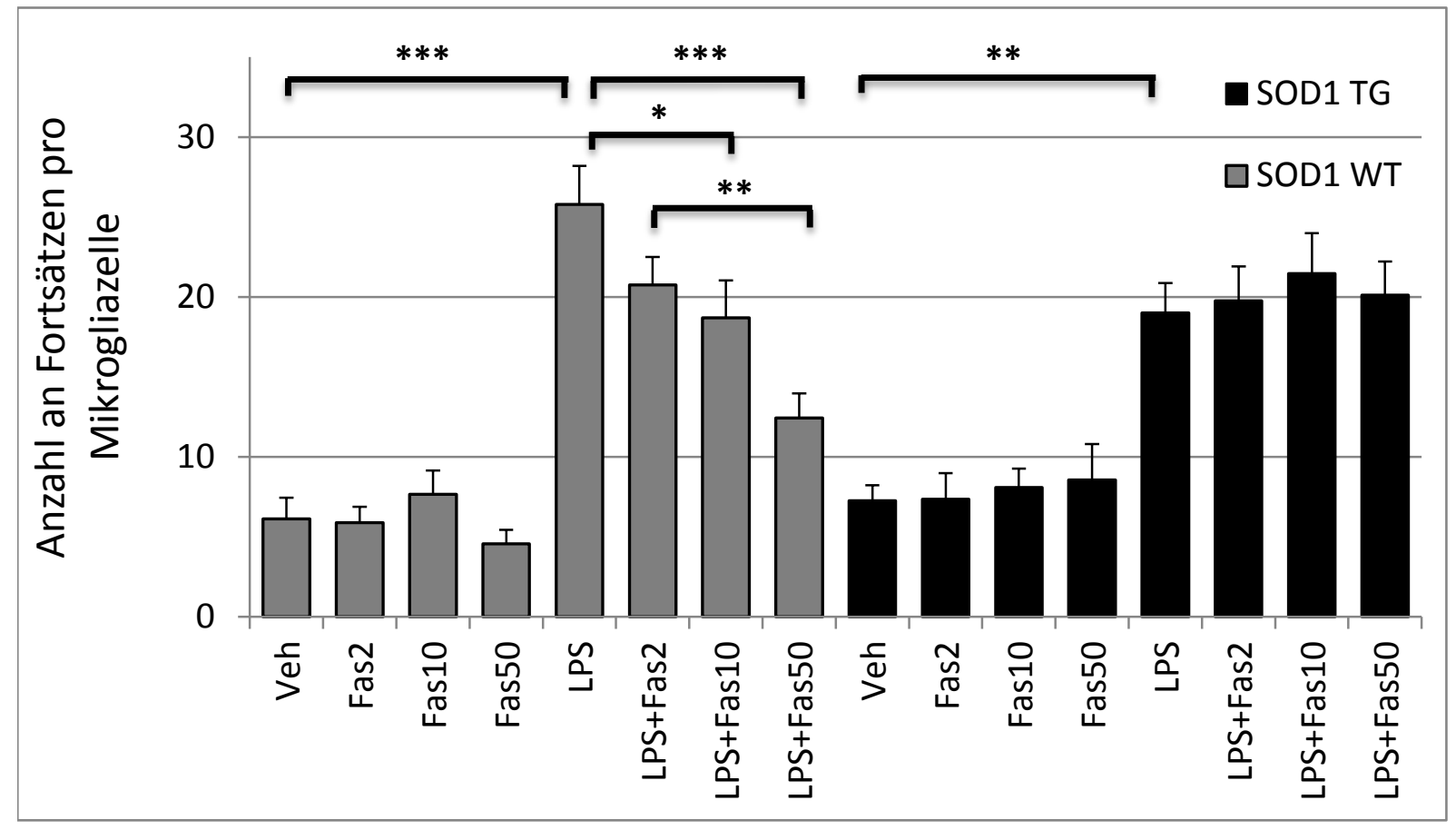

B
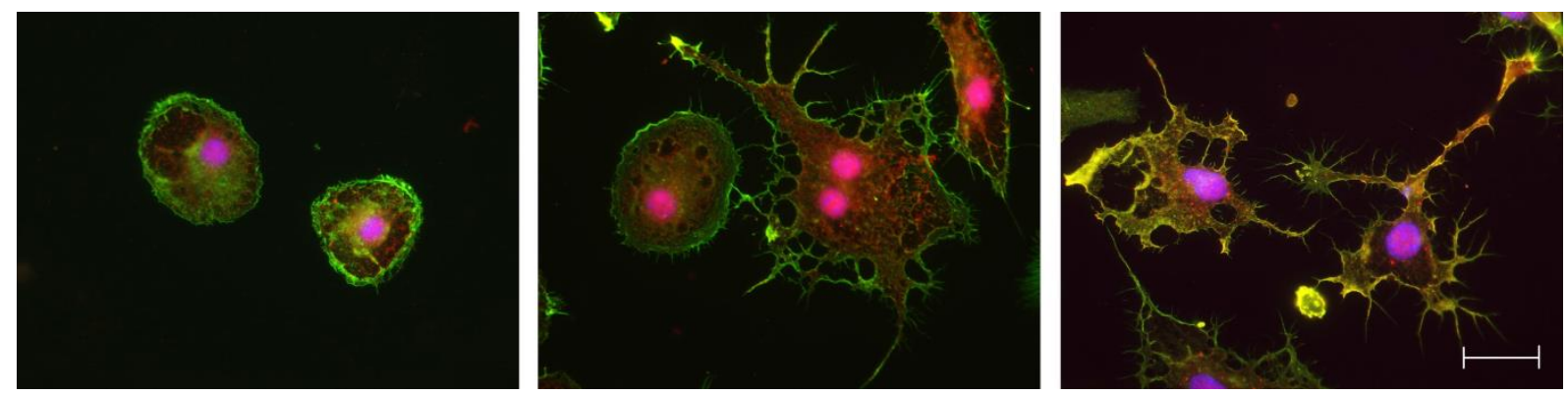

Abbildung 9: Morphologische Erscheinung Iba1-positiver Mikrogliazellen in vitro. A Quantitative Analyse der Anzahl der Fortsätze pro lba1-positiver Mikrogliazelle von SOD1-wildtyp (SOD1 WT) und transgenen Tieren (SOD1 TG), jeweils Vehikel (SOD1 WT: $n=55$; SOD1 TG: $n=28$ ), Fas2 (SOD1 WT: $n=52$; SOD1 TG: $n=25$ ), Fas10 (SOD1 WT: $n=52$; SOD1 TG: $n=26$ ), Fas50 (SOD1 WT: $n=51$; SOD1 TG: $n=25$ ), LPS (SOD1 WT: $n=54$; SOD1 TG: $n=27$ ), LPS+Fas2 (SOD1 WT: $n=53$; SOD1 TG: $n=25$ ), LPS+Fas10 (SOD1 WT: $n=55$; SOD1 TG: $n=26$ ), LPS+Fas50 (SOD1 WT: $n=52$; SOD1 TG: $n=25$ ) behandelt. B Repräsentative Beispielbilder der Mikrogliamorphologie in vivo in 63facher Vergrößerung der Behandlungsgruppen (v.I.n.r.) SOD1 WT Veh, SOD1 WT LPS+Fas2, SOD1 TG LPS+Fas50 [Iba1/Cy3: rot, DAPI: blau, Rhodamine Phalloidin: grün]. Fehlerindikatoren zeigen SEM; n.s. = nicht signifikant; ${ }^{*} p<0,05 ;{ }^{* *} p<0,01 ;{ }^{* *} p<0,001$. Maßstabbalken $50 \mu \mathrm{m}$. 


\subsubsection{Fortsatzlängen pro Mikrogliazelle}

Bei dem Parameter Länge der Fortsätze pro Mikrogliazelle zeigte sich ein signifikanter Anstieg der Länge der Zellfortsätze zwischen den SOD1 Wildtyp-Gruppen Vehikel $(28,03 \mu \mathrm{m}$ $\pm 0,74 \mu \mathrm{m})$ und LPS $(34,16 \mu \mathrm{m} \pm 2,09 \mu \mathrm{m})$. Es lässt sich kein signifikanter Unterschied bei SOD1-wildtyp oder transgenen Zellen zwischen den Behandlungsgruppen mit Unterschiedlichen Konzentrationen von Fasudil erkennen. Ebenso zeigte die LPS-Stimulation bei den SOD1-G93A-transgenen Zellen $(29,05 \mu \mathrm{m} \pm 1,76 \mu \mathrm{m}$ Fortsatzlänge) keinen signifikanten Unterschied zur transgenen Vehikel-Gruppe $(27,19 \mu \mathrm{m} \quad \pm$ 1,15 $\mu \mathrm{m}$ Fortsatzlänge).

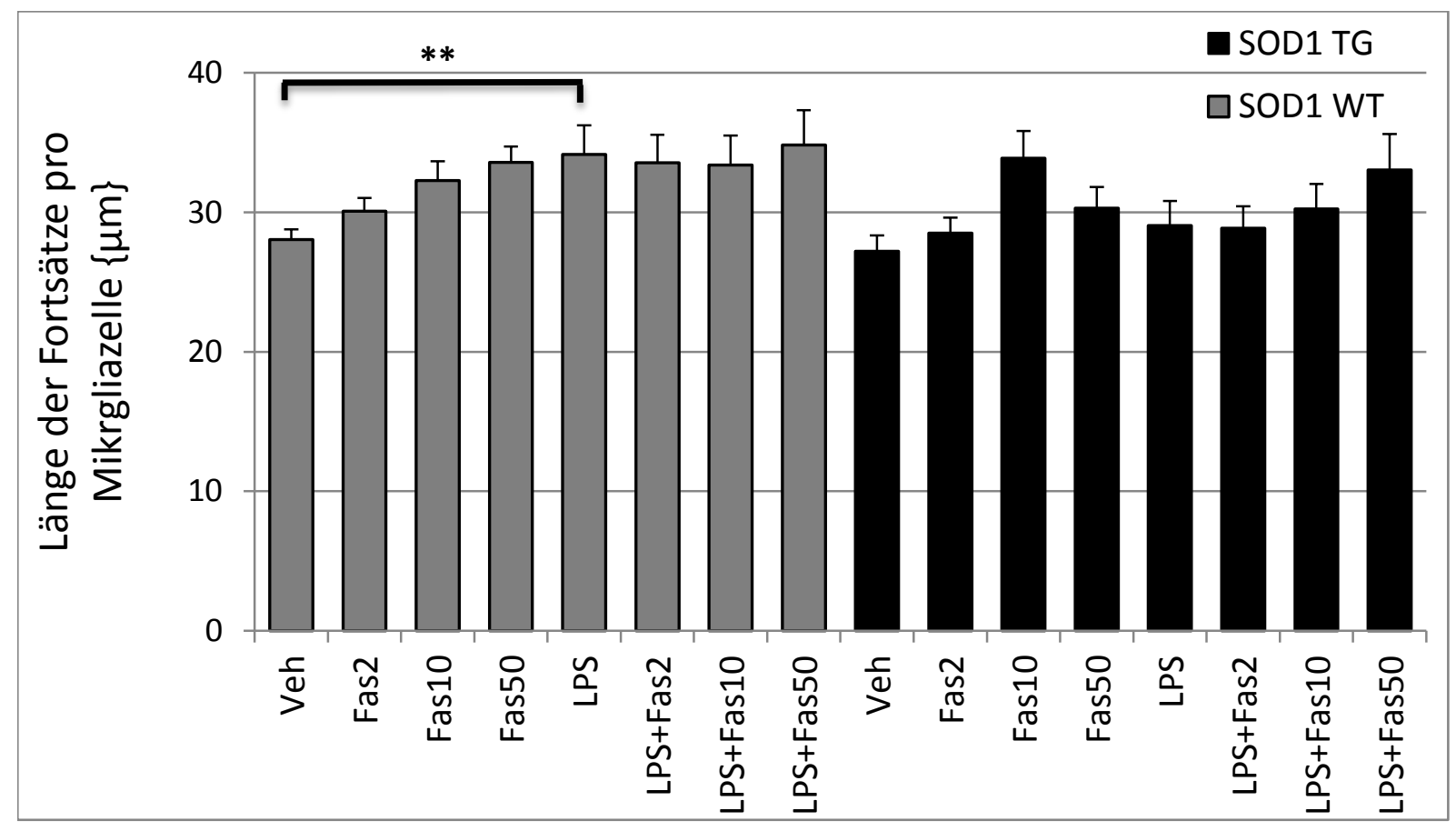

Abbildung 10: Morphologische Erscheinung Iba1-positiver Mikrogliazellen in vitro. Quantitative Analyse der Länge der Fortsätze pro Iba1-positiver Mikrogliazelle in $\mu \mathrm{m}$ von SOD1-wildtyp (SOD1 WT) und transgenen Tieren (SOD1 TG), jeweils Vehikel (SOD1 WT: $n=55$; SOD1 TG: $n=28$ ), Fas2 (SOD1 WT: $n=52$; SOD1 TG: $n=25$ ), Fas10 (SOD1 WT: n=52; SOD1 TG: $n=26$ ), Fas50 (SOD1 WT: $n=51$; SOD1 TG: $n=25$ ), LPS (SOD1 WT: $n=54$; SOD1 TG: $n=27$ ), LPS+Fas2 (SOD1 WT: n=53; SOD1 TG: $n=25$ ), LPS+Fas10 (SOD1 WT: n=55; SOD1 TG: n=26), LPS+Fas50 (SOD1 WT: $n=52$; SOD1 TG: $n=25$ ) behandelt. Fehlerindikatoren zeigen SEM; n.s.= nicht signifikant; ${ }^{* *} p<0,01$. 


\subsubsection{Rundliche Mikrogliazellen}

Der Anteil rundlicher Zellen weist bei den SOD1-wildtyp Mikrogliazellen Werte bis zu 48,69\% $\pm 11,80 \%$ in der WT Fas50-Gruppe auf. Die Zellen der SOD1-G93A-transgenen Tiere wiesen insgesamt einen geringeren Anteil rundlicher Zellen auf (TG Fas50 20,00 \%). Zellen, die durch LPS stimuliert wurden sind bei SOD1 Wildtyp-Tieren mit geringerem Anteil von rundlicher Erscheinung als nicht stimulierte (WT Medium 34,55 \% \pm 0,05 \%; WT LPS 13,05 \% \pm 1,65 \%). Allerdings zeigen sich keine signifikanten Unterschiede.

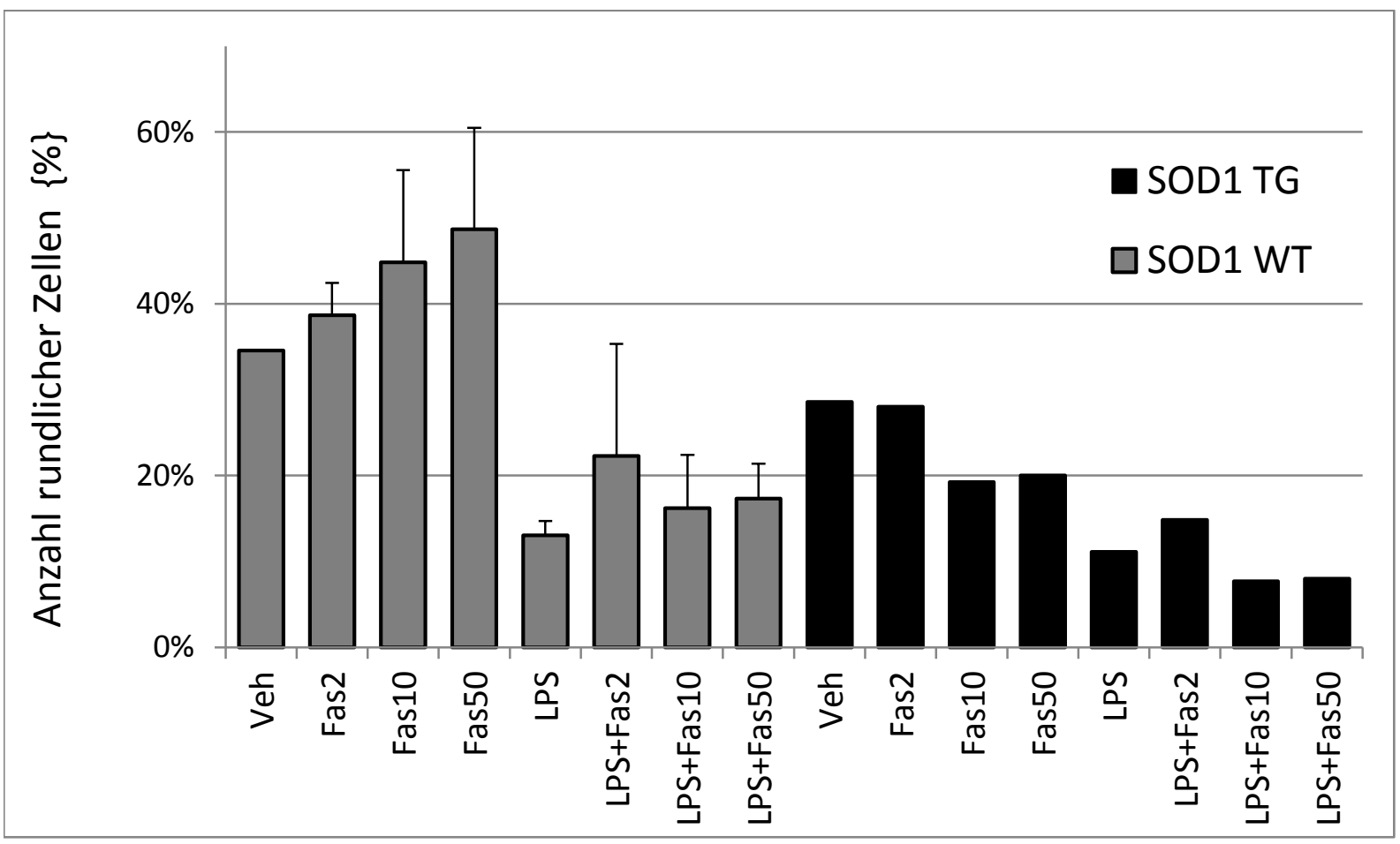

Abbildung 11: Morphologische Erscheinung Iba1-positiver Mikrogliazellen in vitro. Quantitative Analyse der relativen Zellzahlen Iba1-positiver Mikrogliazelle in rundlicher Erscheinungsform von SOD1-wildtyp (SOD1 WT) und transgenen Tieren (SOD1 TG), jeweils Vehikel (SOD1 WT: $n=55$; SOD1 TG: $n=28$ ), Fas2 (SOD1 WT: $n=52$; SOD1 TG: $n=25$ ), Fas10 (SOD1 WT: $n=52$; SOD1 TG: $n=26$ ), Fas50 (SOD1 WT: $n=51$; SOD1 TG: $n=25$ ), LPS (SOD1 WT: $n=54$; SOD1 TG: $n=27$ ), LPS+Fas2 (SOD1 WT: $n=53$; SOD1 TG: $n=25)$, LPS+Fas10 (SOD1 WT: $n=55$; SOD1 TG: $\mathrm{n}=26$ ), LPS+Fas50 (SOD1 WT: $n=52$; SOD1 TG: $n=25$ ) behandelt. Fehlerindikatoren zeigen SEM; n.s.= nicht signifikant. 


\subsubsection{Mikrogliales Profil der Zytokine und Chemokine}

Im Rahmen einer funktionellen Analyse evaluierten wir den Effekt der Rho-Kinase-Inhibition durch Fasudil nach Stimulation durch LPS auf die Zytokinfreisetzung in primären Mikrogliazellkulturen von neugeborenen SOD1-G93A-transgenen bzw. Wildtyp-Tieren.

\subsubsection{Freisetzung von Zytokinen und Chemokinen nach Stimulation mit LPS}

Durch die Behandlung der Zellen allein mit Fasudil $(2 \mu \mathrm{M}, 10 \mu \mathrm{M}, 50 \mu \mathrm{M})$ für 18 Stunden ließ sich kein Anstieg der Zytokine und Chemokine induzieren. Ebenso zeigte die Vehikelbehandelte Gruppe ohne Stimulation durch LPS keine messbaren Werte (Daten nicht dargestellt). Die Stimulation mit LPS $(10 \mathrm{ng} / \mathrm{ml})$ für 18 Stunden führte zu einer kräftigen Freisetzung von TNF $\alpha, \mathrm{IL}-6, \mathrm{CCL} 2, \mathrm{CCL} 3, \mathrm{CCL} 5$ und CXCL1 in SOD1-G93A-transgenen und Wildtyp-Tieren. Jedoch zeigte sich allgemein bei den SOD1-G93A-transgenen Zellen eine geringere Induzierbarkeit der Freisetzung im Vergleich zur Wildtyp-Zellkultur (Abbildung 14). Die SOD1-G93A-transgenen Zellen erreichten durch LPS-Stimulation 55,7 $\pm 3,0 \%$ TNF $\alpha ; 61,6$ $\pm 5,6 \%$ IL6; $54,7 \pm 5,0 \%$ CCL2; 55,7 $\pm 8,2 \%$ CCL3 und 44,1 $\pm 4,0 \%$ CCL5 der Freisetzungsmengen der SOD1-Wildtyp-Zellen. Einzig die Freisetzung von CXCL1 war in SOD1-G93A-transgenen Kulturen stärker (123,8 $\pm 3,8 \%)$. 


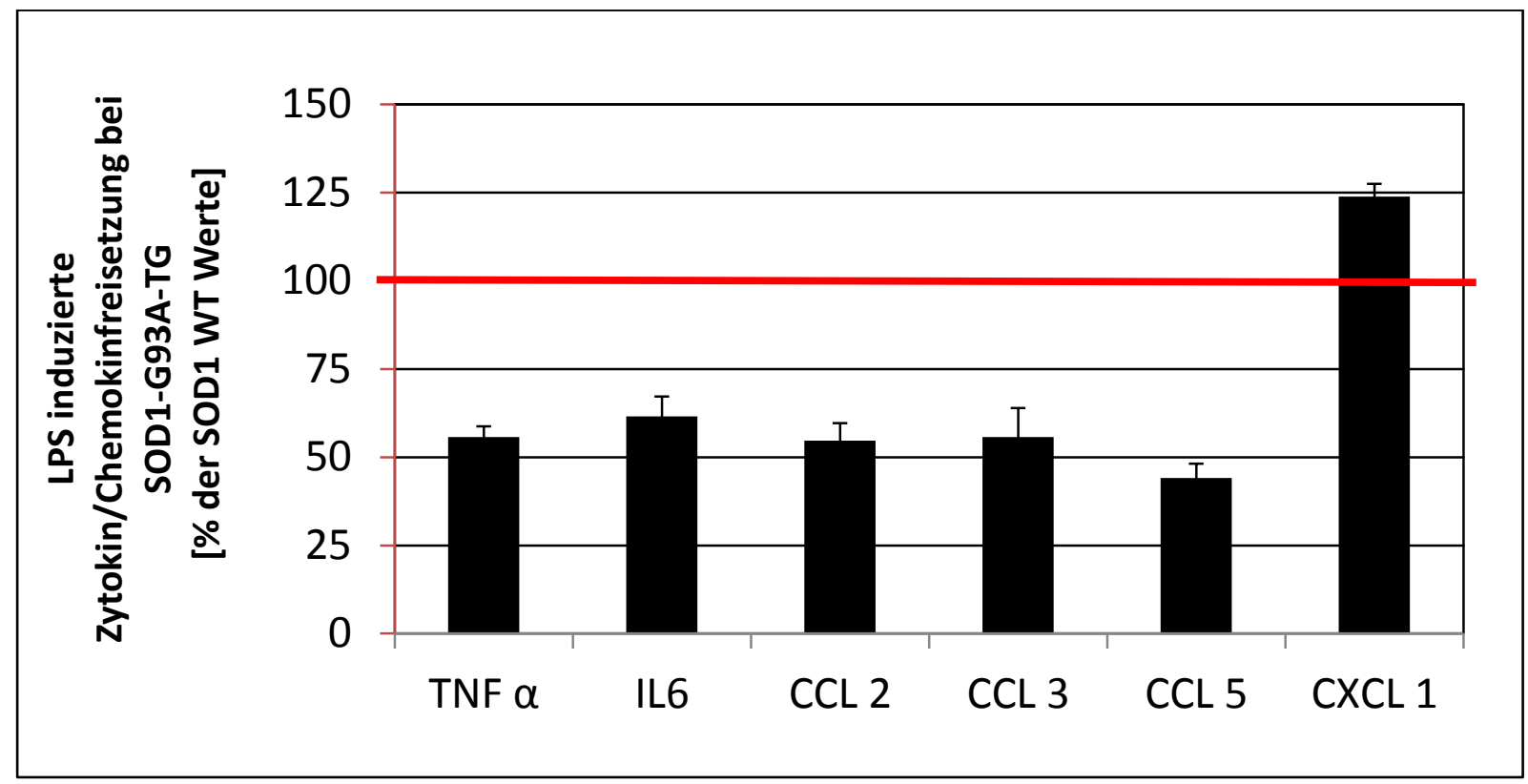

Abbildung 12: Induktion der mikroglialen Zytokin- und Chemokin-Freisetzung durch LPS in primären Mikrogliazellkulturen von neugeborenen SOD1-wildtyp und transgenen Tieren nach Behandlung mit LPS (10 ng/ml) für 18 Stunden inkubiert. Das Zytokin- und Chemokinprofil von TNF $\alpha$, IL6, CCL2, CCL3, CCL5 und CXCL1 ( $n=8)$ wurde im Überstand der Zellkulturen bestimmt. Dargestellt sind relative Daten entsprechend der Werte der LPS induzierten Freisetzung von Zytokinen und Chemokinen der SOD1-wildtyp Mikrogliazellen (festgelegt als $100 \%$ ). Fehlerindikatoren zeigen SEM.

\subsubsection{Kombinierte Behandlung mit LPS und Fasudil}

Bei simultaner Inkubation der Zellen mit LPS $(10 \mathrm{ng} / \mathrm{ml})$ und Fasudil in verschiedenen Konzentrationen $(0 \mu \mathrm{M}, 2 \mu \mathrm{M}, 10 \mu \mathrm{M}, 50 \mu \mathrm{M})$ für 18 Stunden zeigte sich für TNF $\alpha$, IL6, CCL3, CCL5 und CXCL1 bei beiden Genotypen eine dosisabhängige Reduktion der Zytokine und Chemokine mit Fasudil (Abbildung $15 \mathrm{~A}-\mathrm{E}$ ). Während Fasudil $2 \mu \mathrm{M}$ und $10 \mu \mathrm{M}$ nur gering wirksam waren, reduzierte eine Dosis von $50 \mu \mathrm{M}$ Fasudil die Werte deutlich; TNFa: SOD1 WT -76 \%, SOD1 TG -75,1 \%; IL6: SOD1 WT -77,6 \%, SOD1 TG -77,8 \%; CCL3: SOD1 WT -63,6 \%, SOD1 TG -56,9 \%; CCL5: SOD1 WT -39,9 \%, SOD1 TG -39,7 \%; CXCL1: SOD1 WT -66,5 \%, SOD1 TG -71,1\%). Im Gegensatz dazu fand sich bei CCL2 keine Reduktion mit ansteigenden Fasudil-Dosen (SOD1 WT +9,1 \%, SOD1 TG +8,9 \%) (Abbildung 15 F). 
A

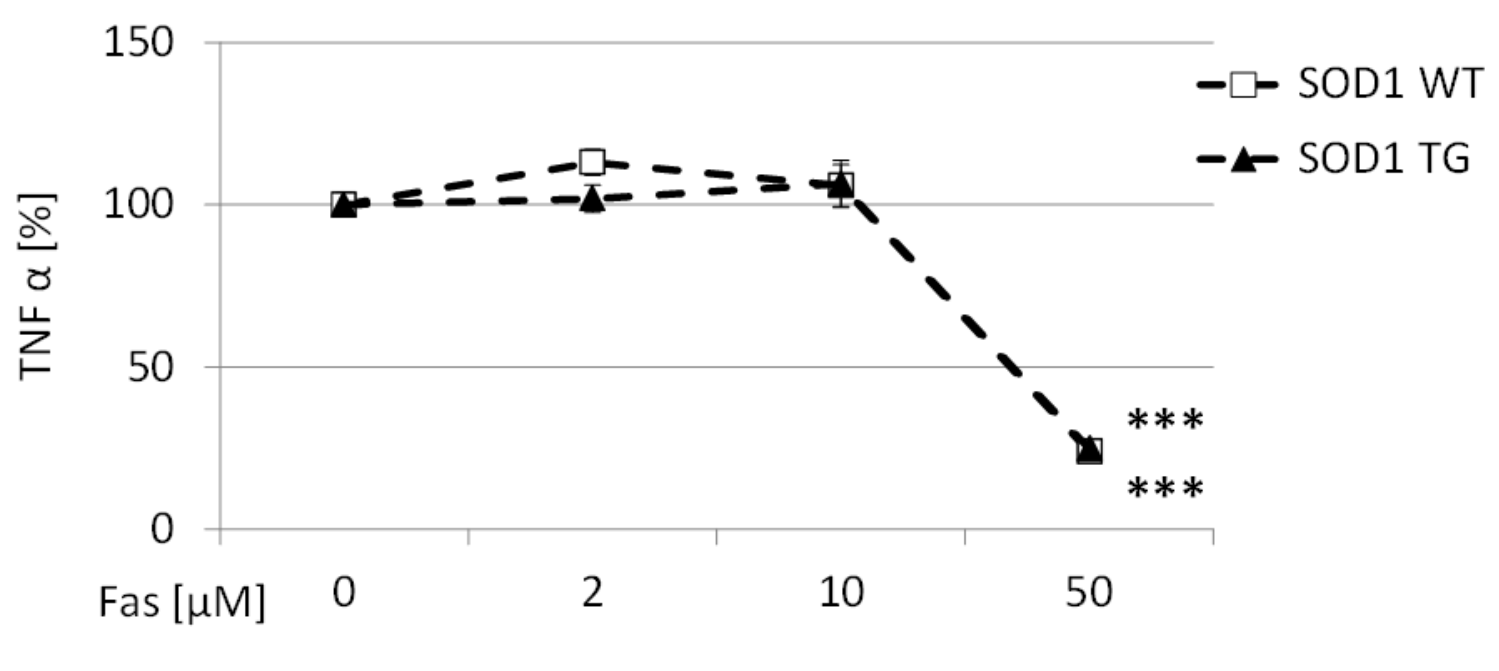

B

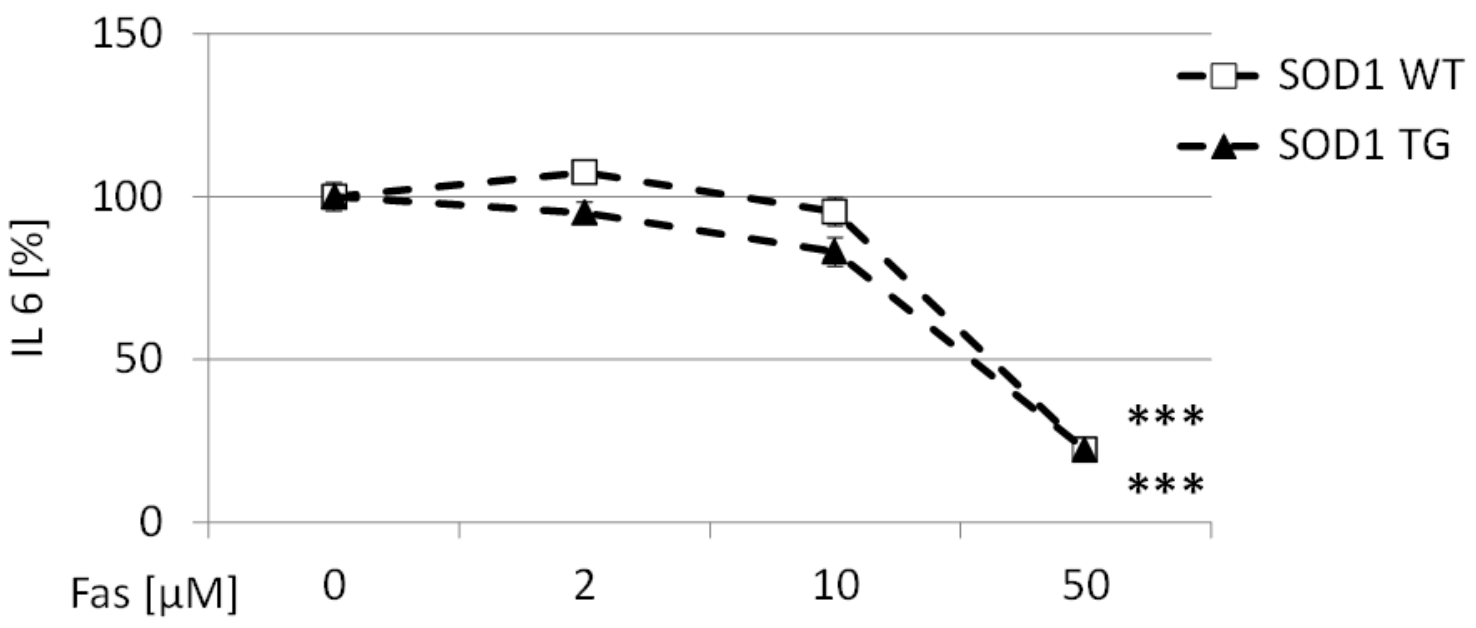

C

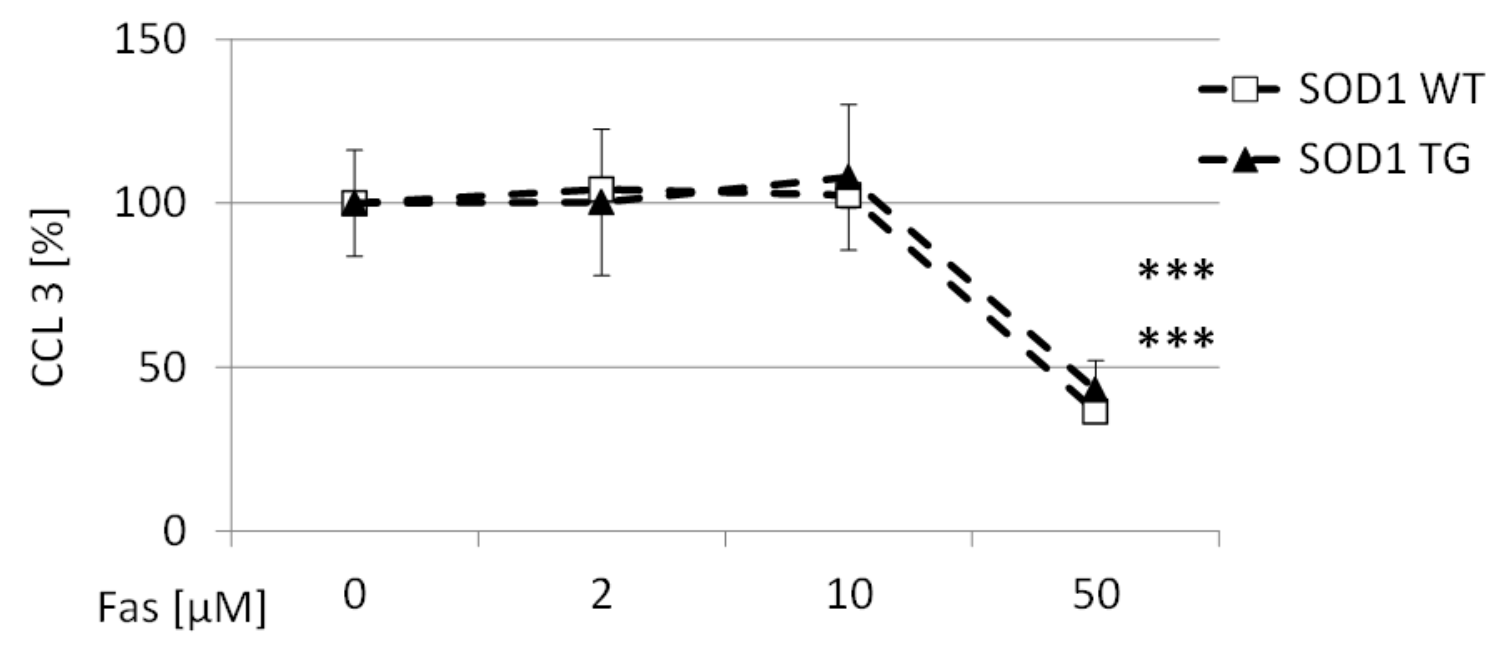


D

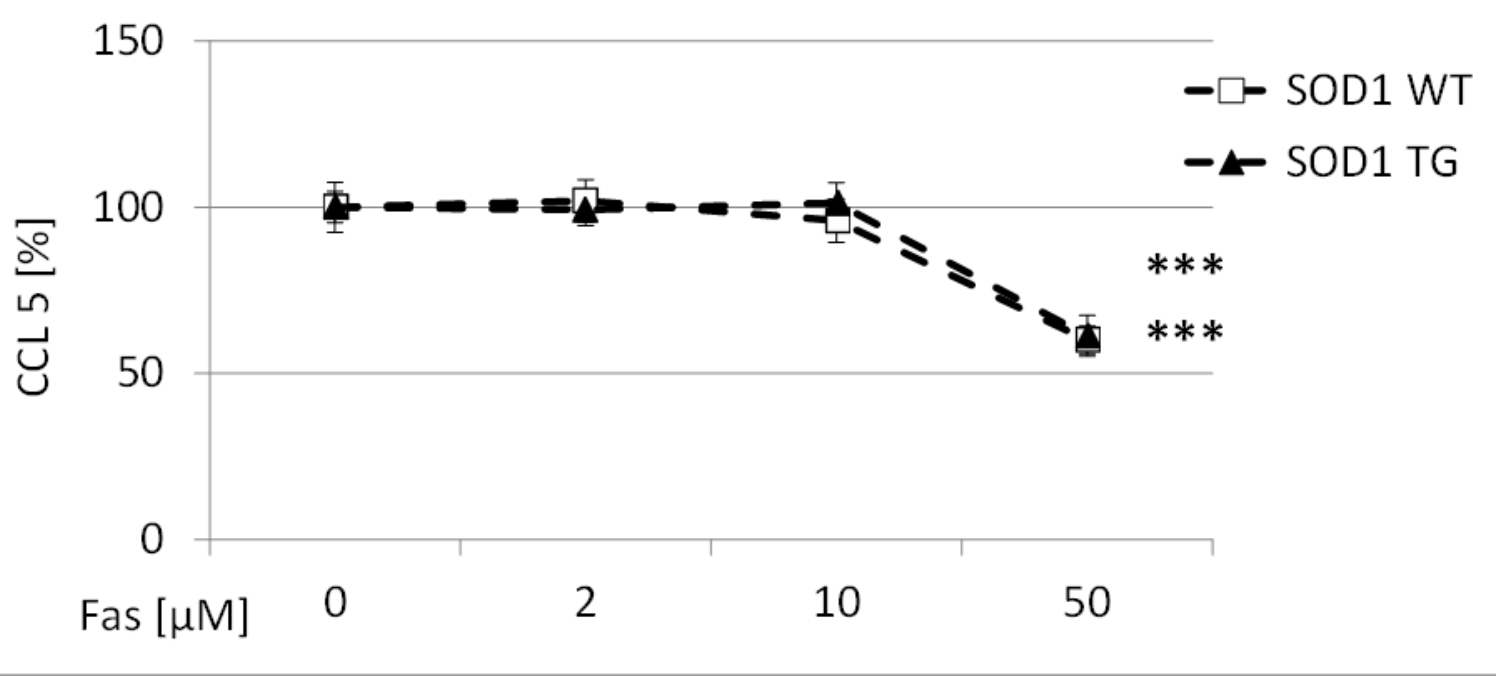

E

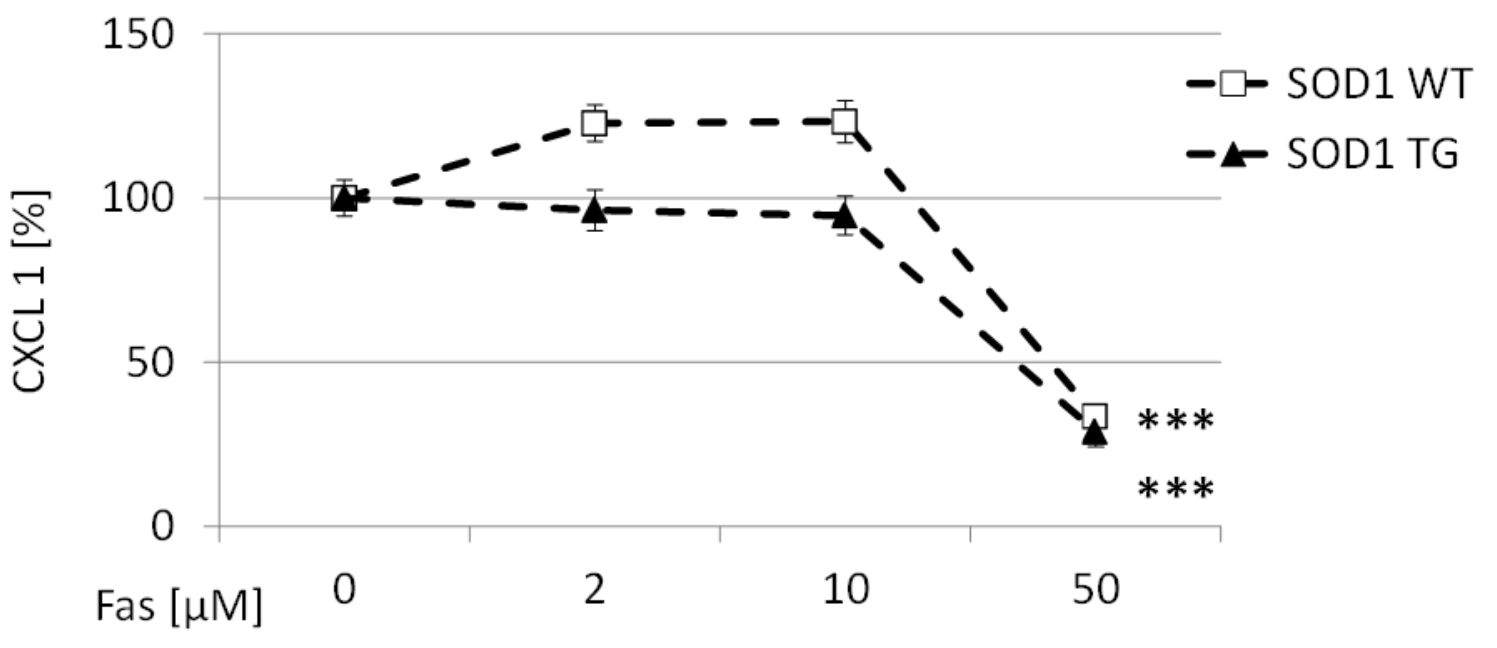

F

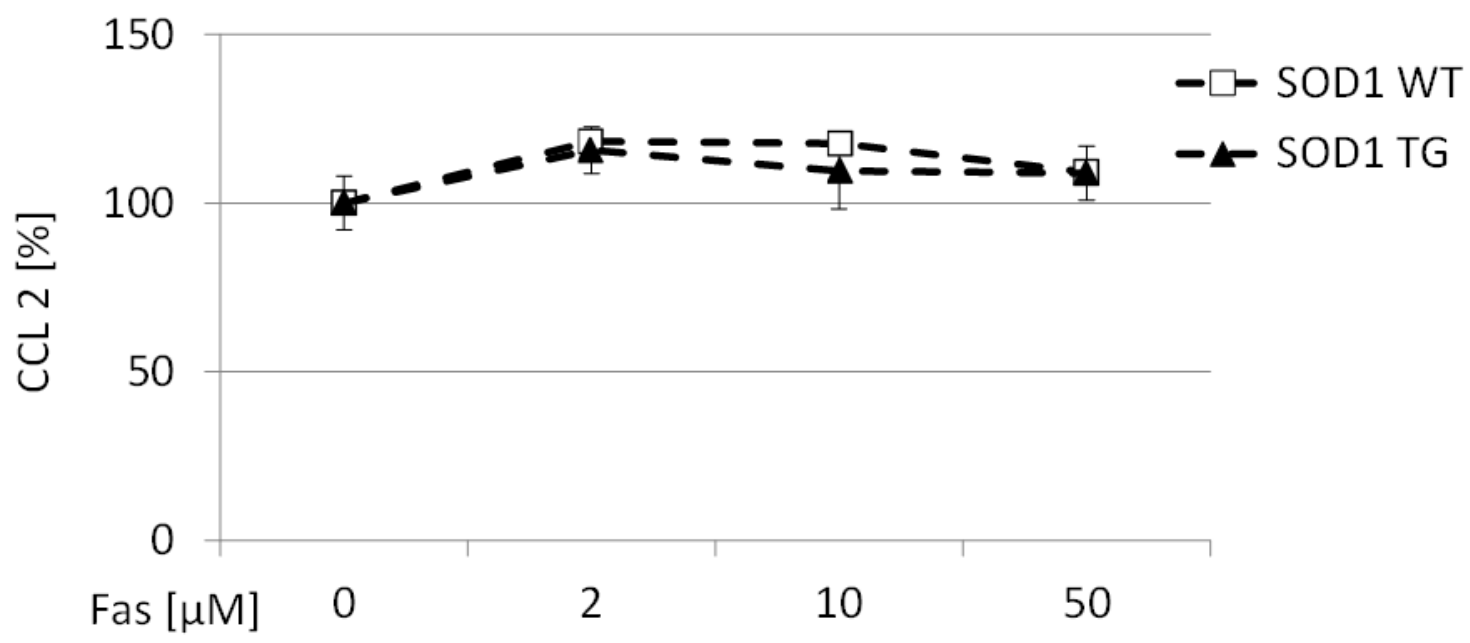


Abbildung 13: Zytokin- und Chemokin-Freisetzung in primären Mikrogliazellkulturen vom SOD1-wildyp und transgenen Tiere nach Behandlung mit LPS $(10 \mathrm{ng} / \mathrm{ml})$ und Fasudil. Die Zellen wurden mit LPS für 18 Stunden unter Gegenwart von Fasudil in verschiedenen Konzentrationen behandelt. TNF $\alpha$ (A), IL6 (B), CCL3 (C), CCL5 (D), CXCL1 (E) und CCL2 (F) ( $n=8)$ wurden im Überstand der Zellkulturen bestimmt. Die Niveaus der Zytokine und Chemokine sind dargestellt als Prozent der Werte der Zellen, die allein mit LPS (Fas0) stimuliert wurden. Fehlerindikatoren zeigen SEM. Signifikanzen beziehen sich auf die Fas $50 \mu \mathrm{M}$ Behandlungsgruppe im Vergleich zur Fas $0 \mu \mathrm{M}$ Gruppe für SOD1 WT (oben) und SOD1 TG Mikrogliazellen (unten). ${ }^{* * *} \mathrm{p}<0,001$. 


\section{Diskussion}

In der vorliegenden Arbeit wurde der Effekt des Rho-Kinase-Inhibitors Fasudil mit Fokus der mikroglialen Pathologie in dem SOD1-G93A-Mausmodell der ALS untersucht. Die In-vivoAnalyse konnte zeigen, dass durch eine Behandlung mit Fasudil eine gesteigerte Infiltration mikroglialer Zellen im Rückenmarksvorderhorn und eine Modulation der Zellmorphologie stattfindet. Ebenso stellten sich Mikrogliazellen in-vitro morphologisch verändert dar. Hier konnte in funktionellen Tests eine Suppression pro-inflammatorischer Zytokine und Chemokine durch Fasudil beobachtet werden.

\subsection{Proliferation mikroglialer Zellen unter Rock-Inhibition}

Um Rückschlüsse auf den Einfluss der ROCK-Inhibition auf die Mikrogliaproliferation ziehen zu können, führten wir eine Quantifizierung der mikroglialen Zellen des Rückenmarksvorderhorns unter Behandlung mit Fasudil $30 \mathrm{mg} / \mathrm{kg} \mathrm{KG}$ an d100, sowie 30 $\mathrm{mg} / \mathrm{kg}$ KG und $100 \mathrm{mg} / \mathrm{kg}$ KG zum Zeitpunkt Endstadium durch. In einer quantitativen Analyse des intermediären Zeitpunkts d100 zeigte sich in der SOD1-Wildtyp-Gruppe die geringste Anzahl an Iba1-positiven Zellen. Bei den Vehikel-behandelten SOD1-G93Atransgenen Tieren fand sich eine im Trend gesteigerte Anzahl an Mikrogliazellen. Mit einer Fasudilbehandlung der SOD1-G93A-transgenen Tiere stieg die Zellzahl im Vergleich zu Vehikel-behandelten Gruppe signifikant an. Die Quantifizierung der Mikrogliazellen zum Zeitpunkt Endstadium wies keinen signifikanten Einfluss einer ROCK-Inhibition auf. Allerdings zeigte sich im Endstadium der Erkrankung im Trend ein Anstieg der Mikrogliazellzahl des Rückenmarksvorderhorns im Vergleich zur intermediären Analyse. Die Zellzahlen waren dabei bei den mit Fasudil behandleten Tieren stets leicht höher als bei den Vehikelbehandelten Tieren.

Bei SOD1-G93A-Mäusen beginnen erste Zeichen der Schwäche und der Motoneuronenverlust um den 80. bis 90. Lebenstag. Dies ist begleitet von einer Mikrogliose (Fischer et al. 2004; Soto 2003). In der Vergangenheit wurde angenommen, dass sich eine Vermehrung von Mikrogliazellen immer negativ auf die Progression von Erkrankungen auswirkt. Jedoch kann allein durch den Anstieg der Mikrogliazellzahl nicht auf die Wirkweise der Zellen geschlossen werden, da sie sowohl neuroprotektives als auch neurotoxisches Potential besitzen (Henkel et al. 2009). Gowing et al. (2008) konnten beispielhaft zeigen, dass die Ablation von proliferierenden Mikrogliazellen die Progression im SOD1-G93AMausmodell nicht beeinflusst. Verschiedene therapeutische Studien mit neuroprotektivem Ergebnis zeigen in Bezug auf die Veränderung der Mikrogliazellzahl eine hohe Divergenz. Im SOD1-G93A-Mausmodell der ALS konnte gezeigt werden, dass Methylenblau durch 
Hemmung der mikroglial vermittelten Neuroinflammation den Krankheitsbeginn und die motorische Dysfunktion hinauszögert, ohne eine erkennbare Veränderung der Mikrogliazellzahl zu bewirken (Dibaj et al. 2012). Dem gegenüber postulieren andere Studien im SOD1-G93A-Mausmodell eine neuroprotektive Wirkung der Antibiotika Minozyklin und Ceftriaxon, die mit einer Veränderung der Mikrogliazellzahl einhergeht. So zeigten Keller et al. (2011), dass Minocyclin, ein Antibiotikum der Klasse der Tetrazykline, eine Mikrogliose auslöst. Andererseits zeigt sich unter der Therapie mit dem beta-Lactamase-Antibiotikum Ceftriaxon, dass auch in Studien zum Morbus Huntington, Apoplex und Multipler Sklerose eine positive Wirkung haben soll, eine Reduktion der Anzahl an Mikrogliazellen (Rothstein et al. 2005; Cudkowicz et al. 2014). Eine solche Reduktion der Mikrogliazellzahl ist auch bei therapeutischen Studien in Modellen anderer Erkrankungen zu beobachten. So konnte gezeigt werden, dass oben genanntes Minozyklin nach Verletzung des Rückenmarks neuroprotektiv wirkt und eine reaktive Mikrogliose vermindert (Festoff et al. 2006). Auch Inhibitoren der Rho-Kinase zeigen in verschiedensten Krannkheitsmodellen eine Wirkung auf die Anzahl von Mikrogliazellen. Zum Beispiel konnte eine Reduktion der reaktiven Mikrogliose durch eine neuroprotektive Behandlung von Retinazellen mit dem spezifischen Rho-Kinase-Inhibitor H-1152P erreicht werden (Tura et al. 2009; Alt et al. 2013).

Mikrogliale Proliferation wird hauptsächlich über Wachstumsfaktoren, im speziellen über den Makrophagen-Kolonie stimulierenden Faktor 1 (CSF1) vermittelt (Yamamoto et al. 2010). Dieser wird zum Beispiel nach Verletzung des Gehirns von Neuronen und später auch von Mikrogliazellen selbst exprimiert und führt zu einer Migration und Proliferation der Mikroglia (Takeuchi et al. 2001). CSF1 bindet über den CSF1 Rezeptor (CSF1R) an den Mikrogliazellen. Zusätzlich wurde kürzlich entdeckt, dass auch Interleukin 34 (IL34) an den CSF1R bindet und ähnliche Wirkung hat (Gómez-Nicola et al. 2013). Fasudil bewirkt als ROCK-Inhibitor eine Enthemmung der Aktivität von PIP3 (Phosphatidylinositol-3,4,5Trisphosphat), das den Signalweg von Wachstumsfaktoren wie CSF1 positiv beeinflusst und dadurch u.a. Zellproliferation begünstigend reguliert (Tönges et al. 2011). Durch diesen Mechanismus könnte die gesteigerte Proliferation der Mikrogliazellen unter Fasudilbehandlung zu erklären sein. Ebenso könnte die gesteigerte Proliferation durch die Involvierung von ROCK in den PTEN/Akt/mTOR Signalweg sowie den Auf- und Abbau des Zytoskeletts zu erklären sein. Zu Letzterem gehören die Hauptbestandteile Mikrotubuli, Intermediärfilamente und Mikrofliamente. Das collapsin response mediator protein-2 (CRMP-2) fördert die Anlagerung von Tubulinheterodimeren bei Mikrotubuli und spielt so eine wichtige Rolle in der neuronalen Polarität (Arimura et al. 2004). Es konnte gezeigt werden, dass CRMP-2, sowie andere mikrotubulusassoziierte Proteine wie MAP2 und Tau durch ROCK phosphoryliert und so die Polymerisation der Mikrotululi inhibiert wird (Arimura et al. 2005; Riento und Ridley 2003). ROCK nimmt somit negativen Einfluss auf Zellwachtum, Zellform und Beweglichkeit. Durch eine Inhibition mit Fasudil könnte dieser negative Einfluss gehemmt werden und eine gesteigerte Proliferation und Migration resultieren.

Mikroglia hat in fortgeschrittenen Stadien vornehmlich die Funktion des Aufspürens und Abräumens apoptotischer Zellen (Yang et al. 2011). Da zu diesem Zeitpunkt schon eine große 
Zahl an Zellen untergegangen ist kann eine allgemein erhöhte Proliferation der Mikrogliazellen nachvollzogen werden. In der Literatur wird beschrieben, dass Mikrogliazellen einem Alterungsprozess unterliegen. Mit höherem Lebensalter ändert sich die Fähigkeit der Zellen ihre normalen Funktionen, wie das Aufrechterhalten der neuronalen Umgebung, das Antworten auf Verletzung und Reparatur, auszuführen (Ojo et al. 2015; Brites und Vaz 2014). Die Zellen werden dysfunktional und zeigen eine verminderte Kapazität auf normale Reize zu reagieren. Davon sind auch die Migration und Proliferation betroffen (Streit 2006; Harry 2013). Durch diesen Prozess könnte der an d100 beobachtete proliferationsfördernde Effekt von Fasudil im Endstadium der Erkrankung gedämpft werden.

\subsection{Veränderungen des morphologischen Phänotyps}

Die Morphologie von Mikrogliazellen ist nach aktueller Meinung in der Literatur eng mit der Funktion der Zellen verknüpft und kann so Einblicke in die Zellfunktion geben (Beynon und Walker 2012). Um Rückschlüsse auf die Auswirkung einer Behandlung mit Fasudil auf Mikrogliazellen ziehen zu können wurden deshalb morphologische Analysen in Zellkultur und im Rückenmarksvorderhorn durchgeführt.

Die Mikrogliazellen in Zellkultur stellten sich in der SOD1-wildtyp Vehikel-behandelten Gruppe mit einer geringen Anzahl und Länge der Fortsätze dar. Die Zellen waren dabei von kleiner Größe und zeigten sich oft von rundlicher Erscheinung. Dieser Phänotyp entspricht auch der in der Literatur beschriebenen Erscheinung von gesunden Zellen ohne pathologischen Stimulus in-vitro (Persson et al. 2005). Durch eine Stimulation der Vehikelbehandelten wildtyp-Mikroglia mit LPS war sowohl ein signifikanter Anstieg der Anzahl als auch der Länge der Fortsätze zu beobachten. Die Zellen nahmen an Größe zu und zeigten selten eine rundliche Erscheinung. Veränderungen der mikroglialen Morphologie unter Stimulation mit LPS, wie wir sie beobachteten, sind in der Literatur gut beschrieben (Nakamura et al. 1999; abd-el-Basset und Fedoroff 1995). LPS ist ein Bestandteil der Zellwand gramnegativer Bakterien und sorgt über den CD14 Rezeptor und den Toll-like Rezeptor 4 (TLR 4) für eine klassische Aktivierung der Mikrogliazellen (Hanisch 2013). LPS gilt in der Literatur als Goldstandard zur Provokation eines zytotoxischen Phänotyps von Mikrogliazellen und wurde in vielen Studien genutzt (Hanisch und Kettenmann 2007). Neben der Aktivierung von Genen, die für die Synthese von Zytokinen und Chemokinen verantwortlich sind, werden auch andere Gene durch LPS beeinflusst. So findet durch die Stimulation eine gesteigerte Expression von Proteinen der Zellmembran und des Zytoskeletts wie Actin, Tubulin oder Vimentin statt. Es wird vermutet, dass dadurch die morphologischen Veränderungen der Mikrogliazellen unter LPS-Stimulation vermittelt werden (abd-el-Basset und Fedoroff 1995). Eine wiederholte LPS-Behandlung verschärft den mikroglial vermittelten Untergang von Motoneuronen in der ALS (Nguyen et al. 2004). Es konnte gezeigt werden, 
dass LPS und die dadurch ausgelöste TNF $\alpha$-Freisetzung die mikrogliale Expression des Glutamattransporters GLT1 und die mikrogliale Glutamataufnahme steigert. Ebenso steigt die Expression von CD68 und von NF-KB (nuclear factor kappa-light-chain-enhancer of activated B-cells), beides Marker für zytotoxische Mikrogliazellen (Kullberg et al. 2001; Zhang et al. 2013).

SOD1-G93A-transgene Vehikel-behandelte Mikroglia stellte sich ähnlich wie die wildtypZellen dar. Durch LPS-Stimulation nahmen diese Zellen an Größe zu und zeigten selten eine rundliche Erscheinung. Allerdings war, im Vergleich zu den SOD1-Wildtyp-Zellen mit LPSBehandlung, eine geringer ausgeprägte Steigerung der Anzahl und Länge ihrer Fortsätze zu beobachten. Diese geringere Reaktion auf die LPS-Stimulation könnte die Meinung unterstützten, dass SOD1-G93A-transgene Mikrogliazellen eine verminderte Kapazität als Sensor für Pathologien gegenüber Wildtyp-Mikroglia hat und größere Stimuli benötigt um physiologische Funktionen auszufüllen (Sargsyan et al. 2011).

Durch eine Behandlung der Mikrogliazellkulturen mit Fasudil in den Konzentrationen 2, 10 und $50 \mu \mathrm{M}$ zeigte sich bei den SOD1-wildtyp Vehikel-behandelten Gruppen kein morphologischer Effekt in Bezug auf die Anzahl der Fortsätze. Die Länge der Fortsätze und die Anzahl runder Zellen stiegen im Trend mit zunehmender Fasudilkonzentration an. Ein deutlicher Effekt von Fasudil zeigte sich bei SOD1-Wildtyp-Zellen unter Stimulation mit LPS. Hier war eine dosisabhängige Reduktion der Anzahl an Fortsätzen pro Mikrogliazelle zu erkennen. Auf die Länge der Fortsätze und die Anzahl runder Zellen scheint die Fasudilbehandlung unter LPS-Stimulation keinen Einfluss zu haben. Bei mSOD1-Zellen zeigte sich kein deutlicher Effekt von Fasudil.

Geht man davon aus, dass durch die LPS-Stimulation die eher toxische Mikrogliazelle entsteht, ist durch eine Stimulation unter Fasudilbehandlung nun eine Abweichung der Morphologie in Richtung des Normalzustandes, ohne LPS, zu beobachten. Das könnte bedeuten, dass Mikrogliazellen bei Fasudilbehandlung weniger aggressiv auf die Stimulation durch LPS reagieren und dadurch möglicherweise auch in ihrer Wirkweise weniger toxisch agieren. Fasudil scheint die oben beschriebenen, LPS induzierten Mechanismen der Änderung der Zellmorphologie dosisabhängig zu hemmen. Einen zugrunde liegenden Wirkmechanismus von Fasudil kennt man bisher nicht. Die Wirkung von ROCK-Inhibitoren auf die Mikrogliamorphologie wird in der Literatur kontrovers diskutiert. So postulierten beispielsweise Hoffman et. al (2008) einen pro-inflammatorischen Phänotyp, ähnlich dem durch LPS, induziert durch den Rho-Kinase-Inhibitor C3-Protein, hergestellt aus dem Clostridium botulinum-Bakterium. Die Autoren kommen so zu dem Schluss, dass Rhoabhängige Signalwege eine zentrale Rolle in der Aufrechterhaltung eines ruhenden Zustandes der Mikrogliazellen spielen. Andere Autoren beschreiben einen durch RhoInhibition ausgelösten ruhenden Phänotyp der Mikroglia (Cordle et al. 2005). Ebenso bleibt unklar, warum dieser Effekt von Fasudil bei SOD1-G93A-transgenen Zellen nicht zu beobachten ist. 
Entgegen den Beobachtungen in Zellkultur zeigen Mikrogliazellen im Rückenmark eine abweichende Morphologie. Hier ist ein Unterschied allein schon dadurch zu erwarten, da das Mikromilieu „in-situ“ deutlich verschieden ist. Prinzipiell wird Wachstum und Differenzierung im Rückenmark von mechanischen Reizen, Wachstumsfaktoren, sowie Zytokinen und Chemokinen beeinflusst. Es hat sich in der Literatur durchgesetzt die Mikrogliazellmorphologie in Gewebeschnitten in-vivo arbiträr in drei Aktivitätszustände einzuteilen. Zellen mit langen, dünn verzweigten Fortsätzen und schmalen Zellsomata werden mit dem ruhenden Zustand im gesunden ZNS assoziiert. Erkennen die Zellen eine Pathologie werden die Fortsätze dicker und kürzer und das Zellsoma erscheint prominenter. Die Zellen werden reaktive oder aktivierte Mikroglia genannt. Eine runde, amöboide Erscheinungsform, ohne Fortsätze, wird eher mit phagozytotisch aktiven Mikrogliazellen in Verbindung gebracht (Graeber 2010; Beynon und Walker 2012; Kettenmann et al. 2011).

Die Analyse in-vivo zeigte, dass Fasudil die Zellmorphologie gegenüber unbehandelten Tieren des SOD1-G93A-Mausmodells an Tag100 modifiziert. Unter Fasudilbehandlung in einer Dosis von $30 \mathrm{mg} / \mathrm{kg}$ KG waren signifikant weniger Zellen mit einer dünn ramifizierten Erscheinung und signifikant mehr Zellen mit einer dick ramifizierten Erscheinung zu beobachten. Wie schon bei der quantitativen Analyse im Rückenmarksvorderhorn ist dieser Effekt von Fasudil im Endstadium der Erkrankung nicht mehr zu beobachten. Aus morphologischer Sicht bewirkt Fasudil also zu diesem frühen Zeitpunkt der Krankheitsprogression eine gesteigerte Aktivierung der Mikrogliazellen.

Morphologische Veränderungen können einen Anhalt für funktionelle Änderungen der Zellen geben. So kann man zum Beispiel aus einer dünn ramifizierten Erscheinung auf eine überwachende Funktion im gesunden ZNS, oder aus einer amöboiden Form auf phagozytotisch aktive Zellen schließen. Jedoch sind aktivierte Mikrogliazellen rein morphologisch nicht einer schützenden oder toxischen wirkweise zuzuordnen (Kettenmann et al. 2011). In der aktuellen Literatur wird allerdings davon ausgegangen, dass an Tag100 vornehmlich mikrogliale Zellen zu finden sind, die durch das Abtragen von Zellmaterial und durch Sekretion von protektiven Faktoren schützende Wirkung auf ihre Umgebung haben (Hanisch und Kettenmann 2007). Fasudil scheint nun dafür zu sorgen, dass zunehmend reaktive Mikroglia dieses Typs vorliegen.

Die Rho-Kinase ist über eine Modulation des Zytoskeletts in Prozesse des zellulären Wachstums, der Zellform und Beweglichkeit eingebunden. ROCK hat dabei zum Beispiel durch den PTEN/Akt/mTOR-Signalweg negativen Einfluss auf den zellulären Metabolismus und das Zellwachstum. Ebenso hemmt ROCK durch eine Inaktivierung von Cofilin den Aufund Abbau von Aktinfilamenten. Diese Mechanismen erklären, warum ROCK einen Schlüsselmediator der axonalen Wachstumshemmung darstellt. Durch eine Fasudilbehandlung in unseren Experimenten könnte der Einfluss von ROCK auf Mikroglia ebenfalls gehemmt werden und dazu beitragen, dass sich die Fortsätze der Mikrogliazellen verdicken und ein Aspekt von reaktiven Zellen entsteht. 
Im Endstadium der Erkrankung scheint Fasudil keinen signifikant alterierenden Effekt auf die Zellmorphologie zu haben. Hier zeigt sich in allen Behandlungsgruppen der SOD1-G93AMäuse eine hohe Anzahl an aktivierten Mikrogliazellen mit der charakteristischen Zellmorphologie. In der Literatur werden Astrozyten-ähnliche Gliazellen mit abweichendem Phänotyp (AbA-Zellen) beschrieben, die nach dem Symptombeginn von SOD1-G93Atransgenen Mäusen benachbart zu Motoneuronen auftreten. Diese Zellen stellen eine Subpopulation von proliferierenden Mikrogliazellen dar und tragen durch ihre Toxizität maßgeblich zur Degeneration von Motoneuronen bei. Aba-Zellen exprimieren sowohl Marker von Astrozyten als auch von Mikrogliazellen und stellen sich morphologisch wie aktivierte Mikroglia dar. Es wird vermutet, dass sich die Zellen aktiv aus aktivierten Mikrogliazellen, induziert durch pro-inflammatorische Stimuli, entwickeln (Trias et al. 2013). Möglicherweise variiert mit dem Auftreten dieser Subpopulation das Ansprechen der Zellen

auf Fasudil. Ebenso könnte der schwindende Effekt von Fasudil auf Zellen im Endstadium durch das Altern der Zellen und die damit einhergehende verminderte Fähigkeit, auf Stimuli zu reagieren, erklärt werden. Alternde Mikrogliazellen können überempfänglich für Stress und Stimuli werden und eine Neuroinflammation ohne adäquaten Reiz herbeiführen. Es wird beschrieben, dass alternde Mikrogliazellen nicht nur eine höhere Expression proinflammatorischer Marker, sondern auch morphologisch Veränderungen zeigen. So sind vermehrt dickere Fortsätze und prominentere Zellsomata zu beobachten (Ojo et al. 2015; Brites und Vaz 2014). Dies lässt vermuten, dass die für reaktive Mikrogliazellen charakteristische Zellmorphologie im Endstadium durch den Alterungsprozess der Mikrogliazellen begünstigt wird. Eine weitere Erklärung für den morphologischen Zustand des größten Teils der Mikrogliazellen in allen Behandlungsgruppen der erkrankten Mäuse im Endstadium könnte auch eine der Hypothesen der Pathogenese der ALS sein. So konnte aktuell (Roberts et al. 2013) zeigen, dass SOD1-Aggregate, die für die Progression der ALS für wichtig gehalten werden, zu einer effizienten mikroglialen Aktivierung führen. Durch die steigende Menge anfallender Aggregate kommt es im Verlauf der ALS zu einer Zunahme der reaktiven Mikroglia.

\subsection{Modifikation inflammatorischer Mechanismen}

Die inflammatorische Immunantwort im ZNS wird durch die Freisetzung von Zytokinen und Chemokinen gesteuert. Mikrogliazellen spielen dabei eine zentrale Rolle, da sie die erste Linie der Verteidigung gegen Infektionen oder Verletzungen sind. Die mikrogliale Antwort ist vielschichtig und wird auch durch umgebende Astrozyten und T-Zellen beeinflusst. Mikrogliazellen können sowohl pro- als auch anti-inflammatorische Mediatoren freisetzen (Philips und Robberecht 2011). Zu den inflammatorisch fördernden Mediatoren gehören TNF $\alpha,\|\beta\| 6,,\|12\|$,23 , Stickstoffmonoxid und reaktive Sauerstoffradikale, sowie CCL2, CCL3, CCL5 und CXCL1. 
In der vorliegenden Arbeit wurden Zytokin- und Chemokinprofile aus primären Mikrogliazellkulturen von neugeborenen SOD1-G93A-transgenen und Wildtyp-Tieren angefertigt. Es konnte dabei, wie erwartet, durch eine Stimulation mit LPS, sowohl bei wildtyp als auch bei transgenen Zellen, eine Induktion der pro-inflammatorischen Mediatoren TNF $\alpha$, IL6, CCL-2, CCL3, CCL5 und CXCL1 erreicht werden. Die Induzierbarkeit der Freisetzung war dabei bei den SOD1-G93A-transgenen Zellen geringer im Vergleich zur Wildtyp-Zellkultur. Als Ausnahme zeigte sich in unseren Experimenten die Produktion von CXCL1, die bei SOD1-G93A-transgenen Zellen höher war als bei Wildtyp-Zellen. Bei simultaner Inkubation der Zellen mit LPS $(10 \mathrm{ng} / \mathrm{ml})$ und Fasudil in verschiedenen Konzentrationen zeigte sich für TNF $\alpha$, IL6, CCL3, CCL5 und CXCL1 bei beiden Genotypen eine dosisabhängige Reduktion. Diese war jeweils bei einer Behandlung mit $50 \mu \mathrm{M}$ Fasudil signifikant. Eine Ausnahme dieses Effekts stellt CCL2 dar, dessen Werte durch gesteigerte Dosen des Medikaments unter LPS-Stimulation sogar leicht anstiegen.

TNF $\alpha$ ist ein multifunktionales pro-inflammatorisches Zytokin, das zur TumornekrosefaktorFamilie gehört. TNF $\alpha$ induziert neben seiner eigenen Freisetzung auch die anderer proinflammatorischer Zytokine und kann zusätzlich Nekrose und Apoptose auslösen (Chu 2013). Eine Überexpression von TNFa im ZNS führt zu Neurodegeneration mit neuronaler Dysfunktion und neuronalem Absterben in Mäusen (Probert et al. 1995). Die Neurodegeneration beginnt nach Meinung vieler Autoren als eine Degeneration der Axone der Motoneurone (Fischer und Glass 2007). Dadurch werden die neuromuskulären Endplatten denerviert. Erst später kommt es zu einer Schädigung des Zellkörpers und zum Zellverlust (Fischer et al. 2004).

116 ist ein zentrales Zytokin bei der Initiierung und Aufrechterhaltung von inflammatorischen Prozessen. So führt es u.a. zu einer Stimulation von Akute-Phase-Proteinen, einer Differenzierung von B-Zellen, Immunglobulinproduktion sowie zur Rekrutierung von immunkompetenten Zellen. Zusätzlich ist es in die Entwicklung vieler Tumoren verwickelt. Es konnte gezeigt werden, dass eine erhöhte IL6 Expression zu einer unkontrollierten inflammatorischen Reaktion führt (Ataie-Kachoie et al. 2014). II12 und II23 sind wichtige Modulatoren der Immunreaktion während der Antigenpräsentation und beeinflussen die Wirkung von T-Zellen. Sie werden besonders als Antwort auf mikrobielle Pathogene exprimiert (Vignali DA und Kuchroo 2012).

Die Chemokine CCL2, CCL3 und CCL5 gehören zu der Familie der beta-Chemokine, CXCL1 zu der Familie der alpha-Chemokine. Sie wirken als Lockstoffe für immunkompetente Zellen zu der Stelle der Entzündung (Cheng und Chen 2014). CCL2 spielt eine wichtige Rolle in der immunologischen Antwort durch die Beeinflussung der Migration von T-Zellen in inflammatorische Gebiete (Huang et al. 2001). CCL5 ist ein Chemokin, das als starker Lockstoff für T-Lymphozyten und Monozyten wirkt (Rentzos et al. 2007). Es konnte gezeigt werden, dass bei inflammatorischen Erkrankungen wie der Multiplen Sklerose (MS), ein erhöhter Spiegel an Chemokinen im Liquor nachweisbar ist. Durch chemotaktische 
Gradienten werden so Immunzellen, die den Chemokinrezeptor tragen, angelockt und die Inflammation verstärkt (Bartosik-Psujek und Stelmasiak 2005).

Fasudil stellt sich in unseren Experimenten als starker Modulator der inflammatorischen Antwort von Mikrogliazellen dar. Der inhibitorische Effekt Fasudils auf die Expression von inflammatorischen Zytokinen und Chemokinen ist auch in der Literatur dokumentiert (Liu et al. 2013). Die genaue Wirkweise allerdings bleibt weiterhin nicht vollständig geklärt. Es wird davon ausgegangen, dass Fasudil eine Inhibierung der inflammatorischen Reaktion von Mikrogliazellen über PI3-Kinase/Akt und $\mathrm{Wnt} / \beta$-Catenin-abhängige Signalwege vermittelt (Zhao et al. 2015). Zusätzlich konnte in jüngeren Studien gezeigt werden, dass durch die Inhibition der Rho-Kinase die Aktivität von NF-KB gehemmt wird (Okamoto et al. 2010). NF$\mathrm{KB}$ ist ein Schlüssel Transkriptionsfaktor, der die Expression einer Vielzahl von proinflammatorischen Mediatoren fördert. Viele Stimuli können die Aktivität von NF-kB induzieren. Zum Beispiel TNFa, dessen pro-inflammatorische Wirkung wahrscheinlich dadurch vermittelt wird (Pozniak et al. 2014). Es konnte gezeigt werden, dass eine Inhibition des NF-kB-Signalweges durch Fasudil zu einer verminderten Expression von proinflammatorischen Mediatoren führt (Chan et al. 2009; Zhang et al. 2013).

Eine Ausnahme des Effekts von Fasudil stellt CCL2 dar, dessen Werte durch gesteigerte Dosen des Medikaments unter LPS-Stimulation sogar leicht anstiegen. CCL2 ist ein Chemokin, das wichtig für die Akkumulation von pro-inflammatorischen Monozyten ist, die in der ALS am Motoneuronenverlust beteiligt sind (Butovsky et al. 2012). Diese Zellen tragen den Rezeptor zu CCL2, CCR2, und spielen auch eine wichtige Rolle bei Infektionen oder Atherosklerose (King et al. 2009). Es konnte in-vivo gezeigt werden, dass diese CCR2positiven Monozyten bei Blut-Hirn-Schranken-Störungen aus dem Blut in das verletzte Gehirn migrieren können und sich dort zu Mikrogliazellen differenzieren (Mildner et al. 2007). Warum sich CCL2 abweichend zu den anderen getesteten Mediatoren auf eine Fasudilbehandlung verhält, ist nicht bekannt.

Wie in Kapitel 4.2 beschrieben sorgt LPS für eine gut dokumentierte, zytotoxische Aktivierung der Mikrogliazellen, die mit der Induktion von Mediatoren wie TNF $\alpha,\|\beta\| 6,, \| 12$, II23, Stickstoffmonoxid und reaktiven Sauerstoffradikalen einhergeht (Weydt et al. 2004). Die Induzierbarkeit der Freisetzung der von uns getesteten Zytokinen und Chemokinen durch LPS bei den SOD1-G93A-transgenen Zellen war in unserem Experiment geringer im Vergleich zur Wildtyp-Zellkultur. Dies könnte im Einklang mit der in dieser Arbeit beschriebenen geringeren morphologischen Reaktion der transgenen Zellen auf LPS-Stimulation stehen. Beide Ergebnisse deuten darauf hin, dass mSOD1-Mikroglia abweichend zu gesunder Mikroglia nur eingeschränkt auf Pathologien, die in unserem Experiment mit LPS kopiert wurden, reagieren kann. Die meisten Autoren postulieren hingegen, dass mSOD1-Mikroglia durch LPS Behandlung mit einer gesteigerten Ausschüttung pro-inflammatorischer Zytokine, im Unterschied zu Wildtyp-Mikroglia, reagiert und dadurch ein höheres neurotoxisches Potential besitzt (Liu et al. 2009; Dimayuga et al. 2007). Als Ausnahme zeigte sich in unseren Experimenten die Produktion von CXCL1, die bei SOD1-G93A-transgenen Zellen höher war, 
als bei Wildtyp-Zellen. CXCL1 ist bekannt als potenter Lockstoff und Aktivator von neutrophilen Granulozyten und spielt dabei eine besondere Rolle als Erkennungssignal bei der Entfernung apoptotischer Zellen (Kielian et al. 2001; Mehrad et al. 1999). Schädliche Zellen werden dann durch Phagozyten abgebaut (Fuchs und Steller 2011). Ein erhöhter Wert von CXCL1 in der mSOD1-G93A-Zellkultur könnte daher auf eine erhöhte Zahl an sterbenden und zu beseitigenden Mikrogliazellen hinweisen.

\subsection{Neuroprotektion und Therapiepotential von Fasudil bei ALS}

Durch die vorliegende Arbeit konnte die These vieler Autoren, dass Mikrogliazellen in der Pathogenese der ALS eine wichtige Rolle spielen, unterstützt werden. Außerdem konnte gezeigt werden, dass Fasudil ein starker Modulator der mikroglialen Morphologie und Funktion ist.

Unsere Ergebnisse zeigen zum einen im Trend eine Steigerung der Anzahl an Mikrogliazellen mit der Progression der ALS. Zum anderen konnte gezeigt werden, dass erkrankte Mikrogliazellen sowohl morphologisch als auch in ihrer Zytokin- und Chemokinfreisetzung abweichend zu gesunden Zellen reagieren. In den Versuchen mit dem ROCK-Inhibitor Fasudil konnte gezeigt werden, dass dieser eine modulatorische Wirkung auf Mikrogliazellen hat. So konnte unter der Behandlung in-vivo eine Zunahme der Zellzahl sowie morphologische Unterschiede im Vergleich zu unbehandelten Tieren festgestellt werden. In-vitro stellte sich Fasudil als starker Suppressor von pro-inflammatorischen Zytokinen und Chemokinen dar.

Die Erforschung der Wirkweise von Mikrogliazellen in neurodegenerativen Erkrankungen ist das Thema einer Vielzahl von Studien in der jüngeren Vergangenheit. Um diese zu entschlüsseln, wird meist anhand von Zytokin- und Chemokin-Profilen auf die Funktion der Zellen geschlossen (Lewis et al. 2012). Nach einhelliger Meinung können dabei zwei Wirktypen, M1- und M2-Mikroglia, unterschieden werden. M1-Mikroglia zeigt einen proinflammatorischen Phänotyp, der charakterisiert ist durch die Produktion von Zytokinen und Chemokinen wie Tumornekrosefaktor alpha (TNF $\alpha$ ), Interleukin 1 beta (II ), Interleukin 6 (II6), Interleukin 12 (II12), Interleukin 23 (II23), sowie erhöhte Mengen an Stickstoffmonoxid (NO) und reaktiven Sauerstoffradikalen. Außerdem werden Chemokine wie der CCChemokin-Ligand-2 (CCL2), der CC-Chemokin-Ligand-3 (CCL3), der CC-Chemokin-Ligand-5 (CCL5) und der Chemokin (C-X-C Motif)-Ligand 1 (CXCL1) freigesetzt (Appel et al. 2011). Es konnte gezeigt werden, dass die genannten Mediatoren allein oder in Kombination zu Schädigung von Neuronen und gesteigertem Zelltod führen (Jeohn et al. 1998). M2Mikrogliazellen setzten dagegen typischerweise Interleukin 10 (II10), Interleukin 4 (II4), Interleukin 13 (II13) und Transforming growth factor beta (TGF $\beta$ ) frei (Appel et al. 2011). I14 zum Beispiel ist ein immunmodulatorischer Mediator, der durch Suppression der Freisetzung von NO und von reaktiven Sauerstoffradikalen des Überleben von 
Motoneuronen fördert (Zhao et al. 2006b). Die Behandlung von kultivierten Mikrogliazellen mit IL4 resultiert in einem M2-Phänotyp der Zellen mit einer gesteigerten Ausschüttung von anti-inflammatorischen Mediatoren wie IL10 und einer Reduktion pro-inflammatorischer Mediatoren wie IL6, IL8, TNF $\alpha$ und CCL5 (Lewis et al. 2012; Ledeboer et al. 2000).

Es konnte gezeigt werden, dass die Wirkweise der Mikrogliazellen anhand des Stadiums der Erkrankung einzuschätzen ist (Henkel et al. 2009). Dabei wird angenommen, dass Mikrogliazellen in frühen Stadien neurodegenerativer Erkrankungen vornehmlich neuroprotektive Wirkung haben und erst im Verlauf schädlich werden (Gao und Hong 2008). Dieser Wechsel der Wirkweise passiert nach Ansicht der Autoren mit anhaltender Pathologie und führt dann zu einer unkontrollierten Inflammation, die die Progression der Erkrankung vorantreibt. Vor dem Hintergrund des lebensverlängernden Effekts von Fasudil in den Vorexperimenten könnte die beobachtete Zunahme der Mikrogliazahl unter Fasudilbehandlung an dem frühen Zeitpunkt d100 daher auf dessen positiven Effekt hindeuten.

Fasudil reduziert in unseren Experimenten signifikant die Freisetzung toxischer Zytokine und Chemokine, die durch die sich selbst stimulierende Inflammation in fortgeschrittenen Stadien der Erkrankung für den Wechsel der förderlichen M2- zu der toxischen M1-Mikroglia verantwortlich sind. Damit entsprechen die Ergebnisse der Meinung der aktuellen Literatur. So beschreibt zum Beispiel Liu et al. (2013) den Wechsel von M1- zu M2-Mikroglia, der mit einem Rückgang pro-inflammatorischer Zytokine vergesellschaftet war, durch intraperetoneale Behandlung mit Fasudil in der experimentellen autoimmunen Enzephalomyelitis (EAE). 


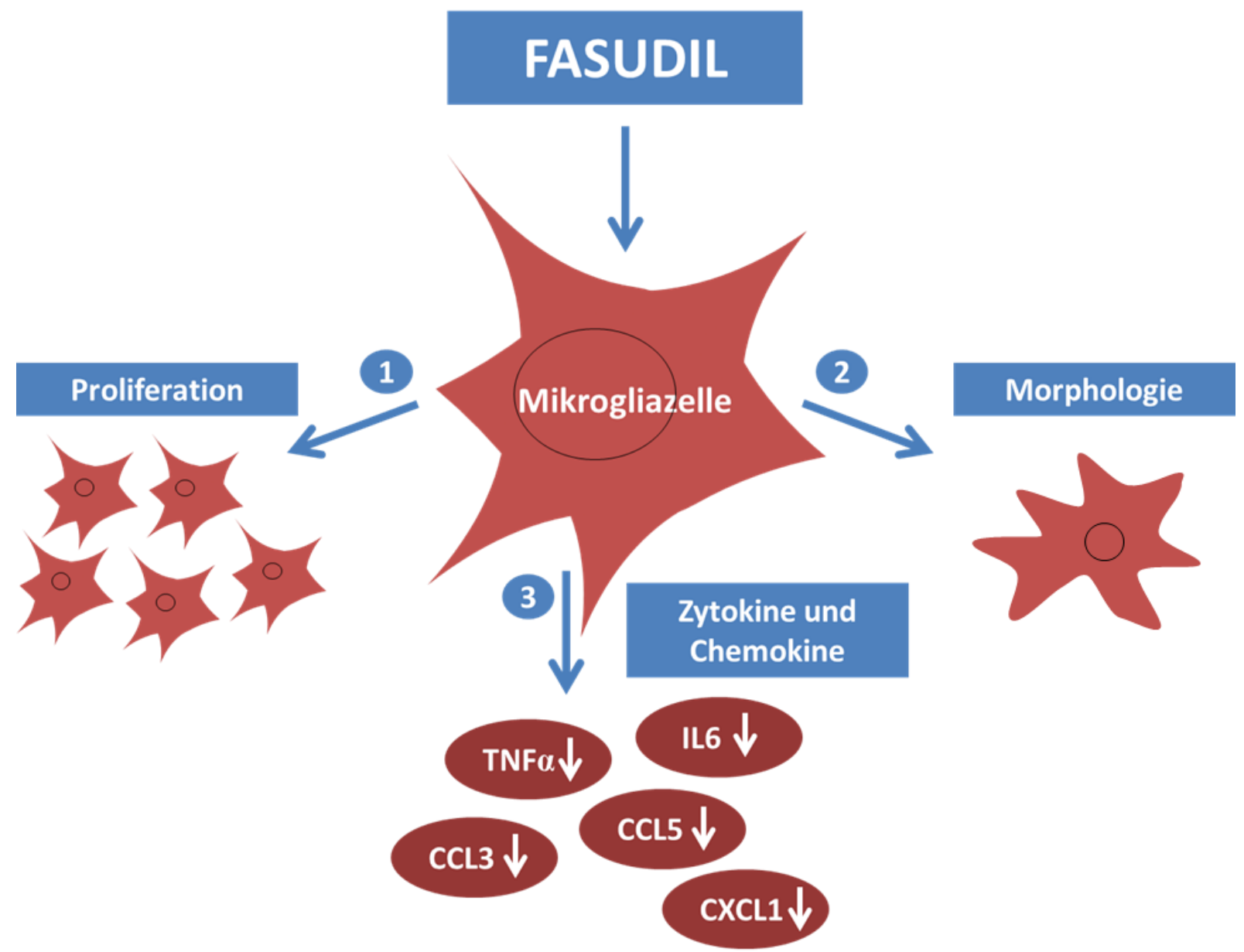

Abbildung 14: Wirkung von Fasudil auf SOD1-G93A-Mikrogliazellen. 1 Fasudil wirkt an d100 proliferationsfördernd. 2 Fasudil bewirkt an d100 eine Modulation der Morphologie zu einem dick ramifizierten Phänotyp, charakteristisch für reaktive Mikroglia. 3 Fasudil ist ein Suppressor proinflammatorischer Zytokine und Chemokine wie TNF $\alpha$, IL6, CCL3, CCL5, CXCL1.

Aufgrund vorheriger Erkenntnisse unserer Arbeitsgruppe und anderer sowie den Ergebnissen dieser Arbeit kann davon ausgegangen werden, dass Fasudil seine positiven Effekte im SOD1-G93A-Mausmodell, wie eine Steigerung des Überlebens der Tiere und des neuronalen Überlebens, der motorischen Funktion, der regenerativen Antwort im ZNS und des axonalen Wachstums, nicht nur über eine Wirkung auf Motoneurone, sondern auch auf Mikrogliazellen vermittelt (Tönges et al. 2014). Ebenso konnten in Modellen anderer neurodegenerativer Erkrankungen positive Effekte von Fasudil nachgewiesen werden. So konnte unter anderem unsere Arbeitsgruppe positive Effekte von Fasudil in Mausmodellen des Morbus Parkinson zeigen. Hier fördert Fasudil nicht nur das Überleben dopaminerger Neurone, sondern schützt auch die axonale Innervation (Tönges et al. 2012). In Mausmodellen der Multiplen Sklerose konnten Studien zeigen, dass Fasudil einen positiven Effekt durch die Reduktion der inflammatorischen Immunantwort auf die Erkrankung hat (Zhao et al. 2014). Für die ALS werden dringend neue Ansätze für wirkungsvolle Therapien benötigt, da das einzig zugelassene Medikament, Riluzol, das Leben der Patienten nur um 
wenige Monate verlängert (Lacomblez et al. 1996). Aufgrund der Vielzahl von Ätiologien und möglichen molekularen Mechanismen, die in der Pathogenese der ALS beteiligt sind, erfordern Therapieansätze wahrscheinlich verschiedene Strategien (Lingor et al. 2012). Fasudil hat dabei aufgrund vielversprechender Befunde das Potential, einen Teil der Therapie darzustellen. Eine gute Verträglichkeit wurde schon gezeigt, da es in Japan wegen seiner vasodilatativen Wirkung für zerebrale Vasospasmen genutzt wird. Dieser Effekt hatte dabei nur minimalen Effekt auf den Blutdruck der Patienten. Angesichts weiterer positiver Effekte auf das kardiovaskuläre System wird Fasudil gerade in vielen Studien getestet (Mueller et al. 2005). Zum heutigen Zeitpunkt ist Fasudil allein als intravenöse Injektion applizierbar und deshalb nur im stationären Rahmen zu nutzen. Ebenso würde die, wenn auch geringe, Auswirkung auf den Blutdruck eine Überwachung der Patienten nötig machen (Zhao et al. 2006a).

Man kann nicht ausschließen, dass Fasudil auch Auswirkungen auf andere Zelltypen wie zum Beispiel Oligodendrozyten oder bisher noch nicht entdeckte intrazelluläre Signalwege hat. Daher müssen in Zukunft weitere Studien folgen, die diese Gebiete weiter aufdecken. Schlussendlich müssen die Schlussfolgerungen, die vornehmlich aus der Forschung mit transgenen Mausmodellen stammen, in klinische Studien übertragen werden und zeigen, ob Fasudil als Medikament in der ALS einen Nutzen für die Patienten aufweist. In China läuft derzeit seit September 2013 eine klinische Phase-II-Studie, die die Wirkung und Sicherheit von Fasudil bei ALS-Patienten zeigen soll (ClinicalTrials.gov Identifier:NCT01935518) und deren Ergebnisse mit Spannung erwartet werden. Insgesamt stellt Fasudil eine potentielle zukünftige Ergänzung der Pharmakotherapie für neurodegenerative Erkrankungen wie der ALS dar.

\section{Zusammenfassung}

Die Amyotrophe Lateralsklerose ist eine unaufhaltsame neurodegenerative Erkrankung, die charakterisiert ist durch eine kombinierte Degeneration des ersten und zweiten Motoneurons und deren Axone, einhergehend mit konsekutivem Muskelschwund und körperlicher Schwäche. Sie ist die häufigste Motoneuron-Erkrankung des Erwachsenenalters und lässt sich in die familiäre und die sporadische ALS unterteilen. Bei beiden Formen spielen genetische Faktoren eine Rolle. Eines der Gene, das für die ALS verantwortlich gemacht wird, ist das SOD1-Gen, das für die Kupfer-Zink-Superoxiddismutase kodiert und auf dessen Mutation die meisten in der Forschung genutzten Mausmodelle basieren. Die Ursache für die neuronale Degeneration ist weiterhin nicht vollständig verstanden. Studien in der jüngeren Vergangenheit haben gezeigt, dass die Progression der ALS stark von den Neurone- umgebenden Zellen wie Mikrogliazellen und Astrozyten, beeinflusst wird. 
Mikrogliazellen spielen in der Progression der ALS eine entscheidende Rolle und wechseln im Verlauf von einem anti-inflammatorischen, eher neuroprotektiven Verhalten zu einem proinflammatorischen, neurotoxischen Phänotyp. Die einzige bisher zugelassene kausal orientierte Pharmakotherapie ist das Medikament Riluzol, das das Leben von ALS-Patienten jedoch nur um wenige Monate verlängern kann. Ein neuer therapeutischer Ansatz ist das Medikament Fasudil. In Vorarbeiten unserer Arbeitsgruppe konnte mit Fasudil als Inhibitor der Rho-Kinase gezeigt werden, dass eine Steigerung des Gesamtüberlebens und des neuronalen Überlebens, der motorischen Funktion, der regenerativen Antwort im ZNS und des axonalen Wachstums im SOD1-G93A-Mausmodell bewirkt wird. In der vorliegenden Arbeit untersuchten wir den Effekt von Fasudil auf Mikroglia im SOD1-G93A-Mausmodell. Methodisch wurden dazu Mikrogliazellen aus Gewebeschnitten von Rückenmärkern, sowie Mikrogliazellkulturen morphologisch analysiert. In-vitro wurden Zytokin- und Chemokinprofile aus Zellkulturen evaluiert.

Allgemein konnten morphologische und funktionelle Unterschiede von erkrankten im Vergleich zu gesunden Zellen festgestellt werden. Durch eine Behandlung mit Fasudil konnte eine gesteigerte Infiltration mikroglialer Zellen im Rückenmarksvorderhorn und eine Modulation der Zellmorphologie, zu einem für den reaktiven Zustand von Mikrogliazellen charakteristischen Phänotyp in-vivo beobachtet werden. Ebenso stellten sich Mikrogliazellen in-vitro unter Behandlung morphologisch verändert dar. Auffallend war hier besonders der dosisabhängig hemmende Effekt von Fasudil auf die Anzahl an Fortsätzen stimulierter Wildtyp-Mikroglia. In funktionellen Analysen zeigte Fasudil eine ausgeprägte immunmodulatorische Wirkung. Ein durch LPS-Stimulation erzeugter zytotoxischer Phänotyp wurde mit Fasudil mittels einer verminderten Expression von TNFa, I16, CCL3, CCL5 und CXCL1 abgemildert.

Die vorliegende Arbeit unterstützt die These, dass Mikrogliazellen eine entscheidende Rolle in der Progression der ALS zukommt und zeigt, dass Fasudil seinen neuroprotektiven Effekt nicht nur über die vorbeschriebene Wirkung auf Motoneurone, sondern auch über eine modulatorische Wirkung auf Mikrogliazellen vermittelt. Fasudil, das aufgrund seiner vasodilatativen Wirkung schon bei humanen Schlaganfallerkrankungen eingesetzt wird, sollte somit zukünftig auch in einer humanen Therapiestudie der ALS evaluiert werden. 


\section{Literaturverzeichnis}

abd-el-Basset E, Fedoroff S (1995): Effect of bacterial wall lipopolysaccharide (LPS) on morphology, motility, and cytoskeletal organization of microglia in cultures. J Neurosci Res $\underline{41}, 222-237$

Alexianu ME, Kozovska M, Appel SH (2001): Immune reactivity in a mouse model of familial ALS correlates with disease progression. Neurology $\underline{57}, 1282-1289$

Alt A, Hilgers R, Tura A, Nassar K, Schneider T, Hueber A, Januschowski K, Grisanti S, Lüke J, Lüke M (2013): The neuroprotective potential of Rho-kinase inhibition in promoting cell survival and reducing reactive gliosis in response to hypoxia in isolated bovine retina. Cell Physiol Biochem $\underline{32}, 218-234$

Appel SH, Zhao W, Beers DR, Henkel JS (2011): The microglial-motoneuron dialogue in ALS. Acta Myol $\underline{30}, 4-8$

Arimura N, Menager C, Fukata Y, Kaibuchi K (2004): Role of CRMP-2 in neuronal polarity. J Neurobiol 58, 34-47

Arimura N, Ménager C, Kawano Y, Yoshimura T, Kawabata S, Hattori A, Fukata Y, Amano M, Goshima $Y$, Inagaki M et al. (2005): Phosphorylation by Rho kinase regulates CRMP-2 activity in growth cones. Mol Cell Biol 25, 9973-9984

Ataie-Kachoie P, Pourgholami MH, Des Richardson R, Morris DL (2014): Gene of the month: Interleukin 6 (IL-6). J Clin Pathol 67, 932-937

Bartosik-Psujek H, Stelmasiak Z (2005): The levels of chemokines CXCL8, CCL2 and CCL5 in multiple sclerosis patients are linked to the activity of the disease. Eur J Neurol 12, 49-54

Beers DR, Henkel JS, Xiao Q, Zhao W, Wang J, Yen AA, Siklos L, McKercher SR, Appel SH (2006): Wildtype microglia extend survival in PU.1 knockout mice with familial amyotrophic lateral sclerosis. Proc Natl Acad Sci USA $\underline{103}, 16021-16026$

Bellingham MC (2011): A review of the neural mechanisms of action and clinical efficiency of riluzole in treating amyotrophic lateral sclerosis: what have we learned in the last decade? CNS Neurosci Ther $\underline{17}, 4-31$

Bensimon G, Lacomblez L, Meininger V (1994): A controlled trial of riluzole in amyotrophic lateral sclerosis. ALS/Riluzole Study Group. N. Engl. J. Med. 330, 585-591

Berlit P: Klinische Neurologie: Mit 382 Tabellen, 2. Auflage; Springer Medizin, Heidelberg 2006 Bermel C, Tönges L, Planchamp V, Gillardon F, Weishaupt JH, Dietz, Gunnar P H, Bähr M, Lingor P (2009): Combined inhibition of Cdk5 and ROCK additively increase cell survival, but not the regenerative response in regenerating retinal ganglion cells. Mol Cell Neurosci $\underline{42}$, 427-437

Beynon SB, Walker FR (2012): Microglial activation in the injured and healthy brain: what are we really talking about? Practical and theoretical issues associated with the measurement of changes in microglial morphology. Neuroscience $\underline{225}, 162-171$

Bogdanov M, Brown RH, Matson W, Smart R, Hayden D, O'Donnell H, Flint Beal M, Cudkowicz M (2000): Increased oxidative damage to DNA in ALS patients. Free Radic Biol Med 29, 652-658 
Boillée S, Yamanaka K, Lobsiger CS, Copeland NG, Jenkins NA, Kassiotis G, Kollias G, Cleveland DW (2006): Onset and progression in inherited ALS determined by motor neurons and microglia. Science $\underline{312}, 1389-1392$

Bowser R, Turner MR, Shefner J (2011): Biomarkers in amyotrophic lateral sclerosis: opportunities and limitations. Nat Rev Neurol $\underline{7}, 631-638$

Brandt R (2001): Cytoskeletal mechanisms of neuronal degeneration. Cell Tissue Res 305, 255-265

Brites D, Vaz AR (2014): Microglia centered pathogenesis in ALS: insights in cell interconnectivity. Front Cell Neurosci $\underline{8}, 117$

Brooks BR, Miller RG, Swash M, Munsat TL (2000): El Escorial revisited: revised criteria for the diagnosis of amyotrophic lateral sclerosis. Amyotroph Lateral Scler Other Motor Neuron Disord 1 , 293-299

Bruijn LI, Miller TM, Cleveland DW (2004): Unraveling the mechanisms involved in motor neuron degeneration in ALS. Annu Rev Neurosci 27, 723-749

Butovsky O, Siddiqui S, Gabriely G, Lanser AJ, Dake B, Murugaiyan G, Doykan CE, Wu PM, Gali RR, Iyer LK et al. (2012): Modulating inflammatory monocytes with a unique microRNA gene signature ameliorates murine ALS. J Clin Invest 122, 3063-3087

Chan G, Bivins-Smith ER, Smith MS, Yurochko AD (2009): NF-kappaB and phosphatidylinositol 3kinase activity mediates the HCMV-induced atypical M1/M2 polarization of monocytes. Virus Res $\underline{144}, 329-333$

Chancellor AM, Warlow CP (1992): Adult onset motor neuron disease: worldwide mortality, incidence and distribution since 1950. J Neurol Neurosurg Psychiatr $\underline{55}$, 1106-1115

Charcot JM, Joffroy A (1869): Deux cas d'atrophie musculaire progressive avec lésions de la substance grise et des faisceaux antérolatéraux de la moelle épinière. Arch Physiol Norm Path $\underline{354}$, 629-744

Cheah BC, Boland RA, Brodaty NE, Zoing MC, Jeffery SE, McKenzie DK, Kiernan MC (2009):

INSPIRATIonAL--INSPIRAtory muscle training in amyotrophic lateral sclerosis. Amyotroph Lateral Scler 10, 384-392

Chen S, Sayana P, Zhang X, Le W (2013): Genetics of amyotrophic lateral sclerosis: an update. Mol Neurodegener $\underline{8}, 28$

Cheng W, Chen G (2014): Chemokines and chemokine receptors in multiple sclerosis. Mediators Inflamm 2014, 659206

Chiò A (1999): ISIS Survey: an international study on the diagnostic process and its implications in amyotrophic lateral sclerosis. J Neurol 246 Suppl 3, III1-5

Chiò A, Benzi G, Dossena M, Mutani R, Mora G (2005): Severely increased risk of amyotrophic lateral sclerosis among Italian professional football players. Brain $\underline{128}, 472-476$

Chiò A, Logroscino G, Traynor BJ, Collins J, Simeone JC, Goldstein LA, White LA (2013): Global epidemiology of amyotrophic lateral sclerosis: a systematic review of the published literature. Neuroepidemiology $\underline{41}, 118-130$

Chiu AY, Zhai P, Dal Canto, Peters TM, Kwon YW, Prattis SM, Gurney ME (1995): Age-dependent penetrance of disease in a transgenic mouse model of familial amyotrophic lateral sclerosis. Mol Cell Neurosci $\underline{6}, 349-362$ 
Chu W (2013): Tumor necrosis factor. Cancer Lett $\underline{328}, 222-225$

Ciura S, Lattante S, Le Ber I, Latouche M, Tostivint H, Brice A, Kabashi E (2013): Loss of function of C9orf72 causes motor deficits in a zebrafish model of amyotrophic lateral sclerosis. Ann Neurol $\underline{74}$, 180-187

Clement AM, Nguyen MD, Roberts EA, Garcia ML, Boillée S, Rule M, McMahon AP, Doucette W, Siwek D, Ferrante RJ et al. (2003): Wild-type nonneuronal cells extend survival of SOD1 mutant motor neurons in ALS mice. Science 302, 113-117

Cleveland DW, Rothstein JD (2001): From Charcot to Lou Gehrig: deciphering selective motor neuron death in ALS. Nat. Rev. Neurosci. 2, 806-819

Cleveland DW, Bruijn LI, Wong PC, Marszalek JR, Vechio JD, Lee MK, Xu XS, Borchelt DR, Sisodia SS, Price DL (1996): Mechanisms of selective motor neuron death in transgenic mouse models of motor neuron disease. Neurology $\underline{47}$, S54-61; discussion S61-2

Coleman M (2005): Axon degeneration mechanisms: commonality amid diversity. Nat Rev Neurosci $\underline{6}, 889-898$

Colton CA (2009): Heterogeneity of microglial activation in the innate immune response in the brain. J Neuroimmune Pharmacol $\underline{4}$, 399-418

Cordle A, Koenigsknecht-Talboo J, Wilkinson B, Limpert A, Landreth G (2005): Mechanisms of statinmediated inhibition of small G-protein function. J Biol Chem 280, 34202-34209

Cudkowicz ME, McKenna-Yasek D, Sapp PE, Chin W, Geller B, Hayden DL, Schoenfeld DA, Hosler BA, Horvitz HR, Brown RH (1997): Epidemiology of mutations in superoxide dismutase in amyotrophic lateral sclerosis. Ann Neurol 41, 210-221

Cudkowicz ME, Titus S, Kearney M, Yu H, Sherman A, Schoenfeld D, Hayden D, Shui A, Brooks B, Conwit $R$ et al. (2014): Safety and efficacy of ceftriaxone for amyotrophic lateral sclerosis: a multistage, randomised, double-blind, placebo-controlled trial. Lancet Neurol $\underline{13}, 1083-1091$

Dal Canto MC, Gurney ME (1994): Development of central nervous system pathology in a murine transgenic model of human amyotrophic lateral sclerosis. Am J Pathol $\underline{145}, 1271-1279$

del Aguila MA, Longstreth WT, McGuire V, Koepsell TD, van Belle G (2003): Prognosis in amyotrophic lateral sclerosis: a population-based study. Neurology $\underline{60}, 813-819$

Dengler R, Petri S (2012): Changes in motor axon $\mathrm{K}(+)$ conductance in ALS. Primary or secondary to motor neuron degeneration? Clin Neurophysiol $\underline{123}, 2326-2327$

DGN (2015): Amyotrophe Lateralsklerose (Motoneuronerkrankungen) Leitlinie für Diagnostik und Therapie in der Neurologie. Hrsg.: Kommission Leitlinie der Deutschen Gesellschaft für Neurologie.

Díaz-Amarilla P, Olivera-Bravo S, Trias E, Cragnolini A, Martínez-Palma L, Cassina P, Beckman J, Barbeito L (2011): Phenotypically aberrant astrocytes that promote motoneuron damage in a model of inherited amyotrophic lateral sclerosis. Proc Natl Acad Sci U S A $\underline{108}, 18126-18131$

Dibaj P, Zschüntzsch J, Steffens H, Scheffel J, Göricke B, Weishaupt JH, Le Meur K, Kirchhoff F, Hanisch $U$, Schomburg ED et al. (2012): Influence of methylene blue on microglia-induced inflammation and motor neuron degeneration in the SOD1(G93A) model for ALS. PloS one $\underline{7}$, e43963 
Dimayuga FO, Wang C, Clark JM, Dimayuga ER, Dimayuga VM, Bruce-Keller AJ (2007): SOD1 overexpression alters ROS production and reduces neurotoxic inflammatory signaling in microglial cells. J Neuroimmunol 182, 89-99

Dion PA, Daoud H, Rouleau GA (2009): Genetics of motor neuron disorders: new insights into pathogenic mechanisms. Nat Rev Genet 10, 769-782

Douglass CP, Kandler RH, Shaw PJ, McDermott CJ (2010): An evaluation of neurophysiological criteria used in the diagnosis of motor neuron disease. J Neurol Neurosurg Psychiatry 81, 646-649 Feinberg DM, Preston DC, Shefner JM, Logigian EL (1999): Amplitude-dependent slowing of conduction in amyotrophic lateral sclerosis and polyneuropathy. Muscle Nerve 22, 937-940

Festoff BW, Ameenuddin S, Arnold PM, Wong A, Santacruz KS, Citron BA (2006): Minocycline neuroprotects, reduces microgliosis, and inhibits caspase protease expression early after spinal cord injury. J Neurochem 97, 1314-1326

Fischer LR, Glass JD (2007): Axonal degeneration in motor neuron disease. Neurodegener Dis $\underline{4}$, 431442

Fischer LR, Culver DG, Tennant P, Davis AA, Wang M, Castellano-Sanchez A, Khan J, Polak MA, Glass JD (2004): Amyotrophic lateral sclerosis is a distal axonopathy: evidence in mice and man. Exp Neurol $\underline{185}, 232-240$

Frank-Cannon TC, Alto LT, McAlpine FE, Tansey MG (2009): Does neuroinflammation fan the flame in neurodegenerative diseases? Mol Neurodegener $\underline{4}, 47$

Frey D, Schneider C, Xu L, Borg J, Spooren W, Caroni P (2000): Early and selective loss of neuromuscular synapse subtypes with low sprouting competence in motoneuron diseases. J Neurosci 20, 2534-2542

Fuchs Y, Steller H (2011): Programmed cell death in animal development and disease. Cell $\underline{147}, 742-$ 758

Gao H, Hong J (2008): Why neurodegenerative diseases are progressive: uncontrolled inflammation drives disease progression. Trends Immunol 29, 357-365

Garden GA, La Spada AR (2012): Intercellular (mis)communication in neurodegenerative disease. Neuron $\underline{73}, 886-901$

Gómez-Nicola D, Fransen NL, Suzzi S, Perry VH (2013): Regulation of microglial proliferation during chronic neurodegeneration. J Neurosci 33, 2481-2493

Goodall EF, Morrison KE (2006): Amyotrophic lateral sclerosis (motor neuron disease): proposed mechanisms and pathways to treatment. Expert Rev Mol Med $\underline{8}, 1-22$

Gordon S (2003): Alternative activation of macrophages. Nat Rev Immunol $\underline{3}$, 23-35

Gould TW, Buss RR, Vinsant S, Prevette D, Sun W, Knudson CM, Milligan CE, Oppenheim RW (2006): Complete dissociation of motor neuron death from motor dysfunction by Bax deletion in a mouse model of ALS. J Neurosci $\underline{26}, 8774-8786$

Gowing G, Philips T, van Wijmeersch B, Audet J, Dewil M, Van Den Bosch, Ludo, Billiau AD, Robberecht W, Julien J (2008): Ablation of proliferating microglia does not affect motor neuron degeneration in amyotrophic lateral sclerosis caused by mutant superoxide dismutase. J Neurosci $\underline{28}$, 10234-10244 
Graber DJ, Hickey WF, Harris BT (2010): Progressive changes in microglia and macrophages in spinal cord and peripheral nerve in the transgenic rat model of amyotrophic lateral sclerosis. $J$

Neuroinflammation $\underline{7}, 8$

Graeber MB (2010): Changing face of microglia. Science $\underline{330}$, 783-788

Günther R, Saal K, Suhr M, Scheer D, Koch JC, Bähr M, Lingor P, Tönges L (2014): The rho kinase inhibitor Y-27632 improves motor performance in male SOD1(G93A) mice. Front Neurosci $\underline{8}, 304$

Gurney ME, Pu H, Chiu AY, Dal Canto, Polchow CY, Alexander DD, Caliendo J, Hentati A, Kwon YW, Deng HX (1994): Motor neuron degeneration in mice that express a human $\mathrm{Cu}, \mathrm{Zn}$ superoxide dismutase mutation. Science 264, 1772-1775

Hall ED, Oostveen JA, Gurney ME (1998): Relationship of microglial and astrocytic activation to disease onset and progression in a transgenic model of familial ALS. Glia 23, 249-256

Hanisch U (2013): Curr Protein Pept Sci. Current protein \& peptide science 14, 3-15

Hanisch U, Kettenmann H (2007): Microglia: active sensor and versatile effector cells in the normal and pathologic brain. Nat Neurosci $\underline{10}, 1387-1394$

Hardiman O, van den Berg LH, Kiernan MC (2011): Clinical diagnosis and management of amyotrophic lateral sclerosis. Nat Rev Neurol $\underline{7}$, 639-649

Harry GJ (2013): Microglia during development and aging. Pharmacol Ther $\underline{139}$, 313-326

Henkel JS, Beers DR, Zhao W, Appel SH (2009): Microglia in ALS: the good, the bad, and the resting. J Neuroimmune Pharmacol $\underline{4}$, 389-398

Hirano A (1996): Neuropathology of ALS: an overview. Neurology 47, S63-6

Hoffmann A, Hofmann F, Just I, Lehnardt S, Hanisch U, Brück W, Kettenmann H, Ahnert-Hilger G, Höltje M (2008): Inhibition of Rho-dependent pathways by Clostridium botulinum C3 protein induces a proinflammatory profile in microglia. Glia $\underline{56}, 1162-1175$

Holloway SM, Emery AE (1982): The epidemiology of motor neuron disease in Scotland. Muscle Nerve $\underline{5}, 131-133$

Huang C, Zhou H, Tong J, Chen H, Liu Y, Wang D, Wei X, Xia X (2011): FUS transgenic rats develop the phenotypes of amyotrophic lateral sclerosis and frontotemporal lobar degeneration. PLoS Genet $\underline{Z}$, e1002011

Huang DR, Wang J, Kivisakk P, Rollins BJ, Ransohoff RM (2001): Absence of monocyte chemoattractant protein 1 in mice leads to decreased local macrophage recruitment and antigenspecific T helper cell type 1 immune response in experimental autoimmune encephalomyelitis. J Exp Med 193, 713-726

Hübers A, Weishaupt JH, Ludolph AC (2013): Genetik der amyotrophen Lateralsklerose. Nervenarzt 84, 1213-1219

Ikeda K, Iwasaki Y, Kinoshita M (1995): Amyotrophic lateral sclerosis associated with isolated adrenocorticotrophic hormone deficiency. Muscle Nerve $\underline{18}, 111-113$

Jeohn GH, Kong LY, Wilson B, Hudson P, Hong JS (1998): Synergistic neurotoxic effects of combined treatments with cytokines in murine primary mixed neuron/glia cultures. J Neuroimmunol $\underline{85}, 1-10$ 
Keller AF, Gravel M, Kriz J (2011): Treatment with minocycline after disease onset alters astrocyte reactivity and increases microgliosis in SOD1 mutant mice. Exp Neurol 228, 69-79

Kettenmann H, Hanisch U, Noda M, Verkhratsky A (2011): Physiology of microglia. Physiol Rev $\underline{91}$, 461-553

Kielian T, Barry B, Hickey WF (2001): CXC chemokine receptor-2 ligands are required for neutrophilmediated host defense in experimental brain abscesses. J Immunol (Baltimore, Md. 1950) 166, 46344643

Kierdorf K, Prinz M (2013): Factors regulating microglia activation. Front Cell Neurosci $\underline{7}, 44$

Kiernan MC, Vucic S, Cheah BC, Turner MR, Eisen A, Hardiman O, Burrell JR, Zoing MC (2011): Amyotrophic lateral sclerosis. Lancet $\underline{377}$, 942-955

King IL, Dickendesher TL, Segal BM (2009): Circulating Ly-6C+ myeloid precursors migrate to the CNS and play a pathogenic role during autoimmune demyelinating disease. Blood $\underline{113}, 3190-3197$

Kirby J, Ning K, Ferraiuolo L, Heath PR, Ismail A, Kuo S, Valori CF, Cox L, Sharrack B, Wharton SB et al. (2011): Phosphatase and tensin homologue/protein kinase $B$ pathway linked to motor neuron survival in human superoxide dismutase 1-related amyotrophic lateral sclerosis. Brain 134, 506-517

Körner S, Petri S, Dengler R, Kollewe K (2011): Amyotrophe Lateralsklerose. Nervenheilkunde, $\underline{30}$, Heft 10, 755-763

Krakora D, Macrander C, Suzuki M (2012): Neuromuscular junction protection for the potential treatment of amyotrophic lateral sclerosis. Neurol Res Int 2012, 379657

Kühnlein P, Gdynia H, Sperfeld A, Lindner-Pfleghar B, Ludolph AC, Prosiegel M, Riecker A (2008): Diagnosis and treatment of bulbar symptoms in amyotrophic lateral sclerosis. Nat Clin Pract Neurol $\underline{4}$, 366-374

Kullberg S, Aldskogius H, Ulfhake B (2001): Microglial activation, emergence of ED1-expressing cells and clusterin upregulation in the aging rat CNS, with special reference to the spinal cord. Brain Res $\underline{899}, 169-186$

Lacomblez L, Bensimon G, Leigh PN, Guillet P, Meininger V (1996): Dose-ranging study of riluzole in amyotrophic lateral sclerosis. Amyotrophic Lateral Sclerosis/Riluzole Study Group II. Lancet $\underline{347}$, $1425-1431$

Leal SS, Cardoso I, Valentine JS, Gomes CM (2013): Calcium ions promote superoxide dismutase 1 (SOD1) aggregation into non-fibrillar amyloid: a link to toxic effects of calcium overload in amyotrophic lateral sclerosis (ALS)? J. Biol. Chem. 288, 25219-25228

Ledeboer A, Brevé JJ, Poole S, Tilders FJ, Van Dam, A M (2000): Interleukin-10, interleukin-4, and transforming growth factor-beta differentially regulate lipopolysaccharide-induced production of pro-inflammatory cytokines and nitric oxide in co-cultures of rat astroglial and microglial cells. Glia 30, $134-142$

Lewis C, Manning J, Rossi F, Krieger C (2012): The Neuroinflammatory Response in ALS: The Roles of Microglia and T Cells. Neurol Res Int 2012, 803701

Li M, Huang Y, Ma, Aye Aye K, Lin E, Diamond MI (2009): Y-27632 improves rotarod performance and reduces huntingtin levels in R6/2 mice. Neurobiol Dis $\underline{36}, 413-420$ 
Li TM, Swash M, Alberman E, Day SJ (1991): Diagnosis of motor neuron disease by neurologists: a study in three countries. J Neurol Neurosurg Psychiatry $\underline{54}$, 980-983

Liao B, Zhao W, Beers DR, Henkel JS, Appel SH (2012): Transformation from a neuroprotective to a neurotoxic microglial phenotype in a mouse model of ALS. Exp Neurol 237, 147-152

Lingor P, Teusch N, Schwarz K, Mueller R, Mack H, Bähr M, Mueller BK (2007): Inhibition of Rho kinase (ROCK) increases neurite outgrowth on chondroitin sulphate proteoglycan in vitro and axonal regeneration in the adult optic nerve in vivo. J Neurochem 103, 181-189

Lingor P, Tönges L, Pieper N, Bermel C, Barski E, Planchamp V, Bähr M (2008): ROCK inhibition and CNTF interact on intrinsic signalling pathways and differentially regulate survival and regeneration in retinal ganglion cells. Brain $\underline{131}$, 250-263

Liu C, Li Y, Yu J, Feng L, Hou S, Liu Y, Guo M, Xie Y, Meng J, Zhang H et al. (2013): Targeting the shift from $M 1$ to $M 2$ macrophages in experimental autoimmune encephalomyelitis mice treated with fasudil. PloS one $\underline{8}$, e54841

Liu Y, Hao W, Dawson A, Liu S, Fassbender K (2009): Expression of amyotrophic lateral sclerosislinked SOD1 mutant increases the neurotoxic potential of microglia via TLR2. J Biol Chem 284, 36913699

Lomen-Hoerth C, Murphy J, Langmore S, Kramer JH, Olney RK, Miller B (2003): Are amyotrophic lateral sclerosis patients cognitively normal? Neurology 60, 1094-1097

Ludolph AC, Bendotti C, Blaugrund E, Chio A, Greensmith L, Loeffler J, Mead R, Niessen HG, Petri S, Pradat $P$ et al. (2010): Guidelines for preclinical animal research in ALS/MND: A consensus meeting. Amyotroph Lateral Scler $\underline{11}, 38-45$

Lulé D, Häcker S, Ludolph A, Birbaumer N, Kübler A (2008): Depression and quality of life in patients with amyotrophic lateral sclerosis. Dtsch Arztebl Int 105, 397-403

Mackenzie IR, Rademakers R, Neumann M (2010): TDP-43 and FUS in amyotrophic lateral sclerosis and frontotemporal dementia. Lancet Neurol $\underline{9}, 995-1007$

Martin D, Thompson MA, Nadler JV (1993): The neuroprotective agent riluzole inhibits release of glutamate and aspartate from slices of hippocampal area CA1. Eur J Pharmacol 250, 473-476

McGoldrick P, Joyce PI, Fisher, Elizabeth M C, Greensmith L (2013): Rodent models of amyotrophic lateral sclerosis. Biochim Biophys Acta 1832, 1421-1436

Mehrad B, Strieter RM, Moore TA, Tsai WC, Lira SA, Standiford TJ (1999): CXC chemokine receptor-2 ligands are necessary components of neutrophil-mediated host defense in invasive pulmonary aspergillosis. J Immunol (Baltimore, Md. 1950) 163, 6086-6094

Menzies FM, Ince PG, Shaw PJ (2002): Mitochondrial involvement in amyotrophic lateral sclerosis. Neurochem. Int. $40,543-551$

Milanese M, Zappettini S, Onofri F, Musazzi L, Tardito D, Bonifacino T, Messa M, Racagni G, Usai C, Benfenati $\mathrm{F}$ et al. (2011): Abnormal exocytotic release of glutamate in a mouse model of amyotrophic lateral sclerosis. J. Neurochem. $\underline{116}, 1028-1042$

Mildner A, Schmidt H, Nitsche M, Merkler D, Hanisch U, Mack M, Heikenwalder M, Brück W, Priller J, Prinz M (2007): Microglia in the adult brain arise from Ly-6ChiCCR2+ monocytes only under defined host conditions. Nat Neurosci $\underline{10}, 1544-1553$ 
Mitchell JD, Borasio GD (2007): Amyotrophic lateral sclerosis. Lancet $\underline{369}$, 2031-2041

Moloney EB, Winter F de, Verhaagen J (2014): ALS as a distal axonopathy: molecular mechanisms affecting neuromuscular junction stability in the presymptomatic stages of the disease. Front Neurosci $\underline{8}, 252$

Mueller BK, Mack H, Teusch N (2005): Rho kinase, a promising drug target for neurological disorders. Nat Rev Drug Discov 4 , 387-398

Nakamura Y, Si QS, Kataoka K (1999): Lipopolysaccharide-induced microglial activation in culture: temporal profiles of morphological change and release of cytokines and nitric oxide. Neurosci Res $\underline{35}$, 95-100

Nayak D, Roth TL, McGavern DB (2014): Microglia development and function. Annu Rev Immunol $\underline{32}$, 367-402

Nguyen MD, D'Aigle T, Gowing G, Julien J, Rivest S (2004): Exacerbation of motor neuron disease by chronic stimulation of innate immunity in a mouse model of amyotrophic lateral sclerosis. J Neurosci $\underline{24}, 1340-1349$

Niederöst B, Oertle T, Fritsche J, McKinney RA, Bandtlow CE (2002): Nogo-A and myelin-associated glycoprotein mediate neurite growth inhibition by antagonistic regulation of RhoA and Rac1. J Neurosci 22, 10368-10376

Nimmerjahn A, Kirchhoff F, Helmchen F (2005): Resting microglial cells are highly dynamic surveillants of brain parenchyma in vivo. Science $\underline{308}, 1314-1318$

Ojo JO, Rezaie P, Gabbott PL, Stewart MG (2015): Impact of age-related neuroglial cell responses on hippocampal deterioration. Front Aging Neurosci $\underline{Z}, 57$

Okamoto H, Yoshio T, Kaneko H, Yamanaka H (2010): Inhibition of NF-kappaB signaling by fasudil as a potential therapeutic strategy for rheumatoid arthritis. Arthritis Rheum $\underline{62}, 82-92$

Okamoto K, Mizuno Y, Fujita Y (2008): Bunina bodies in amyotrophic lateral sclerosis. Neuropathology $\underline{28}, 109-115$

Olney NT, Goodkind MS, Lomen-Hoerth C, Whalen PK, Williamson CA, Holley DE, Verstaen A, Brown LM, Miller BL, Kornak J et al. (2011): Behaviour, physiology and experience of pathological laughing and crying in amyotrophic lateral sclerosis. Brain 134, 3458-3469

Orrell RW (2007): Understanding the causes of amyotrophic lateral sclerosis. N Engl J Med $\underline{357}, 822-$ 823

Pamphlett R, Cheong PL, Trent RJ, Yu B (2013): Can ALS-associated C9orf72 repeat expansions be diagnosed on a blood DNA test alone? PLoS One $\underline{8}$, e70007

Parone PA, Da Cruz S, Han JS, McAlonis-Downes M, Vetto AP, Lee SK, Tseng E, Cleveland DW (2013):

Enhancing mitochondrial calcium buffering capacity reduces aggregation of misfolded SOD1 and motor neuron cell death without extending survival in mouse models of inherited amyotrophic lateral sclerosis. J Neurosci $\underline{33}, 4657-4671$

Pasinelli P, Brown RH (2006): Molecular biology of amyotrophic lateral sclerosis: insights from genetics. Nat Rev Neurosci $\underline{7}, 710-723$ 
Persson M, Brantefjord M, Hansson E, Rönnbäck L (2005): Lipopolysaccharide increases microglial GLT-1 expression and glutamate uptake capacity in vitro by a mechanism dependent on TNF-alpha. Glia $\underline{51}, 111-120$

Philips T, Robberecht W (2011): Neuroinflammation in amyotrophic lateral sclerosis: role of glial activation in motor neuron disease. Lancet Neurol 10, 253-263

Pozniak PD, White MK, Khalili K (2014): TNF- $\alpha$ /NF-KB signaling in the CNS: possible connection to EPHB2. J Neuroimmune Pharmacol $\underline{9}, 133-141$

Probert L, Akassoglou K, Pasparakis M, Kontogeorgos G, Kollias G (1995): Spontaneous inflammatory demyelinating disease in transgenic mice showing central nervous system-specific expression of tumor necrosis factor alpha. Proc Natl Acad Sci U S A $\underline{92}, 11294-11298$

Puls I, Jonnakuty C, LaMonte BH, Holzbaur, Erika L F, Tokito M, Mann E, Floeter MK, Bidus K, Drayna D, Oh SJ et al. (2003): Mutant dynactin in motor neuron disease. Nat Genet 33, 455-456

Regen T, van Rossum D, Scheffel J, Kastriti M, Revelo NH, Prinz M, Brück W, Hanisch U (2011): CD14 and TRIF govern distinct responsiveness and responses in mouse microglial TLR4 challenges by structural variants of LPS. Brain Behav Immun 25, 957-970

Renton AE, Chiò A, Traynor BJ (2014): State of play in amyotrophic lateral sclerosis genetics. Nat. Neurosci. 17, 17-23

Rentzos M, Nikolaou C, Rombos A, Boufidou F, Zoga M, Dimitrakopoulos A, Tsoutsou A, Vassilopoulos $D$ (2007): RANTES levels are elevated in serum and cerebrospinal fluid in patients with amyotrophic lateral sclerosis. Amyotroph Lateral Scler $\underline{8}, 283-287$

Riento K, Ridley AJ (2003): Rocks: multifunctional kinases in cell behaviour. Nat Rev Mol Cell Biol 4 , 446-456

Robelin L, Gonzalez De Aguilar JL (2014): Blood biomarkers for amyotrophic lateral sclerosis: myth or reality? Biomed Res Int 2014, 525097

Roberts K, Zeineddine R, Corcoran L, Li W, Campbell IL, Yerbury JJ (2013): Extracellular aggregated $\mathrm{Cu} / \mathrm{Zn}$ superoxide dismutase activates microglia to give a cytotoxic phenotype. Glia $\underline{61}, 409-419$

Rosen DR, Siddique T, Patterson D, Figlewicz DA, Sapp P, Hentati A, Donaldson D, Goto J, O'Regan JP, Deng HX (1993): Mutations in Cu/Zn superoxide dismutase gene are associated with familial amyotrophic lateral sclerosis. Nature $\underline{362}, 59-62$

Ross MA, Miller RG, Berchert L, Parry G, Barohn RJ, Armon C, Bryan WW, Petajan J, Stromatt S, Goodpasture J et al. (1998): Toward earlier diagnosis of amyotrophic lateral sclerosis: revised criteria. rhCNTF ALS Study Group. Neurology 50, 768-772

Rothstein JD (2009): Current hypotheses for the underlying biology of amyotrophic lateral sclerosis. Ann. Neurol. 65 Suppl 1, 3-9

Rothstein JD, Patel S, Regan MR, Haenggeli C, Huang YH, Bergles DE, Jin L, Dykes Hoberg M, Vidensky $S$, Chung DS et al. (2005): Beta-lactam antibiotics offer neuroprotection by increasing glutamate transporter expression. Nature $\underline{433}, 73-77$

Rowland LP, Shneider NA (2001): Amyotrophic lateral sclerosis. N Engl J Med $\underline{344}, 1688-1700$

Saccon RA, Bunton-Stasyshyn RKA, Fisher EMC, Fratta P (2013): Is SOD1 loss of function involved in amyotrophic lateral sclerosis? Brain 136, 2342-2358 
Sargsyan SA, Blackburn DJ, Barber SC, Grosskreutz J, De Vos, Kurt J, Monk PN, Shaw PJ (2011): A comparison of in vitro properties of resting SOD1 transgenic microglia reveals evidence of reduced neuroprotective function. BMC Neurosci 12, 91

Sephton CF, Cenik B, Cenik BK, Herz J, Yu G (2012): TDP-43 in central nervous system development and function: clues to TDP-43-associated neurodegeneration. Biol Chem $\underline{393}, 589-594$

Shi P, Ström A, Gal J, Zhu H (2010a): Effects of ALS-related SOD1 mutants on dynein- and KIF5mediated retrograde and anterograde axonal transport. Biochim Biophys Acta 1802, 707-716 Shi P, Wei Y, Zhang J, Gal J, Zhu H (2010b): Mitochondrial dysfunction is a converging point of multiple pathological pathways in amyotrophic lateral sclerosis. J Alzheimers Dis 20 Suppl 2, S311-24

Shimokawa $\mathrm{H}$ (2002): Rho-kinase as a novel therapeutic target in treatment of cardiovascular diseases. J Cardiovasc Pharmacol $\underline{39}$, 319-327

Shimokawa H, Seto M, Katsumata N, Amano M, Kozai T, Yamawaki T, Kuwata K, Kandabashi T, Egashira K, Ikegaki I et al. (1999): Rho-kinase-mediated pathway induces enhanced myosin light chain phosphorylations in a swine model of coronary artery spasm. Cardiovasc Res $\underline{43}, 1029-1039$

Simpson EP, Yen AA, Appel SH (2003): Oxidative Stress: a common denominator in the pathogenesis of amyotrophic lateral sclerosis. Curr Opin Rheumatol $\underline{15}, 730-736$

Soto $C$ (2003): Unfolding the role of protein misfolding in neurodegenerative diseases. Nature reviews. Neuroscience $\underline{4}, 49-60$

Stepto A, Gallo J, Shaw CE, Hirth F (2014): Modelling C9ORF72 hexanucleotide repeat expansion in amyotrophic lateral sclerosis and frontotemporal dementia. Acta Neuropathol 127, 377-389

Streit WJ (2006): Microglial senescence: does the brain's immune system have an expiration date? Trends Neurosci $\underline{29}, 506-510$

Sun X, Minohara M, Kikuchi H, Ishizu T, Tanaka M, Piao H, Osoegawa M, Ohyagi Y, Shimokawa H, Kira $J$ (2006): The selective Rho-kinase inhibitor Fasudil is protective and therapeutic in experimental autoimmune encephalomyelitis. J Neuroimmunol $\underline{180}, 126-134$

Takata M, Tanaka H, Kimura M, Nagahara Y, Tanaka K, Kawasaki K, Seto M, Tsuruma K, Shimazawa M, Hara H (2013): Fasudil, a rho kinase inhibitor, limits motor neuron loss in experimental models of amyotrophic lateral sclerosis. Br J Pharmacol 170, 341-351

Takeuchi A, Miyaishi O, Kiuchi K, Isobe K (2001): Macrophage colony-stimulating factor is expressed in neuron and microglia after focal brain injury. J Neurosci Res $\underline{65}, 38-44$

Tandan R, Bradley WG (1985): Amyotrophic lateral sclerosis: Part 1. Clinical features, pathology, and ethical issues in management. Ann Neurol 18, 271-280

Tharaux P, Bukoski RC, Rocha PN, Crowley SD, Ruiz P, Nataraj C, Howell DN, Kaibuchi K, Spurney RF, Coffman TM (2003): Rho kinase promotes alloimmune responses by regulating the proliferation and structure of T cells. J Immunol (Baltimore, Md. 1950) 171, 96-105

Tönges L, Koch J, Bähr M, Lingor P (2011): ROCKing Regeneration: Rho Kinase Inhibition as Molecular Target for Neurorestoration. Front Mol Neurosci 4 , 39

Tönges L, Frank T, Tatenhorst L, Saal KA, Koch JC, Szego ÉM, Bähr M, Weishaupt JH, Lingor P (2012): Inhibition of rho kinase enhances survival of dopaminergic neurons and attenuates axonal loss in a mouse model of Parkinson's disease. Brain $\underline{135}, 3355-3370$ 
Tönges L, Günther R, Suhr M, Jansen J, Balck A, Saal K, Barski E, Nientied T, Götz AA, Koch J et al. (2014): Rho kinase inhibition modulates microglia activation and improves survival in a model of amyotrophic lateral sclerosis. Glia $\underline{62}, 217-232$

Traynor BJ, Alexander M, Corr B, Frost E, Hardiman O (2003): Effect of a multidisciplinary amyotrophic lateral sclerosis (ALS) clinic on ALS survival: a population based study, 1996-2000. J Neurol Neurosurg Psychiatr $\underline{74}$, 1258-1261

Trepel M: Neuroanatomie: Struktur und Funktion, 5. Auflage; Elsevier Urban \& Fischer, München 2012

Trias E, Díaz-Amarilla P, Olivera-Bravo S, Isasi E, Drechsel DA, Lopez N, Bradford CS, Ireton KE, Beckman JS, Barbeito L (2013): Phenotypic transition of microglia into astrocyte-like cells associated with disease onset in a model of inherited ALS. Front Cell Neurosci $\underline{7}, 274$

Tura A, Schuettauf F, Monnier PP, Bartz-Schmidt KU, Henke-Fahle S (2009): Efficacy of Rho-kinase inhibition in promoting cell survival and reducing reactive gliosis in the rodent retina. Invest Ophthalmol Vis Sci $\underline{50}, 452-461$

Turner BJ, Talbot K (2008): Transgenics, toxicity and therapeutics in rodent models of mutant SOD1mediated familial ALS. Prog Neurobiol 85 , 94-134

Turner MR, Hardiman O, Benatar M, Brooks BR, Chio A, Carvalho M de, Ince PG, Lin C, Miller RG, Mitsumoto $\mathrm{H}$ et al. (2013): Controversies and priorities in amyotrophic lateral sclerosis. Lancet Neurol $\underline{12}, 310-322$

Uenal H, Rosenbohm A, Kufeldt J, Weydt P, Goder K, Ludolph A, Rothenbacher D, Nagel G (2014): Incidence and geographical variation of amyotrophic lateral sclerosis (ALS) in Southern Germany-completeness of the ALS registry Swabia. PLoS One $\underline{9}$, e93932

van Damme P, Robberecht W (2013): Clinical implications of recent breakthroughs in amyotrophic lateral sclerosis. Curr Opin Neurol 26, 466-472

Van den Berg, Leonard H (2014): Therapy of amyotrophic lateral sclerosis remains a challenge. Lancet Neurol $\underline{13}, 1062-1063$

Vignali DA, Kuchroo VK (2012): IL-12 family cytokines: immunological playmakers. Nat Immunol $\underline{13}$, $722-728$

Vinsant S, Mansfield C, Jimenez-Moreno R, Del Gaizo Moore, Victoria, Yoshikawa M, Hampton TG, Prevette D, Caress J, Oppenheim RW, Milligan C (2013): Characterization of early pathogenesis in the SOD1(G93A) mouse model of ALS: part I, background and methods. Brain Behav $\underline{3}$, 335-350

Wang I, Wu L, Chang H, Shen CJ (2008): TDP-43, the signature protein of FTLD-U, is a neuronal activity-responsive factor. J Neurochem $\underline{105}, 797-806$

Wang Y, Martin-McNulty B, da Cunha V, Vincelette J, Lu X, Feng Q, Halks-Miller M, Mahmoudi M, Schroeder M, Subramanyam B et al. (2005): Fasudil, a Rho-kinase inhibitor, attenuates angiotensin IIinduced abdominal aortic aneurysm in apolipoprotein E-deficient mice by inhibiting apoptosis and proteolysis. Circulation 111, 2219-2226

Weydt P, Hong SY, Kliot M, Möller T (2003): Assessing disease onset and progression in the SOD1 mouse model of ALS. Neuroreport 14, 1051-1054 
Wijesekera LC, Mathers S, Talman P, Galtrey C, Parkinson MH, Ganesalingam J, Willey E, Ampong MA, Ellis CM, Shaw CE et al. (2009): Natural history and clinical features of the flail arm and flail leg ALS variants. Neurology $\underline{72}, 1087-1094$

Wu AS, Kiaei M, Aguirre N, Crow JP, Calingasan NY, Browne SE, Beal MF (2003): Iron porphyrin treatment extends survival in a transgenic animal model of amyotrophic lateral sclerosis. J Neurochem $\underline{85}, 142-150$

Yamamoto S, Nakajima K, Kohsaka S (2010): Macrophage-colony stimulating factor as an inducer of microglial proliferation in axotomized rat facial nucleus. J Neurochem 115, 1057-1067

Yang N, Higuchi O, Ohashi K, Nagata K, Wada A, Kangawa K, Nishida E, Mizuno K (1998): Cofilin phosphorylation by LIM-kinase 1 and its role in Rac-mediated actin reorganization. Nature $\underline{393}$, 809812

Yang WW, Sidman RL, Taksir TV, Treleaven CM, Fidler JA, Cheng SH, Dodge JC, Shihabuddin LS (2011): Relationship between neuropathology and disease progression in the SOD1(G93A) ALS mouse. Exp Neurol 227, 287-295

Zhang H, Li Y, Yu J, Guo M, Meng J, Liu C, Xie Y, Feng L, Xiao B, Ma C (2013): Rho kinase inhibitor fasudil regulates microglia polarization and function. Neuroimmunomodulation 20, 313-322

Zhao J, Zhou D, Guo J, Ren Z, Zhou L, Wang S, Xu B, Wang R (2006a): Effect of fasudil hydrochloride, a protein kinase inhibitor, on cerebral vasospasm and delayed cerebral ischemic symptoms after aneurysmal subarachnoid hemorrhage. Neurol Med Chir $\underline{46}, 421-428$

Zhao W, Xie W, Xiao Q, Beers DR, Appel SH (2006b): Protective effects of an anti-inflammatory cytokine, interleukin-4, on motoneuron toxicity induced by activated microglia. J Neurochem $\underline{99}$, 1176-1187

Zhao Y, Zhang X, Ding Z, Yang X, Zhang H, Yu J, Li Y, Liu C, Zhang Q, Zhang H et al. (2014): The Therapeutic Potential of Rho Kinase Inhibitor Fasudil Derivative FaD-1 in Experimental Autoimmune Encephalomyelitis. J Mol Neurosci $\underline{5}, 725-732$

Zhao Y, Zhang Q, Xi J, Xiao B, Li Y, Ma C (2015): Neuroprotective effect of fasudil on inflammation through PI3K/Akt and Wnt/ $\beta$-catenin dependent pathways in a mice model of Parkinson's disease. Int J Clin Exp Pathol $\underline{8}, 2354-2364$

Zoccolella S, Beghi E, Serlenga L, Logroscino G (2005): Classification of amyotrophic lateral sclerosis cases at presentation in epidemiological studies. Neurol. Sci. 26, 330-333 


\section{Anhang}

\subsection{Abbildungsverzeichnis}

Abbildung 1: Abbau von Superoxidradikalen

Abbildung 2: Präsymptomatische ROCK-Inhibition mit Fasudil verbessert das Überleben bei weiblichen SOD1-G93A-Mäusen .

Abbildung 3: Repräsentatives Bild der Immunofluoreszenz-Färbung der Iba1-positiven

Mikrogliazellen des Rückenmarks

Abbildung 4: Infiltration Iba1-positiver Mikrogliazellen im Vorderhorn des lumbalen

Rückenmarks an d100

Abbildung 5: Morphologie Iba1-positiver Mikrogliazellen im lumbalen

Rückenmarksvorderhorn an d100.

Abbildung 6: Infiltration Iba1-positiver Mikrogliazellen im Vorderhorn des lumbalen

Rückenmarks zum Zeitpunkt Endstadium

Abbildung 7: Morphologische Erscheinung Iba1-positiver Mikrogliazellen im lumbalen Rückenmarksvorderhorn zum Zeitpunkt Endstadium

Abbildung 8: Infiltration Iba1-positiver Mikrogliazellen im Vorderhorn des lumbalen

Rückenmarks zu den Zeitpunkten Tag100 und Endstadium .45

Abbildung 9: Morphologische Erscheinung Iba1-positiver Mikrogliazellen in-vitro, Anzahl an Fortsätzen

Abbildung 10: Morphologische Erscheinung Iba1-positiver Mikrogliazellen in-vitro, Länge der Fortsätze 48

Abbildung 11: Morphologische Erscheinung Iba1-positiver Mikrogliazellen in-vitro, rundliche

Zellen 49

Abbildung 12: Induktion der mikroglialen Zytokin- und Chemokin-Freisetzung durch LPS .... 51

Abbildung 13: Zytokin und Chemokin Freisetzung 52

Abbildung 14: Wirkung von Fasudil auf SOD1-G93A-Mikrogliazellen 65 


\subsection{Tabellenverzeichnis}

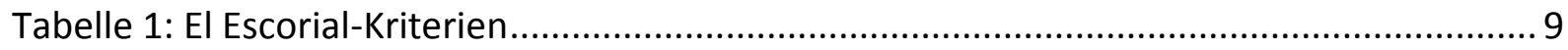

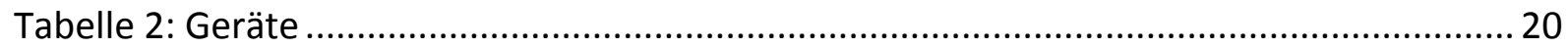

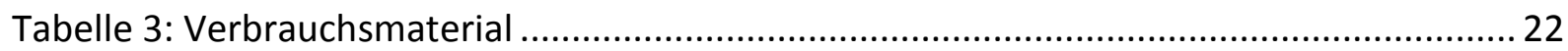

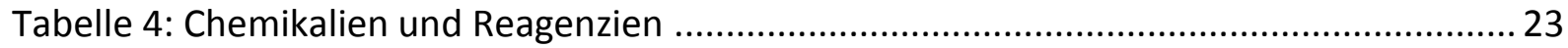

Tabelle 5: Substanzen für Polymeraseketten reaktion ........................................................ 23

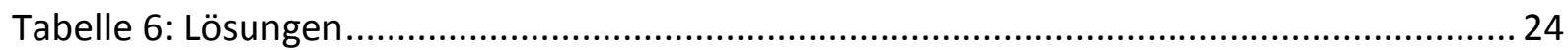

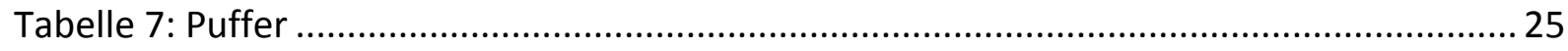

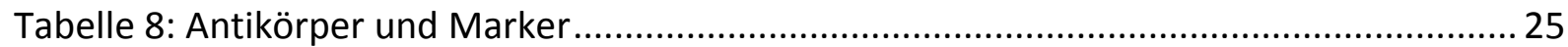

\subsection{Abbildungs- und Tabellennachweise}

Abbildung 1: $\quad$ Abbau von Superoxidradikalen, verändert nach:

Berlit P: Klinische Neurologie: Mit 382 Tabellen, 2. Auflage; Springer Medizin, Heidelberg 2006

Lizenznummer: 3640091316307

Lizenzdatum:

01.06 .2015

Lizenzgebender Verlag: $\quad$ Springer-Verlag Berlin/Heidelberg

Abbildung 2: $\quad$ Präsymptomatische ROCK-Inhibition mit Fasudil verbessert das Überleben bei weiblichen SOD1-G93A-Mäusen, übernommen aus:

Tönges L, Günther R, Suhr M, Jansen J, Balck A, Saal K, Barski E, Nientied T, Götz AA, Koch J et al. (2014): Rho kinase inhibition modulates microglia activation and improves survival in a model of amyotrophic lateral sclerosis. Glia 62, 217-232

Lizenznummer:

3621290335355

Lizenzdatum:

03.05.2015

Lizenzgebender Verlag: John/Wiley \& Sons, Inc.

Abbildung 4: $\quad$ Infiltration Iba1-positiver Mikrogliazellen im Vorderhorn des lumbalen Rückenmarks an d100, verändert nach: 
Tönges L, Günther R, Suhr M, Jansen J, Balck A, Saal K, Barski E, Nientied T, Götz AA, Koch J et al. (2014): Rho kinase inhibition modulates microglia activation and improves survival in a model of amyotrophic lateral sclerosis. Glia 62, 217-232

Lizenznummer: 3640130897450

Lizenzdatum: 01.06 .2015

Lizenzgebender Verlag: John/Wiley \& Sons, Inc.

Abbildung 5: $\quad$ Morphologie Iba1-positiver Mikrogliazellen im lumbalen Rückenmarksvorderhorn an d100, verändert nach:

Tönges L, Günther R, Suhr M, Jansen J, Balck A, Saal K, Barski E, Nientied T, Götz AA, Koch J et al. (2014): Rho kinase inhibition modulates microglia activation and improves survival in a model of amyotrophic lateral sclerosis. Glia 62, 217-232

Lizenznummer: 3640130897450

Lizenzdatum:

01.06 .2015

Lizenzgebender Verlag: John/Wiley \& Sons, Inc.

Abbildung 13: $\quad$ Zytokin und Chemokin Freisetzung, verändert nach:

Tönges L, Günther R, Suhr M, Jansen J, Balck A, Saal K, Barski E, Nientied T, Götz AA, Koch J et al. (2014): Rho kinase inhibition modulates microglia activation and improves survival in a model of amyotrophic lateral sclerosis. Glia 62, 217-232

Lizenznummer: 3640130897450

Lizenzdatum: 01.06 .2015

Lizenzgebender Verlag: John/Wiley \& Sons, Inc.

Tabelle 1:

El Escorial-Kriterien, verändert nach:

Brooks BR, Miller RG, Swash M, Munsat TL (2000): El Escorial revisited: revised criteria for the diagnosis of amyotrophic lateral sclerosis. Amyotroph. Lateral Scler. Other Motor Neuron Disord. 1, 293-299 Lizenznummer: 3640140596732

Lizenzdatum: 01.06 .2015

Lizenzgebender Verlag: Informa Healthcare 


\subsection{Publikation zum Thema der Doktorarbeit}

L. Tönges, R. Günther, M. Suhr, J. Jansen, A. Balck, K. A. Saal, E. Barski, T. Nientied, A. Götz, J.

C. Koch, B. K. Mueller, J. H. Weishaupt, M. W. Sereda, U. K. Hanisch, M. Bähr, P. Lingor

„Rho Kinase Inhibition Modulates Microglia Activation and Improves Survival in a Model of Amyotrophic Lateral Sclerosis"

Glia. 2014 Feb; 62(2): 217-32 


\section{Lebenslauf}

Geboren wurde ich, Johannes Jansen, am 29. April 1986 in Wiesbaden als Kind von Regina Anita Jansen (geb. Eckelt) und Ullrich Jansen. Aufgewachsen bin ich in Wiesbaden. Dort besuchte ich von 1992 bis 1996 die Otto-Stückrath Grundschule. Meine weitere Schullaufbahn verbrachte ich von 1996 bis 2006 am Dilthey-Gymnasium in Wiesbaden und schloss diese mit dem Abitur ab. Nach dem Abitur leistete ich den Zivildienst im Psychosozialen Zentrum Süd in Wiesbaden ab. Im Wintersemester 2007/2008 begann ich ein Studium der Biologie an der Universität Bayreuth. Dieses brach ich zugunsten des Studiums der Humanmedizin, dass ich im Wintersemester 2007/2008 an der Georg-August Universität Göttingen aufnahm, ab. Das Physikum absolvierte ich im März 2010. Vom 19.08.2013 bis zum 20.07.2014 leistete ich mein Praktisches Jahr in Korbach (Innere Medizin), Bremerhaven, Sri Lanka (Chirurgie) und in Göttingen (Hals-Nasen-Ohren Heilkunde) ab. Mein Studium habe ich am 25.11.2014 mit dem Zweiten Abschnitt der Ärztlichen Prüfung abgeschlossen. Am 07.01.2015 wurde mir die Approbation als Arzt erteilt. Während des Studiums entstand meine Dissertation: „Einfluss der Rho-Kinase-Hemmung auf Mikrogliazellen im SOD1-G93A-Mausmodell der Amyotrophen Lateralsklerose“. Seit dem 01.08.2015 bin ich als Assistenzarzt in der Hals-Nasen-Ohren-Heilkunde des Klinikums Kassel tätig. 